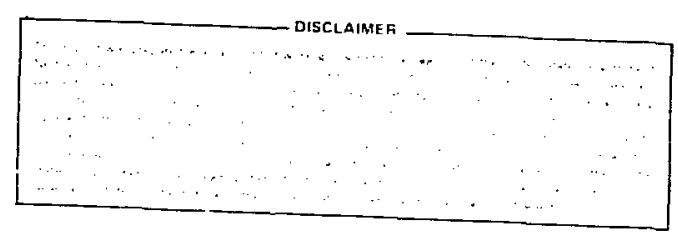

\title{
Instrumentation Report 1: Specification, Design, Calibration, and Installation of Instrumentation for an Experimental, High-Level, Nuclear Waste Storage Facility
}

\author{
W. G. Brough \\ W. C. Patrick
}

Manuscript Date: January 1982

LAWRENCE LIVERMORE LABORATORY University of California $\bullet$ Livermore, Californial 94550 
CONTEN'TS

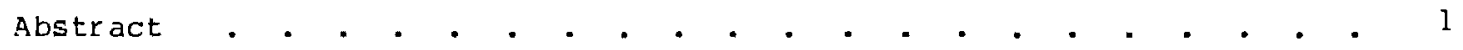

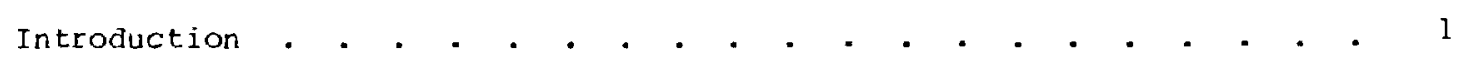

Radiation Monitors . . . . . . . . . . . . . . . . . . . 8

Introduction . . . . . . . . . . . . . . . . . . . 8

Criteria . . . . . . . . . . . . . . . . . . . . 9

Design . . . . . . . . . . . . . . . . . . . . . 10

Procurement . . . . . . . . . . . . . . . . . . 15

Installation . . . . . . . . . . . . . . . . . . 17

Calibration . . . . . . . . . . . . . . . . . . . 20

Results to Date . . . . . . . . . . . . . . . . . . . 21

Radiation Dosimeters . . . . . . . . . . . . . . . . . . 21

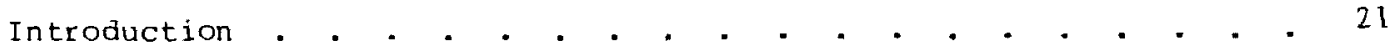

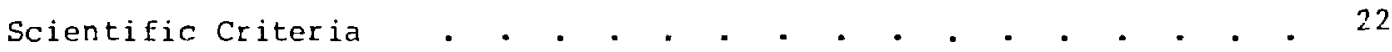

Design Criteria . . . . . . . . • . . . . . . . . . . 22

Procurement . . . . . . . . . . . . . . . . . . . 24

Installation . . . . . . . . . • . . . . . . . . . 24

Calibration . . . . . . . . . . . . . . . . . . . . . 24

Results to Date. . . . . . . . . . . . . . . . . 25

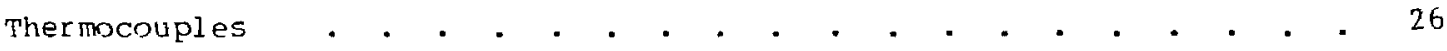

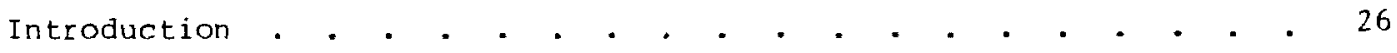

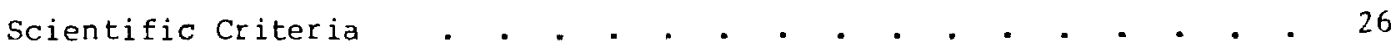

Design Criteria . . . . . . . . . . . . . . . . . . 27

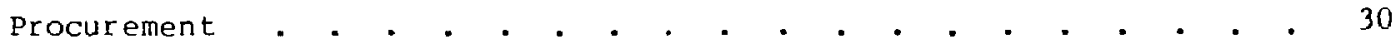

Installation . . . . . . . . . . . . . . . . . . . 34

Calibration . . . . . . . . . . . . . . . . . . . . 4 42

Results to Date . . . . . . . . . . . . . . . . . . 46

Dew-Point Sensors . . . . . . . . . . . . . . . . . . 47

Scientific Criteria . . . . . . . . . . . . . . . . . . . . . 47

Mesign Criteria . . . . . . . . . . . . . . . . . . . 48

Procurement . . . . . . . . . . . . . . . . . . . . 4 49

Installation . . . . . . . . . . . . . . . . . . . . . 49

Calibration . . . . . . . . . . . . . . . . . . . 51

Results to Date . . . . . . . . . . . . . . . . . . 52 
INSTRUMENTATION REPORT 1 :

\author{
SPECIFICATION, DESIGN, CALIBRATION, AND INSTALLATION \\ OE INSTRUMENTATION FOR AN EXPERIMENTAL, HIGH-LEVEL, \\ NUCLEAR WASTE STORAGE FACILITY
}

\begin{abstract}
The Spent Fuel Test-Climax (SFT-C) is being conducted 420 m underground at the Nevada Test Site under the auspices of the U.S. Department of Enerqy. The test facility houses 11 spent fuel assemblies from an operating commercial nuclear reactor and numerous other thermal sources used to simulate the near-field effects of a large repository.

We developed a large-scale instrumentation plan to ensure that a sufficient quality and quantity of data were acquired during the three- to five-year test. These data help satisfy scientific, operational, and radiation safety objectives.

Over 800 data channels are being scanned to measure temperature, electrical power, radiation, air flow, dew point, stress, iisplacement, and equipment operation status (on/off). This document details the criteria, design, specifications, installation, calibration, and current performance of the entire instrumentation package.
\end{abstract}

\title{
INTRODUCTION
}

In the fall of 1976, the Department of Energy Nevada Operations Office (DOE-NV) requested that the Lawrence Livermore National Laboratory (LLNL) assist in preparing a plan for a nuclear waste isolation experiment in the Climax granite, located at the Department of Energy Nevada Test Site approximately $100 \mathrm{~km}$ northwest of Las Veqas, NV. The proposal finally chosen resulted in a small-scale in situ heater test in 1977 for granite characterization. In January of 1978, a technical concept document for a spent fuel experiment was delivered to DOE-HQ, and approval to start work was given in June 1978. September of the same year saw a revision of the technical concept that became the final version. 1 
LLNL was the principal contractor and provided technical direction to other DOE-NV contractors on the project (Holmes \& Narver, Fenix and Scisson, Reynolds Electrical and Engineering Co., and Westinghouse Electric Corp.). Within LLNL, the organization consisted of a Technical Project officer, a Task Director, a Project Quality Engineer, and four Subtask Leaders

(Scientific, Mechanical Engineering, Electronics Engineering, and Field Construction!. The LLNL Technical Project officer was given overall project responsibility.

The DOE requested a Quality Assurance Plan ${ }^{2}$ from LLNL for the Spent Fuel Test-Climax (SFT-C) experiment. The organization within LLNL for the project is shown in Fiq. 1, and has been taken from the QA Plan. The flow of criteria, specifications, and instructions between LLNL and NV/NTSSO contractors is shown Fiq. 2. NTSSO stands for the Nevada Test site Support Operations orqanization, which manaqes site contractors.

Developing the instrumentation plan was the responsibility of the Scientific Subtask Leader. He determined the parameters that would confirm excavation stability, improve general understanding of jointed rock mass

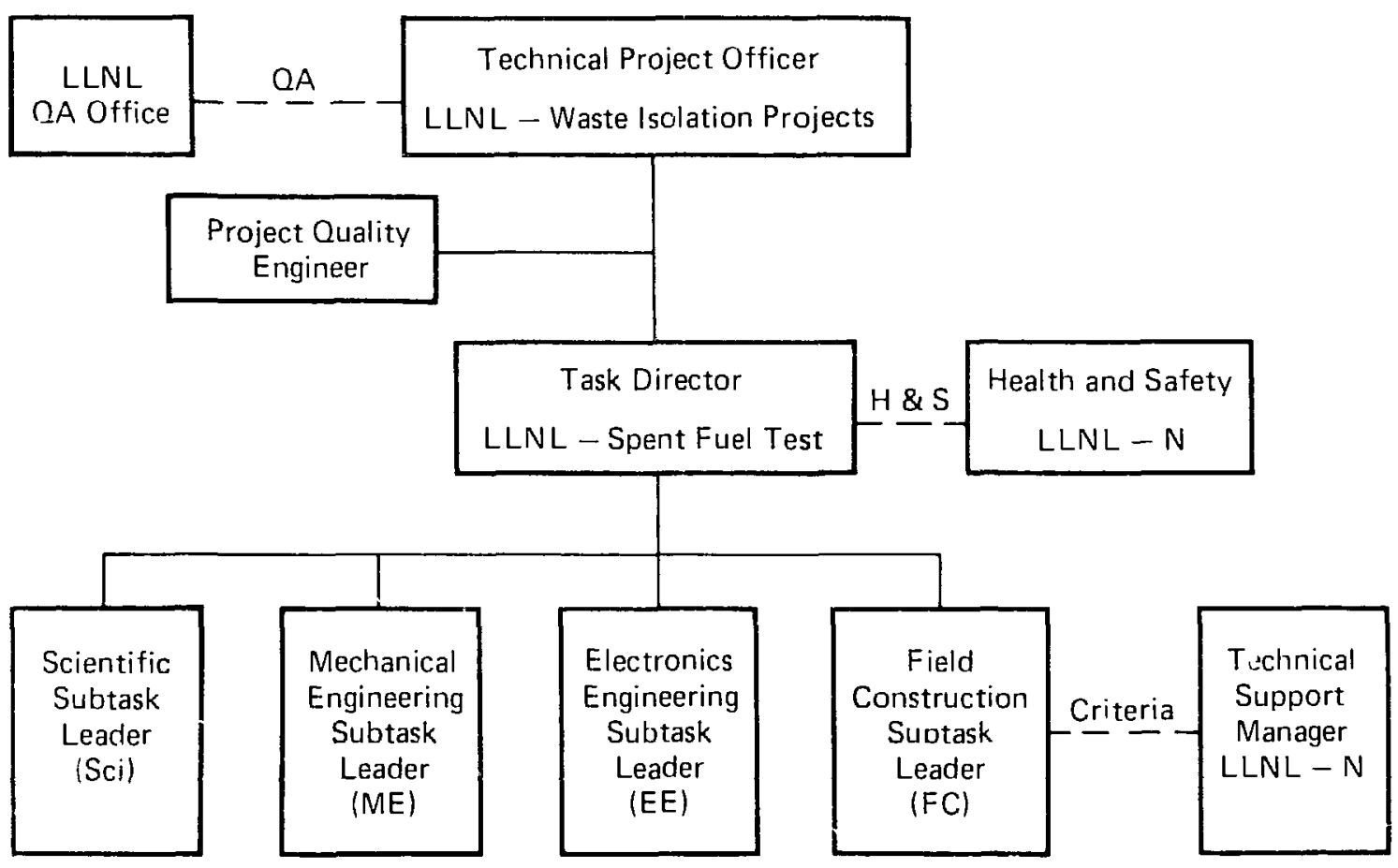

Figure 1. LLNL organization for the SFT-C. 


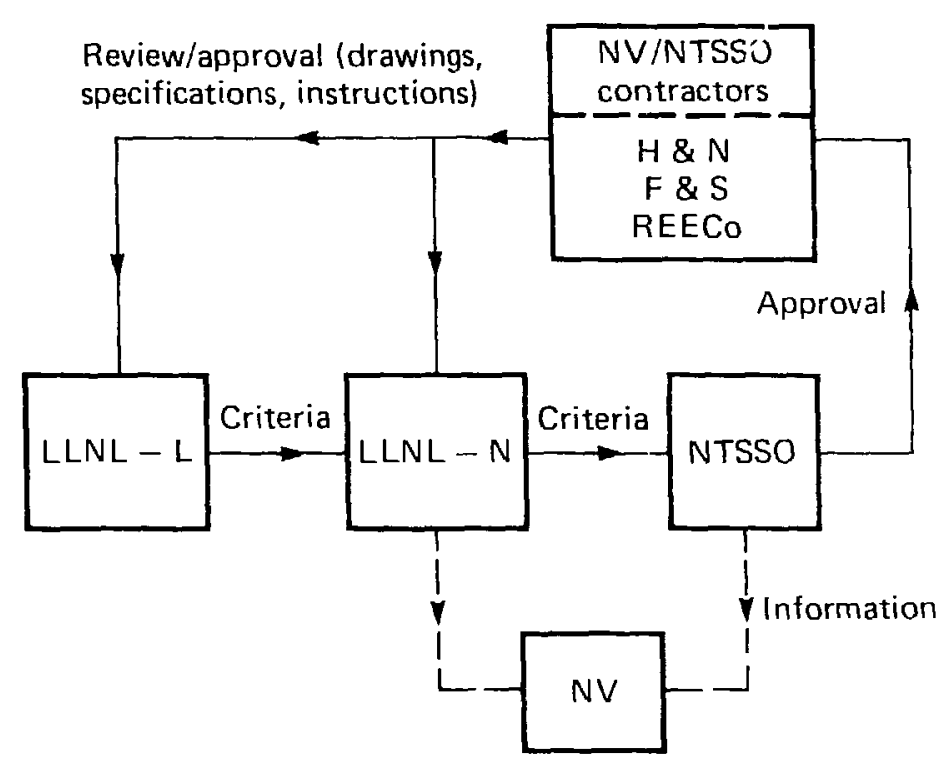

Fiqure 2. Flow of criteria, specifications, and instructions.

behavior, validate existing modeling codes, or be used to develop more realistic models for such codes. The number of measurement points, the measurement accuracy required, and the location of the instruments was also determined by the Scientific Subtask Leader. With support from the Electronics Engineering Subtask Leader, a compromise was struck between desirable and obtainable instrumentation criteria.

In May 1979, a technical design review was presented by the scientific support group to in-house scientists and engineers. A summary of the presentations and the resulting criteria for each type of instrument appears in this document in the criteria sections under each instrument type. Generally, the directives from DOE stipulated the use of off-the-shelf technology (unless instrumentation development would not affect the fuel emplacement datel and of only a minimal amount of instrumentation to verify modeling codes.

In addition to scientific instrumentation, there are two other types. One type of instrumentation consists of the radiation monitors for personnel safety, and the other consists of status monitors for the Data Acquisition system (DAS) support facilities and equipment. All of these instruments are discussed in this report. 
The SFT-C experimental facility consists of three parallel drifts (tunnels) $65-\mathrm{m}(210-\mathrm{ft})$ long and spaced about $10 \mathrm{~m}(30.5 \mathrm{ft})$ center to center (see Fig. 3). The drifts are joined at either end in the receiving and railcar rooms. An adjacent instrumentation alcove was provided for the underground electronics.

The experimental facility was mined out of granite, and was built $420 \mathrm{~m}$ $(1370 \mathrm{ft})$ below the ground surface. Seventeen storage wells were drilled in the floor of the center drift. Eleven nuclear spent fuel assemblies and six electrical simulators were installed in the wells. Each of the two side drifts were fitted with 10 electrical heaters, which simulate the thermal regime of a large repository, in the middle one-third of the center drift. The ventilation air, electrical lights, nuclear fuel assemblies; and electrical simulators and heaters are the "sources" that cause the "events" measured by the instrumentation to occur. There are also a. few instruments

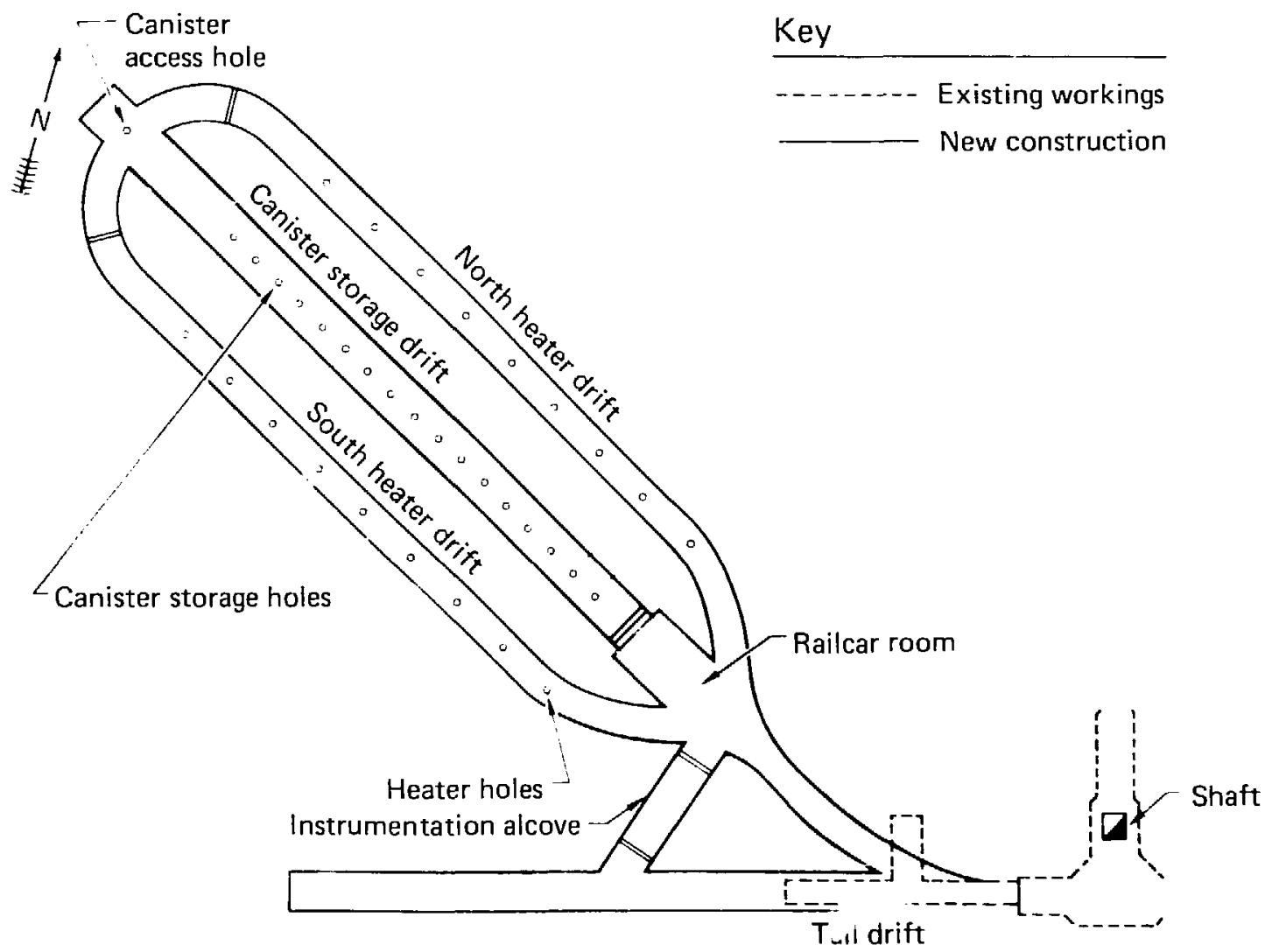

Figure 3. Plan view of the SFT-C underground facility. 
on the ground surface that monitor radiation levels, air temperatures, and equipment status. All the signals from the various instruments are wired into the underground instrumentation alcove (Fig. 4) where they are scanned, digitized, and transmitted to the DAs surface facility.

A double-wide $(6 \times 16-m)$ trailer on the surface houses the main portions of the DAS. Figure 5 is a block diagram of the DAS and Fig. 6 shows the DAS configuration inside the trailer. Because a complete docurent on the DAS is currently in preparation, we do not report on it here. It suffices for now to say that the DAS is a disc-based dual computer system that scans all the instruments at preset intervals, and which is not expected to have any significant effects on instrument accuracy. Manufacturer specifications for the digital voltmeters and scanners are listed in Appendix A. Later sections discuss in detail the effects of the

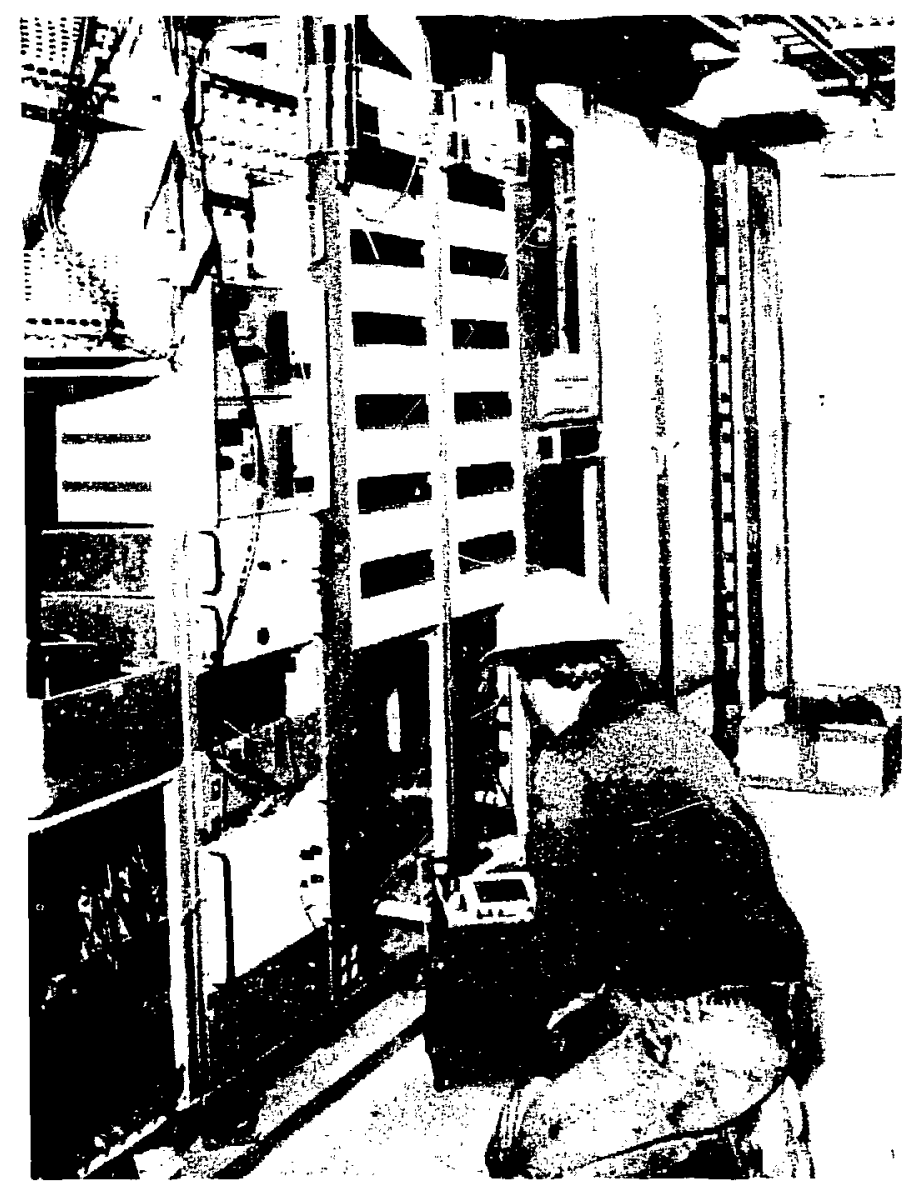

Figure 4. Underground instrumentation alcove. 


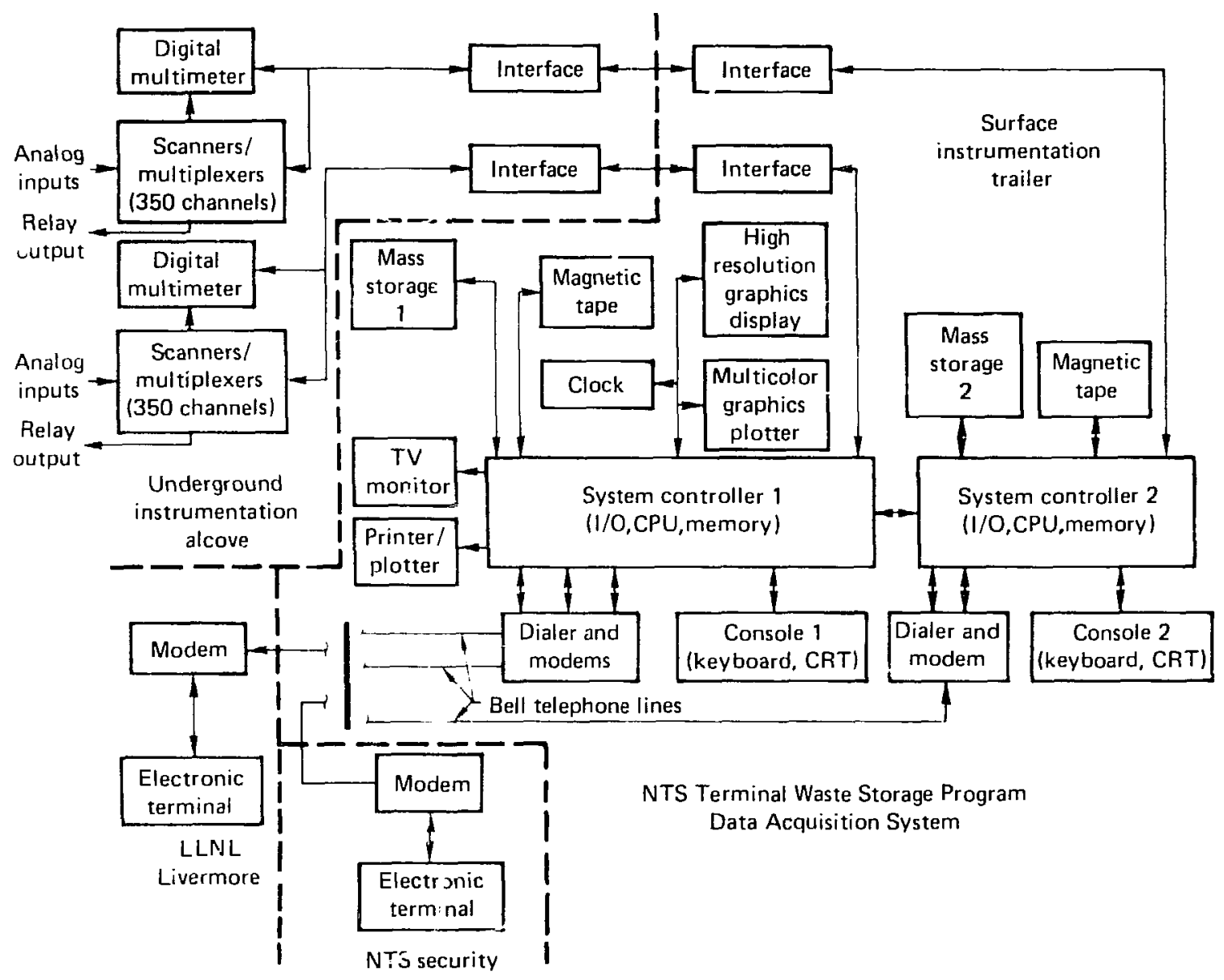

Figure 5. Data Acquisition System (DAS) block diagram.

DAS on the accuracy of the instrument being reviewed. Table 1 summarizes the number and types of instruments used.

A few of the area radiation monitors for personnel safety are not wired into the DAS, using local readouts only. Those few monitors are used only during fuel handling operations. 


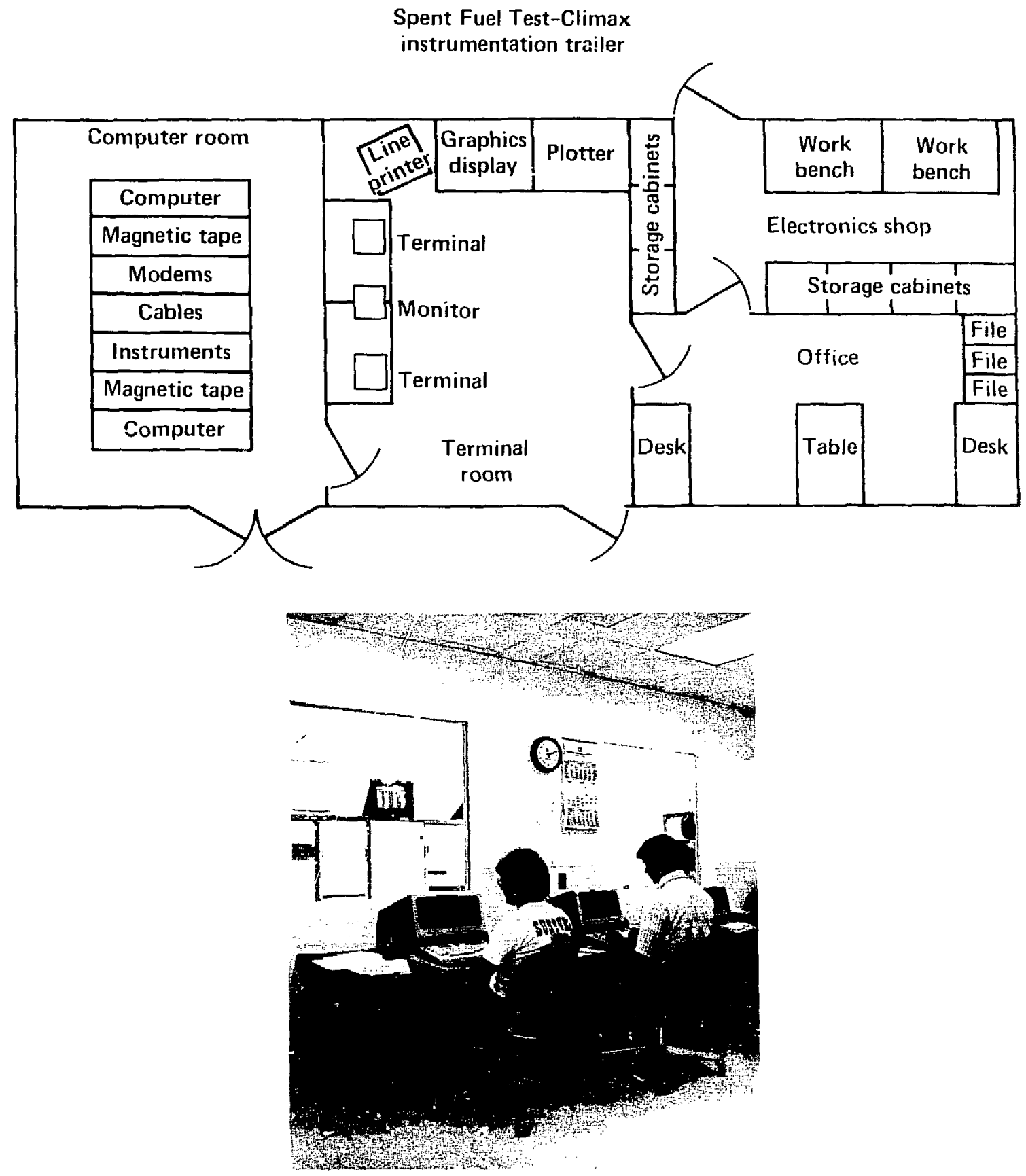

Figure 6. DAS configuration inside the SFT-C instrumentation trailer. 
Table 1. SFT-C instrumentation summary .

\begin{tabular}{|c|c|c|c|}
\hline $\begin{array}{l}\text { Instrument } \\
\text { type }\end{array}$ & Computer 100 & Computer 200 & Total \\
\hline Thermocouples & 255 & 227 & 482 \\
\hline wire extensometers & 13 & 42 & 55 \\
\hline Extensometer excitation supplies & 16 & 18 & 34 \\
\hline watt transducers & 19 & 0 & 19 \\
\hline Vibrating wire stressmeters & 18 & 0 & 18 \\
\hline Rod extensometers & 58 & 58 & 116 \\
\hline Status devices & 10 & 8 & 18 \\
\hline Misc. I inear devices & 27 & 13 & 40 \\
\hline${ }^{3} \mathrm{H}-{ }^{85} \mathrm{Kr}$ monitors & 8 & 8 & 16 \\
\hline Be'sa monitors & 11 & 11 & 22 \\
\hline Platinum resistance thermometers & 12 & 13 & 25 \\
\hline Miscellaneous devices & 2 & $\underline{2}$ & 4 \\
\hline Total instruments & 449 & 400 & 849 \\
\hline
\end{tabular}

RADIATION MONITORS

INTRODUCTION

In keeping with Nevada Test site policies regarding safe handling of radioactive material, a plan was developed for the spent Fuel Test to minimize the possibility of personnel exposure to radiation from the nuclear fuel assemblies during transport and storage, and to monitor the environment for any potential release of radioactive particulates or gases. The development of the plan was coordinated by LLNL, with final approval by LLNL-NTS Health and Safety and by the DOE-NV.

The first aspect of personnel safety covered is the design of shielding and remote handling equipment to minimize the potential for exposure. The second aspect is a monitor and alarm system to warn personnel in the event any hazardous radioactive material is released into the environment or if unacceptable levels of ionizing radiation are present. The third aspect 
covers contingency plans should an accident lead to personnel exposure. Each of these aspects is discussed in a previously prepared document. 3 We intend here only to discuss the radiation monitoring instrumentation at the test facility (subsurface and surface areas). This set of instrumentation is active during fuel handling operations at the mine and during the interim storage modes. Activities at the Engine Maintenance Assembly and Disassembly (EMAD) facility and enroute to the Area 15 test facility are not discussed here.

Besides the electronic radiation monitoring equipment permanent $1 \%$ installed as part of the test facility, other types of radiation moniturs (neutron detectors, geiger counters, and an assortment of personnel dosimeters) were used by LLNL and NTS Health and Safety Groups during fue $L$ handling operations to monitor personnel exposure und potential defects in the fuel shielding equipment. These radiation monitors were essential to fuel handling operations (especially during the emplacement of thermocouples on the fuel canisters in the storage wells). However, only those instruments that tie into the DAS or are permanently incorporated into the test facility concern us here.

\section{CRITERIA}

Page 38 of the technical concept document ${ }^{1}$ states that, "Radiation detectors will be deployed in the test area as appropriate to assure personnel safety and to document any release of radioactive effluents. These instruments will include both Remote Area Monitors (RAMs) and Continuous Air Monitors (CAMs), located in the underground area and on the surface."

More specific criteria for radiological protection are stipulated in the safety assessment document ${ }^{3}$ (parts of which are also quoted here).

"4.5.1 Continuous reading radiation monitoring equipment, with appropriate alarms, to detect airborne radioactivity and z'jove-normal direct radiation levels shall be operable in the underground space'j whenever these spaces are occupied by personnel.

4.5.2 Continuous reading radiation monitoring equipment, with appropriate alarms, to detect radiation shall be strategicaliy located on the surface, during Euel canister handling operations, to alert operating personnel in case of abnormal radiation levels. 


\subsubsection{Continuous reading radiation monitoring equipment, with}

appropriate alarms located on and off the Climax site, shall be provided on the ventilation system exhaust."*

These criteria inspired the design of the radiation monitoring system row in use.

DESIGN

Beta and gamma are the two types of radiation which must be closely monitored to detect ionizing radiation and any particulate releases from the fuel assemblies. It would be desirable if the radiation monitors were much more sensitive than they actually needed to be to monitor acceptable levels of radiation for workers, and also able to avoid saturation of the instruments in case of the most severe credible accident. In terms of the Spent Fuel Test, this would necessitate radiation monitoring instruments with ranges or about 4 orders of magnitude.

The two areas that require monitoring for personnel safety are the center (canister) drift underground, its adjacent areas, and the surface control skid and canister hoist. These areas consist of about $560 \mathrm{~m}^{2}$ $\left(6,000 \mathrm{ft}^{2}\right)$, and they must both be monitored differently during fuel handling and storage. Inderground monitoring is essentially the same during these two modes, while surface monitoring is quite different, depending on which mode is in operation. During the storage mode only the exhaust ventilation is monitored, while during the fuel handling mode, several other points are monitored in and around the control skid.

Local readouts and alarms were needed along with electronic signals to be sent to the DAS for processing and storage. Those monitors used only during fuel handling operations do not need to be measured by the DAS.

\section{Remote Area Monitors (RAMs)}

A typical instrument used to measure gamma radiation is the Remote Area Monitor (RAM). Two ranges are needed to measure low- and high-level radiation. The low range needed is $0.1 \mathrm{mR} / \mathrm{h}$ to $1000 \mathrm{R} / \mathrm{h}$. The locations for

* The offsite monitoring mentioned in paragraph 4.5 .3 is not handled by SFT-C Fersonnel. 
these units, shown in Figs. 7 and 8, are based on air flow: fuel transpret paths, and fuel storage location. Bulkheads were desiqned co act as barriers and to allow for limited reentry of the underground facility in the event of an accident or breach of other radiation barriers during fuel storage.

The RAMs were designed to permit local readout and alarming without tho aid of the DAS. The units were also designed to operate for about $1 \mathrm{~h}$ after a power failure to cover the periodic outages present at the test location. A total of 11 low-level and 3 high-level RAMs are required. The hiqh-level RAMs are used where the greatest potential for direct exposure (shine paths) from the fuel canisters exists. This occurs while the fuel canisters are being loaded/unloaded into/out of the surface Transfer and the underground Transport Vehicles while positioned in the receiving room.

By using the ventilation system with fans, bulkheads, and louvres, any potential radioactive contamination in the underground facility should be

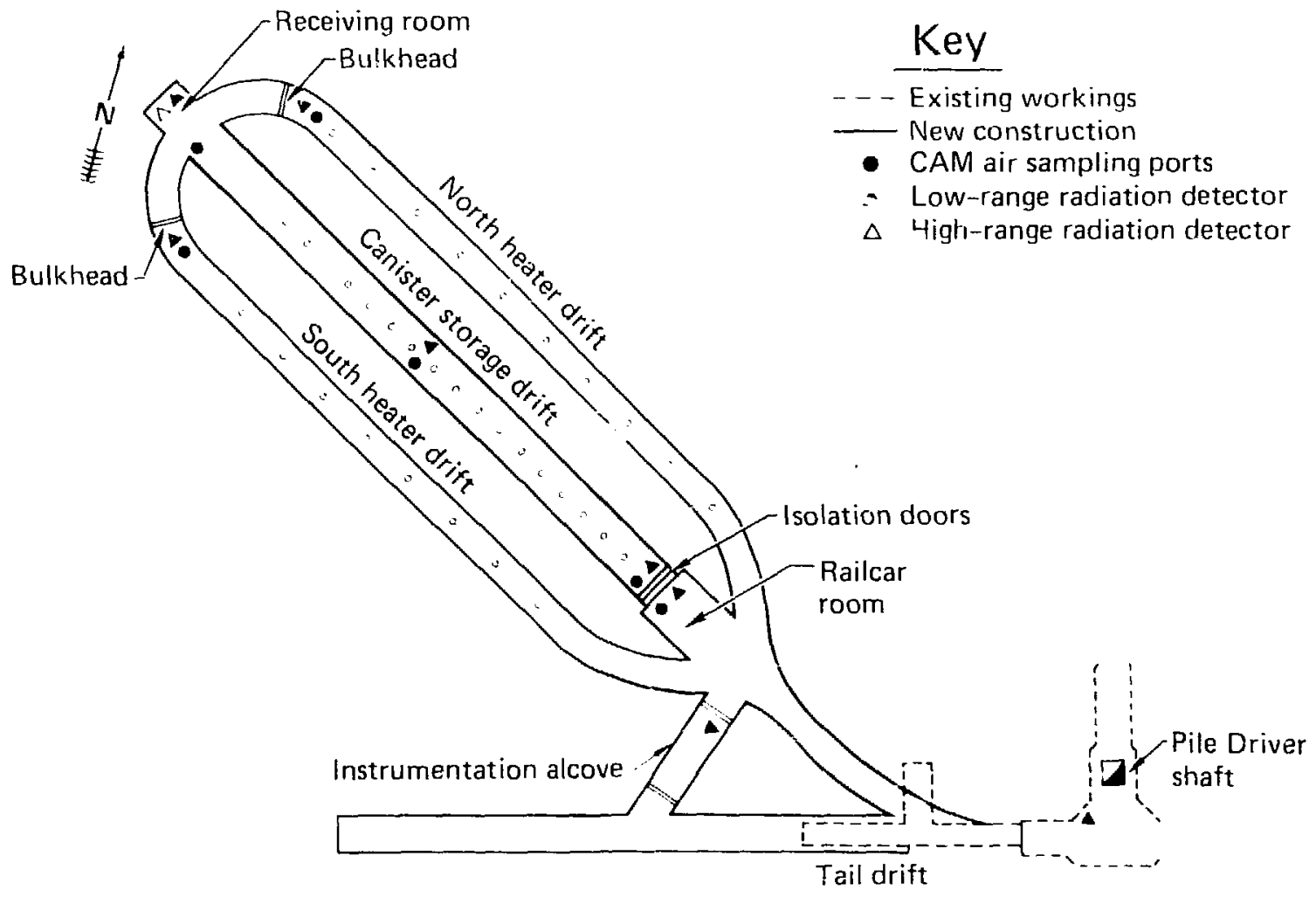

Figure 7. Underground radiation monitor locations. 


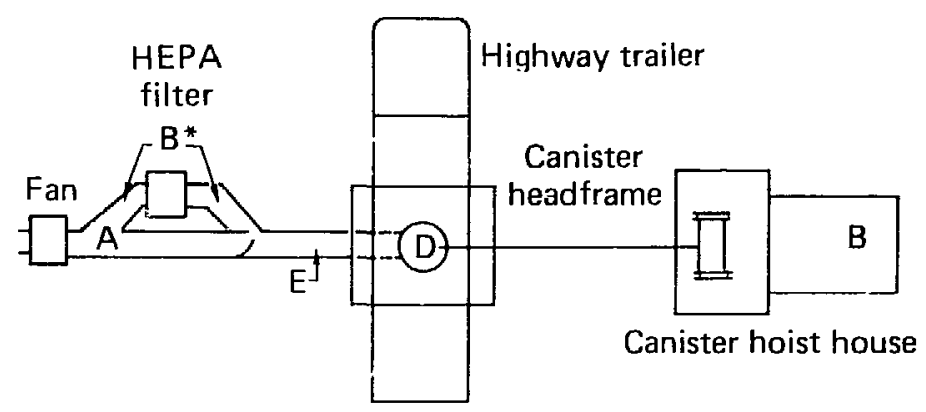

\footnotetext{
$A=$ Fixed CAM sampling ports.

$B=$ Low-level RAM detectors $\left(B^{*}=\right.$ normal mode $)$.

$D=$ High-level RAM detectors.

$E=$ Particulate sampling port.
}

Figure 8. Surface radiation monitor locations.

limited to the canister drift and receiving room. The RAMs monitor the activity at four points within the confined area and at three points immediately adjacent to $i t$, as well as at two other key access points underground (i.e., the Instrumentation Alcove and the shaft station at the 420-m level). These points would be used during reentry after an accident. The underground area is cleared of personnel during fuel handing operations, so the primary purpose of the RAMs would be to assist in reentry operations.

The surface facilities constitute a greater potential for accidental exposure during fuel handling operations, but these are not confined areas. Points to be monitored with RAMs include the ventilation line, both upstream and downstream from the high-efficiency particulate absolute (HEPA) Filters, hoist headframe area, and the control skid, which is manned. Four RAMs are used in those areas. One low-level and two high-level RAMs are needed on the headframe, and one low-level in the control skid. During the fuel handling or storage modes, the two low-level units can be positioned on either side of the HEPA filters. Only the low-level units are routed to the DAS. Local alarms and readouts are provided on the surface. Strip chart recorders are provided for a continuous plot. 
In the event of damage to or corrosion of the fuel assembilies resulting in the release of radioactive material, the most likely material to be sensed first would be the radioactive gases tritium ${ }^{3} \mathrm{H}$ ) and krypton $\left({ }^{85} \mathrm{Kr}\right)$, which emit beta and gamma radiation. These gases diffuse rapidiy into the air and could be sensed quickly with a few sampling points. The Continuous Air Monitor (CAM), which consists basically of an air pump, a particulate filter, an ionization chamber, and an electrometer sensor, is used to measure ${ }^{3} \mathrm{H}$ and ${ }^{85} \mathrm{Kr}$.

Underground, two CAM units work in parallel to provide redundancy in the measurements. Each CAM sequentially measures samples of the air taken from six different locations. Three of the air sampiing ports are located in the canister drift--one at either end and one in the middle. Th- other three are located (as with the RAMs) at the adjacent entry points to the canister drift. Local readout, alarms, and strip chart recorders are provided along with the electronic output signals that go to the DAs for processing and storing.

To provide different samples to a common ionization chamber, LLNL designed an air sampling system that consists of 3/8-in.-diam stainlesssteel air sampling 1 ines, air control valves, manifolds, water traps, and the related electronics to control the sampling sequence and to measure and store locally the signals heing generated for local and remote readout.

On the surface, two CAM units monitor the underground exhaust air from a port in the exhaust duct on the downstream side of the HEPA filter. A sample 1 ine is run to the CAM units for monitoring. An automatic temperatire control system is incorporated to keep the temperature of the air sample entering the CAM unit the same as that of the air in the ventilation duct. This prevents moisture condensation in the ionization chamber.

One of the two CAM units has the primary function of monitoring the air for ${ }^{3} \mathrm{H}$ gas in the range of $0.7-1000 \mu \mathrm{Ci} / \mathrm{m}^{3}$. This unit uses an ion chamber to detect beta emissions. The other CAM unit (whose entrance window is too thick to be sensitive to ${ }^{3} \mathrm{H}$ loh-energy, beta emission! is used to detect the high-energy betas emitted from ${ }^{85} \mathrm{Kr}$.

In addition to the fixed units for the underground and surface RAMs and CAMs, there are two edditional units. A portable CAM unit and a portable 
beta-gamma particulate monitor will be used on the surface or underground in the event radioactive material is reieased. Their functions will be to collect additional data and also localize the source to one of the storage wells.

Underground, two sampling ports are located at each storage well. Several 3/8-in.-diam stainless-steel sampling lines are run to accessible locations in the south drift and railcar room (Fig. 9). Should the on-line monitors detect a release, the 34 individual iines can be sampled with the portable CAM units to determine the source of the leak if it is in one of the storage wells. On the surface, there is also a sampling port upstream of the HEPA filter that san be used during emergency conditions.

Designed into the monitoring sytem are several emergency power systems that will generate power to the underground units for $l \mathrm{~h}$, and to the surface CAM units and strip chart recorder for $24 \mathrm{~h}$.

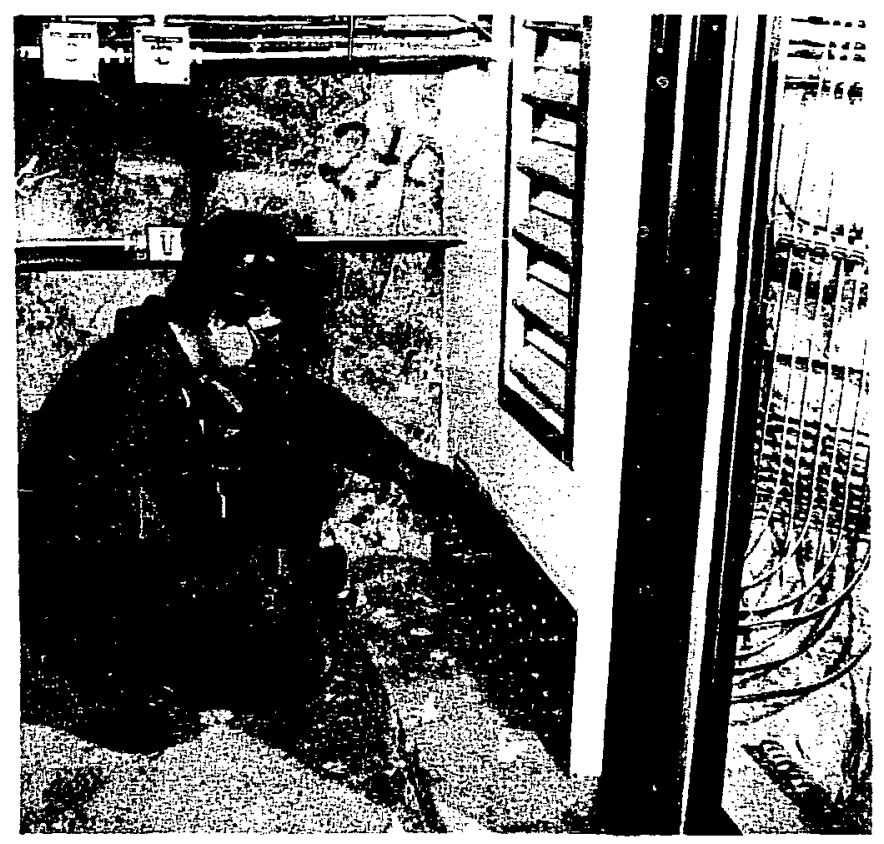

Figure 9. Location of sampling ports outside the canister drift doors. 
PROCUREMENT

RAMS

A purchase order was piaced in september 1979, for 11 low-level RAM units, which included 3 prewired instrument bins, and spare probes. The RAM units are Nuclear Measurements Corp. Model GA-3M. Some of the manufacturer's specifications are as follows:

- Activity detected--gama, $580 \mathrm{KeV}$.

- Precision-- \pm 158 .

- Stability - \pm 28 of reading.

- Detector scintillator--plastic.

- Meter and alarm response time--<1 5 .

The ranges selected were

- High-level units--10 mR/h-1000 R/h (5-decade).

- Low-level units--0.1 mR/h-10 R/h (5-decade).

Final delivery of all items ordered was in Fehruary 1980.

CAMs, ${ }^{3} \mathrm{H},{ }^{85} \mathrm{Kr}$

Two Overhoff and Associates, Inc., Betatec Model 210 CAMs were ordered in August 1979 (P.O. \#6167109). Each unit was a flow-through, 2-1itre ionization chamber and electrometer-type instrument. Some specific features ordered were

- 2-litre detached chamber without vacuum pump.

- Supersensitive $0.6-\mu \mathrm{Ci} / \mathrm{m}^{3}$ definition.

- 4-decade logarithmic meter readout (nondigital).

- Radon, thoron data correction.

- Two independent analog signal outputs $10-\mathrm{V}$ max for full scale.

- Calibration for ${ }^{3} \mathrm{H}$ in $\mu \mathrm{Ci} / \mathrm{m}^{3}-1$ inear scales.

The units were delivered in November 1979. An assortment of components, including some Rustrak Model 288 strip chart recorders and some diaphragm pumps were procured to build the LLNL design for sample sequencing and measurement storage in the sample-and-hold circuitry. 
A Nuclear Measurements Corp. (NMC) Model SA-2 flow counter and Model CRM-71 count-rate meter were procured in September 1979. The flow counter had the following features:

- 4-Pi (full-coverage) . ielding with $76 \mathrm{~mm}$ ( 3 in.) of lead.

- $18 \mathrm{~cm}^{3}$ effective chal. Der capable of a $0.1 \mu \mathrm{Ci} / \mathrm{m}^{3}$ sensitivity to ${ }^{85} \mathrm{Kr}$.

- Beta scintillation counter type SC-2B.

The unit was delivered in January 1980.

Portable CAM $\left({ }^{3} \mathrm{H},{ }^{85} \mathrm{Kr}\right)$

A portable ac/dc tritium monitor was ordered in August 1979 from Overhauf and Associates, Inc. The Overhoff Model 786 has a fully self-contained $80 u-\mathrm{cm}^{3}$-vol, shielded, and removable ion chamber, and 0 to 50 - and 0 to $500-\mu \mathrm{Ci} / \mathrm{m}^{3}$ linear scales. The accuracy is \pm 208 of reading and the overall. time constant for response is about 12-15 $\mathrm{s}$. The unit was delivered in November 1979.

\section{Portable Particulate CAM}

A portable beta-gamma CAM was purchased from Eberline Instrument Corp. in June 1979. The unit (Eberline Model AMS-3) continuously monitors air for beta emitters. Some of its features are

- Detectors: 2 pancake-type G-M tubes.

- Background subtraction: using a second detector compensates for approximately 908 of gamma background.

- Sensitivity: $11 \mathrm{cpm}$ for $1 \times 10^{-12} \mu \mathrm{Ci} / \mathrm{cm}^{3}{ }^{90} \mathrm{Sr}-{ }^{90} \mathrm{Y}$ after $4 \mathrm{~h}$ a $60 \mathrm{litre} / \mathrm{m}$ air-flow rate.

- Range: logarithmic scale from 10-100,000 cpm.

- Response time: logarithmic (varies with count rate).

- Linearity: within \pm 108 of reading.

- Recorder: Simpson strip chart recorder and rate meter. The unit was delivered in July 1979. 
INSTALLATION

Underground RAMS

The detector units were located at the points indicated in Fig. 7. A typical installation is shown in Fig. 10. Signal cables were run from the detector unit into the instrument bins located in the Instrumentation Alcove. From these, the signals go to the DAS ard into the local alarm circuitry. The installation was straightforward and few problems were encountered. Two bins were requirnd for the one high-level RAM and the nine low-level RAMS. Emergency power for the RAMs was provided by the 1 -h 115 Vac UtS emergency power system in the aicove.

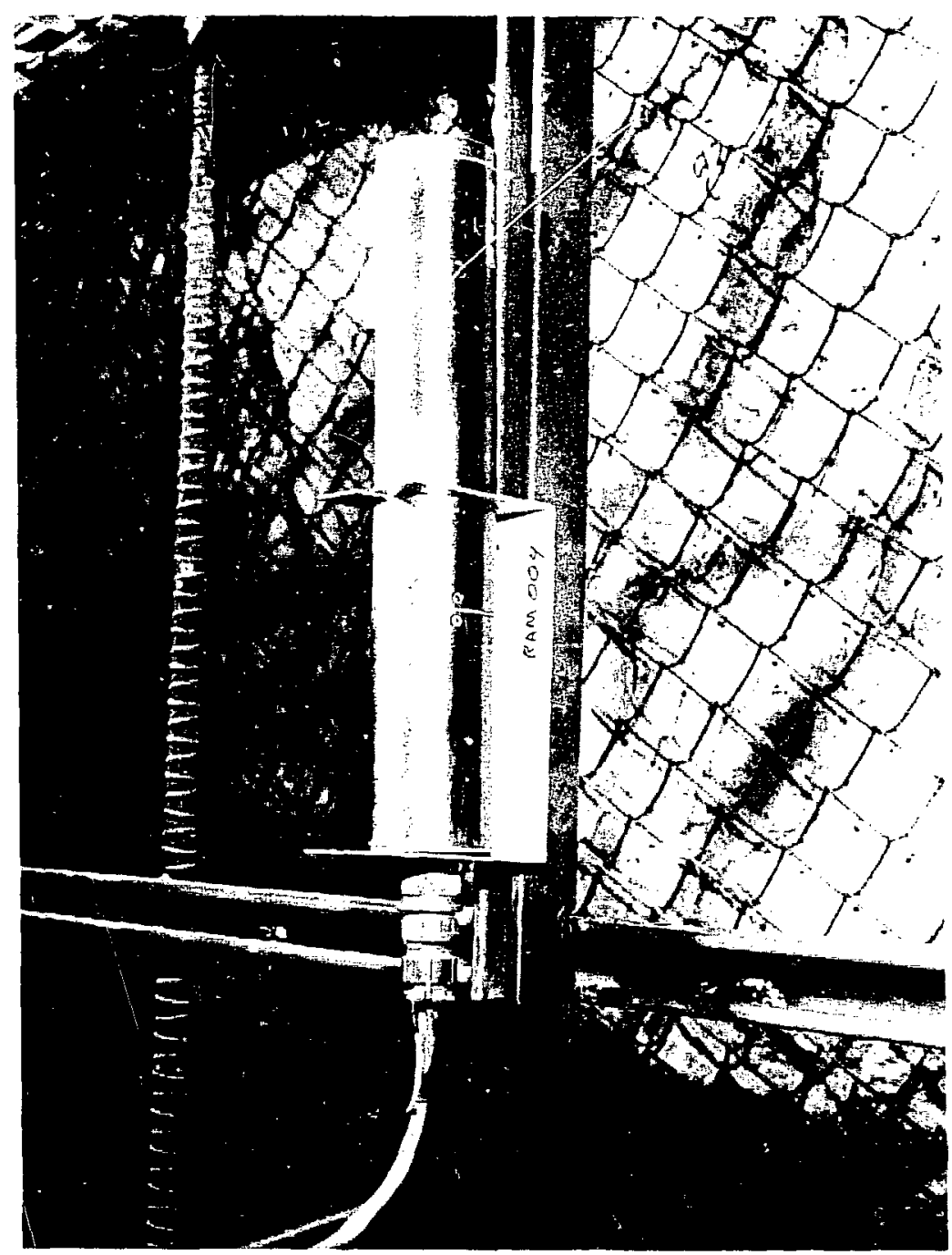

Figure 10. Typical RAM installation in the canister storage drift. 
Two fixed, high-level RAM probes were located on the canister headframe--one at the top looking down at the highway trailer cask, and the other at the bottom facing the access hole interface (see Fig. 8). The signal cables were run to the instrument bin located in the control skid, about $30 \mathrm{ft}$ away. The two low-level detector units have two different mounting locations, depending on which mode of operation the test is in.

During fuel handing operations, one detector is placed on the canister hoist headframe and the other is placed in the control skid with the operators. Additional mounting fixtures were provided so detectors could be located on either end of the HEPA filter to monitor its effectiveness during emergency operations. Two sets of cable runs were emplaced to facilitate the relocation of the detectors. The signal cables from the detectors go to the same instrument bin in the cratrol skid. From there, the signals go to the alarm circuitry and underground to the Drs multiplexers and digital voltmeters (the high-level units have local readout only). This installation was also straightforward.

Underground CAMs

All the air sample tubes wers installed by REECo. Additional sampling ports not normally plumbed into the CAM ionization chambers are shown in Fig. 9. Care was taken to keep a continual, gradual slope in the tubes to prevent water irom collecting in traps. The two ionization chambers were located in a NEMA enclosure in the Railcar Room (Fig. 11). The water trap, water collection tank, air flow pumps, and control valves were also located in the NEMA-type enclosure. The various signals were run back for signal processing to the Instrumentation Alcove and into the Overhauf and LLNL chassis. From these, the signals went to the alarm circuitry and the DAS.

\section{Surface CAMs}

Stainless-steel tubing was run from the port in the ventilation duct to the two CAM units in the control skid. The NMC ${ }^{85} \mathrm{Kr}$ unit mounts in the instrument bin used for the RAM units, and the overhauf ${ }^{3} \mathrm{H},{ }^{85} \mathrm{Kr}$ is mounted in an adjacent rack. An electrical heating wire was installed in 


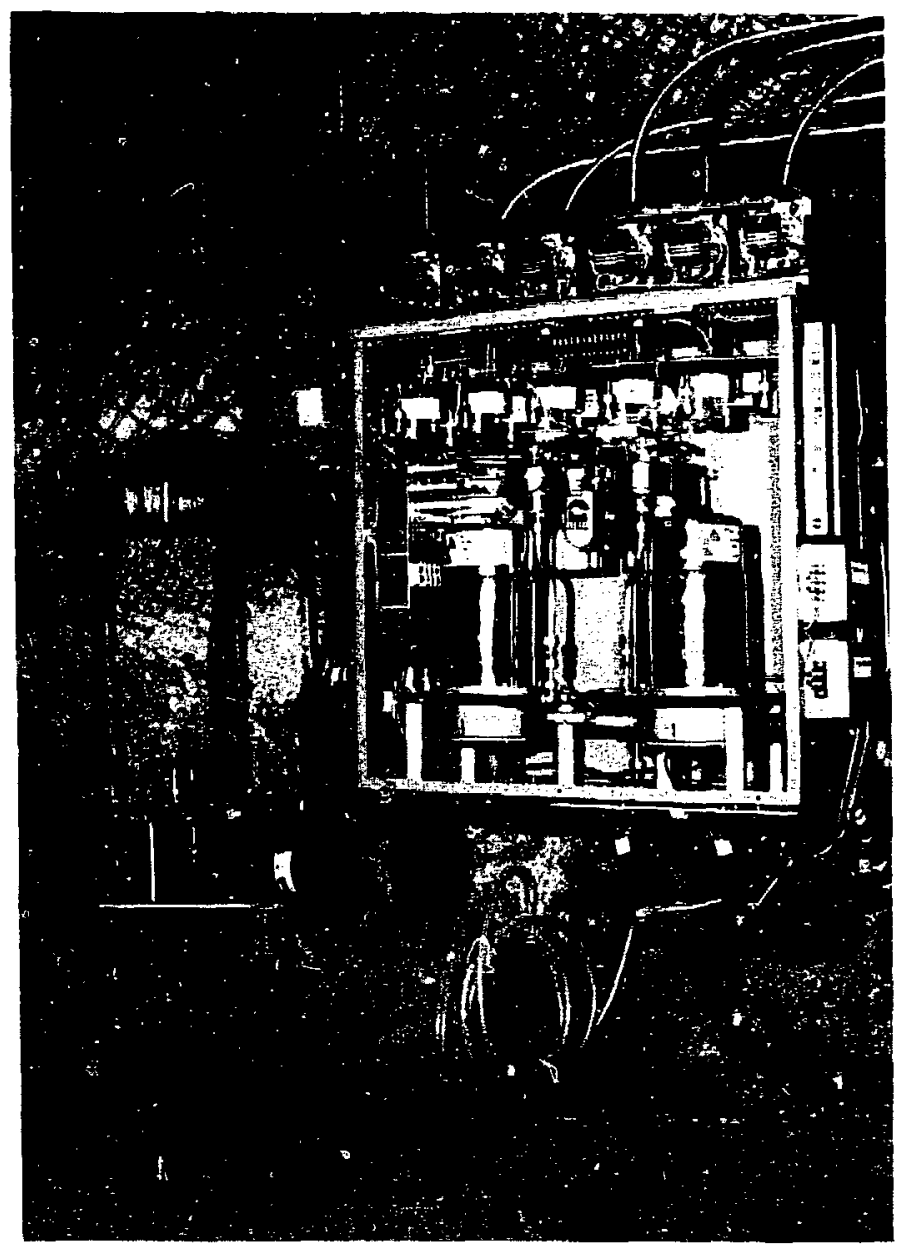

Figure 11. Underground CAM ionization chambers and tubing.

the air sample tube to prevent conder. tion of water and freezing during the colder months when the ambient air te.perature is lower than that of the underground exhaust air.

Local alarm circuitry is provided and electronic signals are routed underground to be read by the DAS. Twenty-four-hour emergency power is generated by a battery pack located next to the winch adjacent to the control skid. 
The portable ${ }^{3} \mathrm{H},{ }^{85} \mathrm{Kr}$ CAM and the portable beta-qamma, particulate CAM are stored at the test facility and are not powered up under normal zonditions. These units are to monitor the underground and exhaust air in case of emergency conditions. An unused sampling port is located on the exhaust duct on the surface, and 34 spigots with valves are underground for storage well sampling.

CALtBRATION

$\underline{\text { RAMS }}$

The RAMs have a pulsed light-emitting diode (LED) as an internal calibration source that can be turned on and off at the control module. More meaningful and accurate calibrations are performed periodically at the test facility by using ${ }^{226} \mathrm{Ra}$ sources $(5-90 \mathrm{mR} / \mathrm{h})$. Accuracy is not as critical as with the other :cientific instrumentation being used (as can be seen by the manufacturer's specifications!.

In calibration it is important to determine that the units are functioning properly and that they are performing at the same level of accuracy as when they were procured from the manufacturer. The high sensitivity of these units, which is required to measure low levels of radioactivity, makes it very difficult to achieve accuracy better than the \pm 158 reading. The units, which hüve calibrated quite well, are adjusted about every six months, and they continue to monitor personnel safety effectively.

\section{CAMS}

The chambers for the Betatec 210 CAM units have been modified to include $a^{90} \mathrm{Sr}$ calibration source. When put in the calibrate moce, a 0.4- $\mathrm{CC}$ source is exposed at the chamber, producing a reading equivalent to $\sim 180 \mu \mathrm{Ci} / \mathrm{m}^{3}$.

The NMC ${ }^{85} \mathrm{Kr}$ CAM and the portable CAM units are calibrated at LLNL, using radioactive sources. 
Both the RAM and CAM unit have performed quite well. There were some defects and damage when the units were first delivered. These were either repaired at LLNL or returned to the manufacturer for correction.

Circuitry stability has been an ongoing problem with the CAM units. The drift has been greater than what we hoped would be the worst case, which has set off alarms through the DAS when the siqnals dropped below the minimum set points.

The units were designed for personnel safety and they are performing that function adequately. From a scientific standpoint, the RAM and CAM units serve little, if any, purpose in the development of waste repository models.

RADIATION DOSIMETERS

\section{INTRODUCTION}

The original conception of tre Spent Fuel Test did not foresee the necessity of field measuring the nuclear radiation being propaqated from the spent fuel assemblies into the surrounding rock mass. Although a primary objective was to quantify any differences between the effects of heat alone and heat plus radiation, it was generally understood that radiation transport calculations would produce more accurate results than would radiation dose measurements.

However, a peer dejign review conducted by DOE-NV in June 1979, recommended that radiation dosimetry be included in the test. The rationale for this was summarized in a July 1979 memorandum to DOE-NV from LLNL, which stated, in part, that dosimetry was highly pertinent because of the uniqueness of spent fuel as a heat/radiation source. LLNL's basic premise was that it is better to calculate the radiation dosage to the rock than it is to measure it, since the dose cannot be measured in any statistically significant way. LLNL was very concerned about installing instruments in and near the canister emplacement holes (CEH) because of possible radiation shine paths. However, after extensive consideration of alternatives, LLIL devised a method of inserting dosimeters into the annulus between the steel 
liner and rock wall. Furthermore, radiation dose will be measured periodically during the test on some canisters. LLNL also included some measurements in the near-field (20 and $36 \mathrm{~cm}$ from the storage hole wall) thermocouple roles to check attenuation in the rock (see Table 2 ). Nonetheless, it was decided that the basic estimate of dose would still be based on calculations and initial dose measurements on the spent iuel assemblies themselves.

We concluded that the geometry of the spent fuel assembly was difficult to calculate, but that the calculation error was still comparable to that of existing measurement techniques. The basic accuracy of dosimeters is poor, (TLD crystals have a quoted accuracy of \pm 208 ) and the nature of spent fuel is such that there are nonlinear radiation variations of up to 158 both radially and axially, which can be calculated, but which would require ar extensive sy -em to measure.

LLNL has an ongoing program to evaluate the effects of radiation on the Climax granite, which has already subjected the rock to significant doses compared with that to be received during the SFT-C duration. Despite the fact that initial results indicated no deleterious effects, it was conceivable that some unknown effect might occur in situ. Nevertheless, even if such an effect would occur, it seemed relatively unimportant whether we knew the dose itself any better than it could be calculated.

Because of the aforementioned considerations, LLNL did not initially plan in situ dosimetry. We are now including some to increase th? credibility of the calculations.

\section{SCIENTIFIC CRITERIA}

The criteria for radiation dosimetry measurements stipulated the measurement of gamma and neutron levels on a few of the nuclear fuel assemblies. Because of time constraints, an intense and comprehensive measurement scheme was not required, and the accuracy was left at a best-effort level.

\section{DESIGN CRITERIA}

Several dosimetry techriques were reviewed and evaluated by LLNL. The sutcome was the selection of a technique proposed by EG\&G, Santa Barbara 
Table 2. Dosimeter locations in the field installation. 4

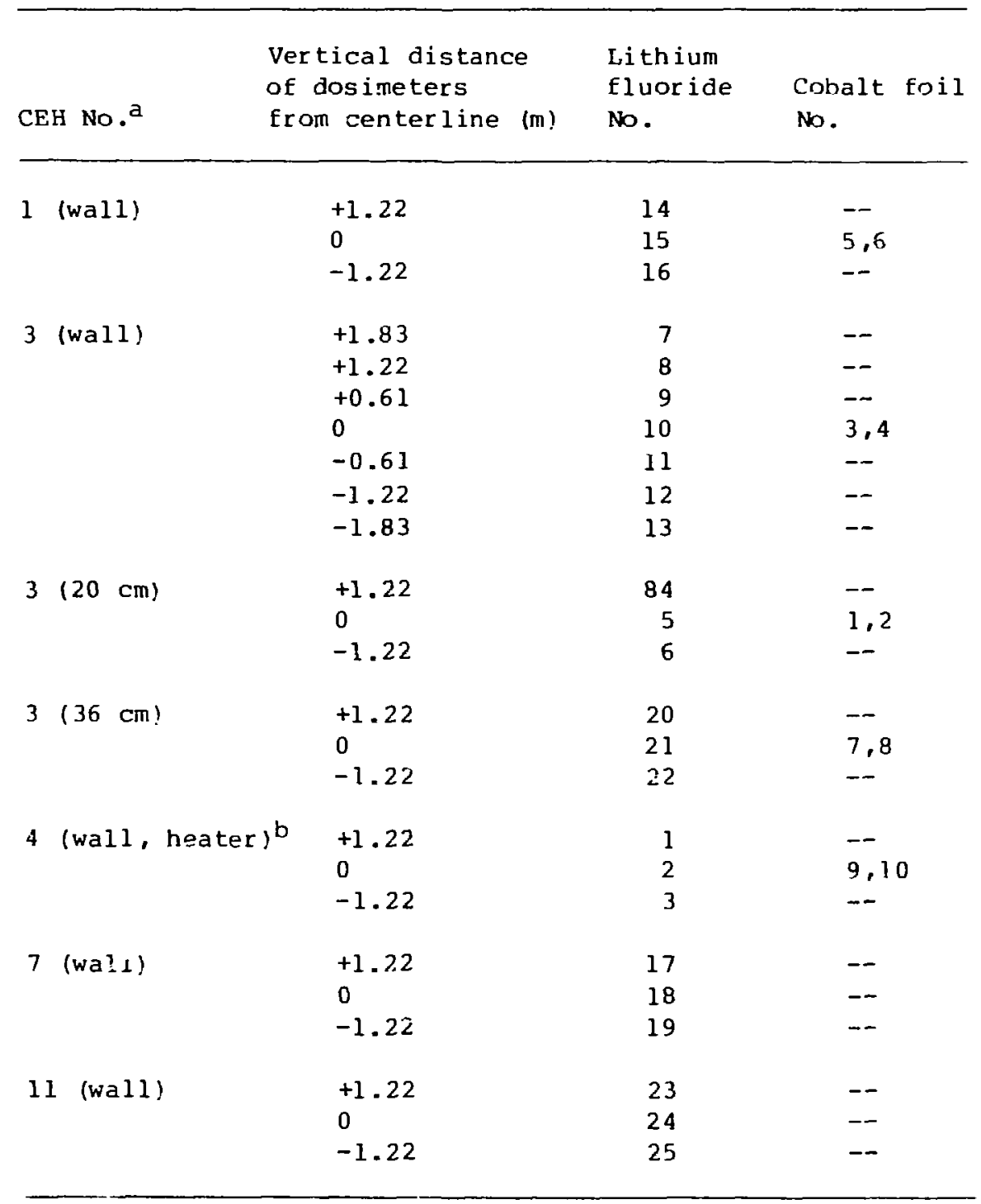

a Data in parentheses are used to denote radial locations of dosimeters relative to the borehole wall.

b $\mathrm{CEH} 4$ is an electrical simulator used as a nonradiative control.

Operations. They were contracted to design, construct, calibrate, install, remove, and evaluate the results of the dosimeters.

The technique involves use of lithium fluoride prisms to make gamma measurements. Both cobalt and nickel are used as neutron activation detectors. 
The dosimeter measurement scheme involved five of the 17 storage wells--one contairing an electrical simulator, and the other four containing spent fuel assemblies. Due to the annealing effect that heat has on the dosimeters, the electrical simulator dosimeters were required to facilitate consensuticn for annealing. The dosimeters associated with the electrical simulator were irradiated hefore emplacement to permit this.

The dosimeter quide tube assemblies, which were required to reduce radiation shine paths and to ease emplacement and retrieval, were the overriding factors in the design.

PROCUREMENT

A contract was let in Auqust 1979 with EG\&G, Santa Barbara for all work pertaining to radiation dosimetry measurements except for the quide tubes, which were hancled at LINI, and EG\&G, Las Vegas. The work ' ne by EG\&G was well documented by that company and will not be repeated here. 4

INSTALLATION

The dosimeters were installed without problem in February 1980.4 Figure 12 shows a dosimeter assembly being installed.

Table 2 summarizes the location of the 7 dosimeter assemblies, which contained 25 gamma dosimeter subassemblies and 5 neutron dosimeter subassemblies.

At the time of the fuel exchange exercise in January 1981, the radiation dosimeters were replaced with a new set of dosimeters. The first set is presently being evaluated and a report is forthcoming.

\section{CALIBRATION}

The radiation dosimeters were calibrated in the EG\&G laboratory before going to the field. ${ }^{4}$ 


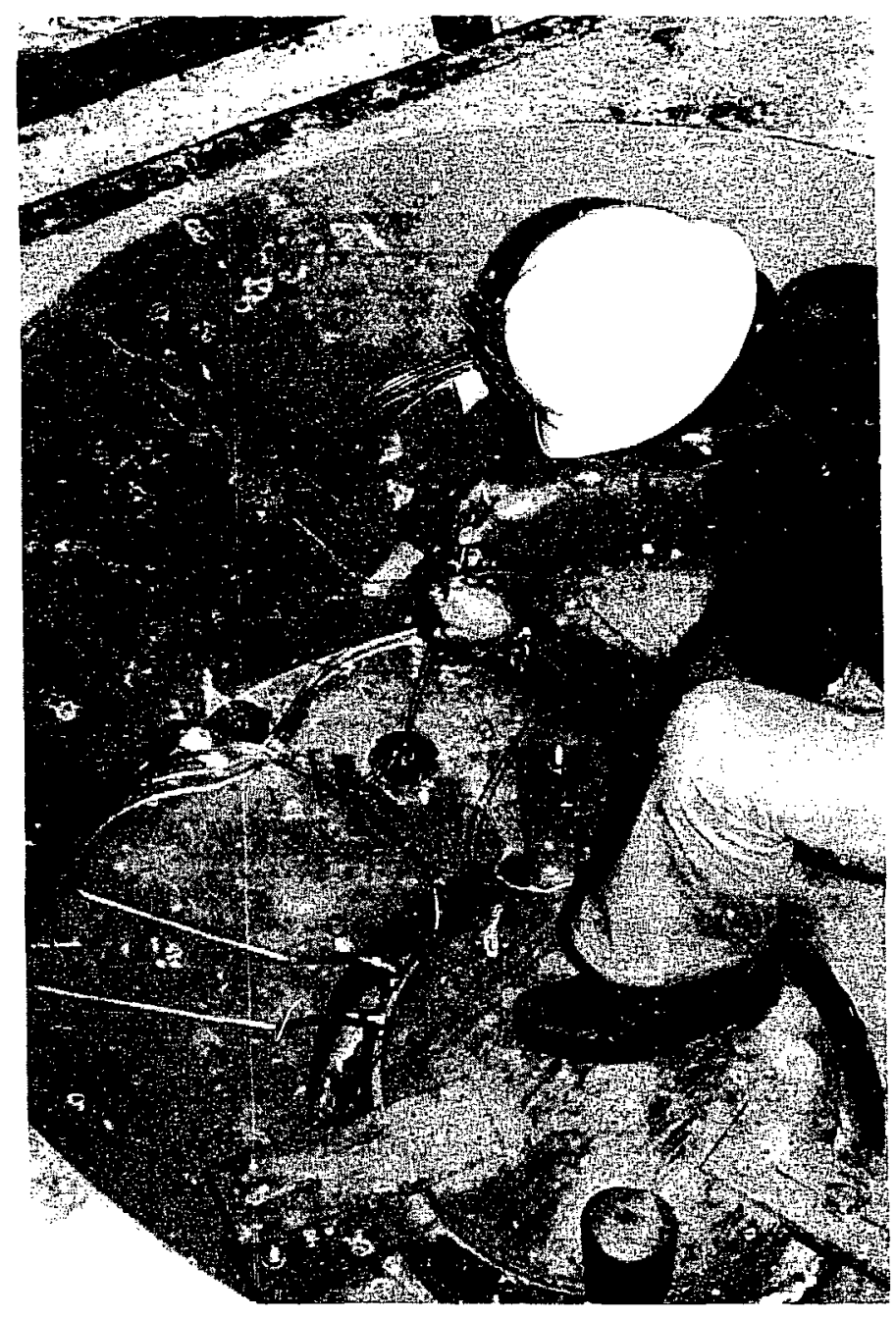

Fiqure 12. Installation of a radiation dosimeter assembly.

RESULTS TO DATE

The mechanical design of the dosimeter assemblies has proved very practical, and a full evaluation from EGaG on the first set of dosimeters is Forthcoming. 
INTRODUCTION

The SFT-C experiment has four objectives that require temperature measurement:

- Documentation of near-field simulation of a large array of spent fuel canisters.

- Determination of differences between spent fuel and thermally identical electrical simulators, as indicated by changes in near-field heat transfer.

- Description of the gross thermal field throughout the test facility.

- Maintenance of nuclear fuel assembly temperatures below a maximum permissible cladding temperature of $380^{\circ} \mathrm{C}$ las part of safe handling and storage objectives).

A total of 482 thermocouples are being used to determine the thermal field and fuel assembly temperatures. Voltages and resistances are measured and recorded by the DAS. The Livermore scientific group will compare these data with thermal calculations, which were made using various analytic, finite difference (TRUMP), and finite element (ADINA) codes. Use of these heat-flow codes in this test has been documented. $5-7$

\section{SCIENTIFIC CRITERIA}

The primary scientific interest in thermal measurements is to quantify and adequately describe the thermal field. This requires near-field thermal measurements around the spent fuel assemblies and electrical simulators, as well as intermediate-field thermal measurements in the rock mass around the storage drifts. The desired accuracy of these measurements was requested to be within $\pm 1.5^{\circ} \mathrm{C}$.

A secondary reason for thermal measurements was the desire for thermal correction of other instruments. No particular accuracy was specified. However, it was understood that greater accuracy than that of the thermal field measurements was desirable.

As explained in the technical concept document, 306 thermocouples measure the thermal field immediately around the 17 storage wells in the 
center drift (18 the emocouples per well). Another 116 thrimocouples are used to measure the temperatures along the multiple-point rod extensometers located in all three drifts. The remaining 60 thermocouples measure intermediate-field rock, drift air, stressmeter gage, and guard heater temperatures, as well as a reference electronic ice bath.

\section{DESIGN CRITERIA}

Listed below are the characteristics of a thermal sensing device that would be required in the spent Fuel Test. for near-field applications:

- Thermal range of $0^{\circ}-350^{\circ} \mathrm{C}$

- Insensitivity to high nuclear radiation fields

- Fairly high sensitivity $\left(\sim 40 \times 10^{-6} \mathrm{v} /{ }^{\circ} \mathrm{C}\right)$, accuracy, and long-term stability to provide an overall accuracy to within $\pm 1.5^{\circ} \mathrm{C}$ for $5 \mathrm{yr}$.

- Waterproof and corrosion resistant.

c Easily installed and removed for repair and calibration in small diameter boreholes $(5-10 \mathrm{~mm})$ to depths of $12 \mathrm{~m}$.

For intermediate-field applications, the immunity to high nuclear radiation fields would not be required, nor would the thermal range need to be as large $\left(0^{\circ}-100^{\circ} \mathrm{C}\right.$ would suffice).

Three basic sensing devices were considered for thermal measurements: the platinuin resisti ce thermometer (PRT), * the thermocouple, and the thermistor. Each of the devices has one or more "best features" for the needed application. Both the PRT and the thermistor were superior to the thermocouple in sonsitivity, eccuracy, and stability. The thermocouple was selected, however, dive to the other characteristics required, i.e., it would have a better chance of survival while still meeting the minimum requirements for sensitivity, accuracy, and stability.

A design incorporating a mixture of the three devices would have been acceptable, but the efforts required for additional designs, procurements, calibration and installation procedures would not have been cost-effective for the modest gain in already more than adequate data.

* RTD (the more familiar term) is used in other segments of this report interchangeably with platinum resistance thermometer (PRT). However, not all RTDs are of platinum. 
The next step was to select the appropriate type of thermocouple and related material, such as sheathing, insulation, and reference junctions. of the various types of common thermocouples, those of base-metal were considered a more appropriate group because of their greater sensitivity compared to noble- or refractory-netal thermocouples. Within the base-metal thermocouples (types $-T,-J,-E$, and $-K$ ), type-K (Chromel-Alumel) appeared to be the most promising from the literature ${ }^{8}$ detailing the use of thermocouples in environments similar to those expected in the spent Fuel Test. The Nicrosil-Nisil, a newer type of thermocouple, was reported ${ }^{9}$ to be similar to the type-K, with several inherent advantages. Hawever, the Nicrosil-Nisil was not readily available at the time, so the decision was made to use the type-K thermocouple for most temperature measurements. The next pilase required the selection of appropriate insulators, sheathing, and thermocouple terminations. Because of the likelihood that some thermocouples wold be immersed in water, a solid metal sheath was chosen. After chemically analyzing the groundwater at the site, the LLNL Materials Science Group recommended Inconel 500 as an appropriate sheathing naterial.

A standard insulating material used with metal-sheathed thermocouples is magnesium oxide. The only potential problem in using magnesium oxide is related to its hygroscopic characteristic. If the sheath has perforations, or the two ends of a tnerinocouple are not woll sealed, water will eventually penetrate the magnesium oxide and reduce its electrical resistivity. This oun affect the accuracy of the thermocouple. Extra care was, therefore, taken in inanufacturing and during installation to ensure good seals.

in selecting thermocouple terminations, it was understood that the time constants for most temperatures to be measured were on the order of hours, days, and weeks. Therefore, it was not critical to have a lo:v-mass or zxposed thermocouple junction. All instruments (whenever possible) were to nave a single electrical ground point as close as Easible to the point of signal generation. In terins of the thermocouples, this meant using the grounded configuration Eor the "hot" (measuring) junction. For the rhernacuple "cold" (reference) junction, pigtail leaks with an epoxy seal vere Eabicats furing thermocouple installation and connection to the reference block. To minimize errors and reduce the possibility of water fanage an corrosion, the thermocouples were designed with a continuous 
metal sheath from the measuring junction to the reference junction. This required thermocouple lengths Erom 9-50 $\mathrm{m}$ (30-160 ft).

The 1.6-mm (1/16-in.) diameter of the thermocouples was selected to Eacilitate installation in other instruments and assemblies already Eabricated or designed to accommodate 1.6-mm (1/16-i:t.)-diam thermocouples. Some thermocouples would be emplaced in holes drilled in the granite. To minimize air circulation in the holes and to facilitate thermocouple replacement and repair, small-diameter tubes up to $14 \mathrm{~m}$ (45 ft) long were grouted in the holes. The thermocouple had to be the appropriate diameter to allow enough flexibility for routing to the appropriate junction box, yot stiff enough to be pushed into the thermocouple tubes.

\section{Reference Block Design}

The reference block or zone box (as it is sometimes called! plays an important role in establishing the overail accuracy of the thermocouple measurements. The stability of the reference block or the extent to which its temperature can be accurately measured is very important. The overall accuracy of the the thermocouple temperatura measurement will never be better than the accuracy of the reference block temperature measurements. If the reference block temperature cannot be measured with greater accuracy than $\pm 0.1^{\circ} \mathrm{C}$, the thermocouple measurements will always be less accurate.

Several reference blocks were required due to the large number of thermocouples and the large physical area through which they were distributed. If the reference junctions were to be located in the Electronics Engineering Alcove, the thermocouples would have runs of over $120 \mathrm{~m}(400 \mathrm{ft})$ that would require a thermocouple extension wire and an additional mechanical connection between the thermocouple and the extension wire.

This could be improved if the reference blocks were located throughout the drifts at multiple stations. Available were 32-channel, passive reference blocks with a temperature uniformity specification of less than $0.03^{\circ} \mathrm{C}$ maximum temperature difference between channels for normal ambient variations, as well as a platinum resistance temperature detector (RTD) attached to the block to measure its temperature. Using the reference block and the RTD, an expected accuracy of $\pm 0.10^{\circ} \mathrm{C}$ could he achieved for the thermocouple reference block temperature. Actual accuracy would be 
determined during field thermocouple calibrations and would be integral to overall system accuracy.

In evaluating thermocouple distribution, a total of 20 reference blocks would be required: 14 in the central drift, 3 in the northern drift, 2 in the southern drift, and 1 in the Electronics Engineering Alcove. The reference blocks (though thermally insulated to maintain block temperature uniformity) would be enclosed in large, NEMA type-12, electrical enclosures to protect them from dust and damage due to rock spalling, which occurs naturally after mining a drift.

PROCUREMENT

After a review of the bids from several vendors, a purchase order was placed in August 1979 with the following technical specifications:

"1. 450 thermocouples $60 \mathrm{ft} \pm_{1} 0^{1},(\sim 18.3 \mathrm{~m})$ long.

2. 25 thermocouples $80 \mathrm{ft} \pm 0_{0}^{\prime}(\sim 24.4 \mathrm{~m})$ long.

3. 10 thermocouples with lengths of $160 \mathrm{ft} \pm 0_{0}^{1},(\sim 48.8 \mathrm{~m})$ long.

4. All thermocouples should be:

a. Inconel 600 sheath.

b. 1/16-in. O.D. (1.6 mm) .

c. Chromel-Alumel (type-K) with special limits of errors per ANSI* circular MC 96.1-1975.

d. Maqnesium oxide insulation.

e. Grounded junction.

f. 1-in. (25-mm) lead wires.

g. Thermocouple wire diam $0.012 \mathrm{in} . \pm 0.0015 \mathrm{in}$. $(0.305 \pm 0.038 \mathrm{~mm}$ ! .

5. All materials certification, fabrication, testinq, calibration, and other applicable procedures shall be done in conformance with ASTMT E585-76, standard specification for sheathed base-metal thermocouple materials, with the following modifications, exceptions, and options to that standard:

Paragraph 5.6--As specified (except the value of 100,000 Ma given in Table 2, which shall be replaced with 1,000 Mむft!.

* ANSI = American National Standards Institute.

$\dagger$ ASTM = American Society for Testing and Materials. 
Paragraph 5.7--As specified (except that minimum density shall be $65 \%$ instead of 708 ).

Paragraph 8.4.2--This test shall be performed before closures of the type-G (grounded) measuring junctions.

Paragraph 8.4.3--As specified (except for actual calibration

temperatures!. See comments on Section 57 below for actual

temperatures.

Paragraph 9.1--As specified (also copies of all test data, materials certifications, and calibration procedures called for

with this purchase order shali be provided with the thermocouples ).

The following supplementary requirements shall apply:

S2 As specified.

S3 As specified.

56 As specified.

S7 Prior to calibration of the sample thermocouples, thermal cycling of the measuring junctions shall be performed per Section 6.8 of ASTM E 235-76, except that the test medium temperature shall be $300 \pm 10^{\circ} \mathrm{C}$, and the immmersion time will be at least 5 minutes.

Instead of calibration temperatures called for in Table 4 (ASTM E 585-76), the following calibration temperatures and allowable deviations shall be used:

1. $0 \pm 1^{\circ} \mathrm{C}$.

2. $30 \pm 2^{\circ} \mathrm{C}$.

3. $100 \pm 5^{\circ} \mathrm{C}$.

4. $160 \pm 10^{\circ} \mathrm{C}$.

5. $300 \pm 15^{\circ} \mathrm{C}$.

\$9 As specified."

In selecting a standard for thermocouple fabrication, the following existing standards were evaluated:

"ASTM E235-76, Standard Specification for Thermocouples, Sheathed, Type-K, for Nuclear or for Other High-Reliability Applications. ASTM E585-76, Standard Specification for Sheathed Base-Metal Thermocouples Materials. 
ASTM E6u8-77 Standard Specification for Metal-Sheathed Base-Metal Thermocouples.

MIL-T 22300(SHIPS) Military Specification, Thermocouples, CorrosionResistant, Metal-Sheathed, for Nuclear Reactors.

RDT C7-6T (1975) Standard for Thermocouple Material and

Thermocouple Assembly, Chromel-p vs Alumel,

Stainless-Steel-Sheathed, Magnesium Oxide-Insulated.

RDT C7-16T (1976) Standard for Thermocouple Assemblies, Magnesium Oxide-Insulated, Stainless-Steel Sheathed."

The standard ASTM E235-76 was too rigorous for this application, necessitating an upgrade of ASTM E585-76, which fell somewhere between the two standards. The other standards listed were not as comprehensive or applicable to this project.

The thermocouples were received in November 1979 and forwarded to EG\&G, Las Vegas for acceptance testing and calibration. At the request of the scientific project personnel, some instrumentation was added to the experiment, which meant the procurement of additional thermocouples.

The second order included:

"1. 25 thermocouples $40 \mathrm{ft} \pm 1 \mathrm{ft}(\sim 12.2 \mathrm{~m})$

2. 10 thermocouples $60 \mathrm{ft} \pm 1 \mathrm{ft}(\sim 18.3 \mathrm{~m})$

3. 5 thermocouples $80 \mathrm{ft} \pm 1 \mathrm{ft}(\sim 24.4 \mathrm{~m})$

4. All other specifications are the same as the first order." This order was placed in October and EG\&G received the thermocouples in Deceminer 1979.

\section{Reference Blocks}

In July of 1979, 20 reference blocks were ordered. Each one had 32 channels, 3 wires, and a shielded plate with enclosure. The manufacturer's specification included:

"1. Temperature uniformity: $<0.03{ }^{\circ} \mathrm{C} \max$. temp. difference between channels for normal ambient variations.

2. Internal noise: none.

3. Electrical resistance: $1000 \mathrm{M} \Omega$ channel to channel and channel to ground. 
4. Capacitance: $8 \mathrm{pF}$ channel to channel and channel to shield; $2 \mathrm{pF}$ shields to ground."

The reference blocks were received in October 1979 and mounted in the NEMA electrical enclosures (Fig. 13).

A total of 25 (including 5 spares) modified platinum RTDs were procured from the same vendor. The specifications for the RTDs wert

"1. Resistance: $100 \mathrm{si} \pm 0.18$ a $0^{\circ} \mathrm{C}$.

2. Sensitivity: $0.00385 \frac{\Omega}{\delta 0^{\circ} \mathrm{C}}$.

3. Stability: $0.028 / y r$.

4. Operating range: $0^{\circ}-100^{\circ} \mathrm{C}$.

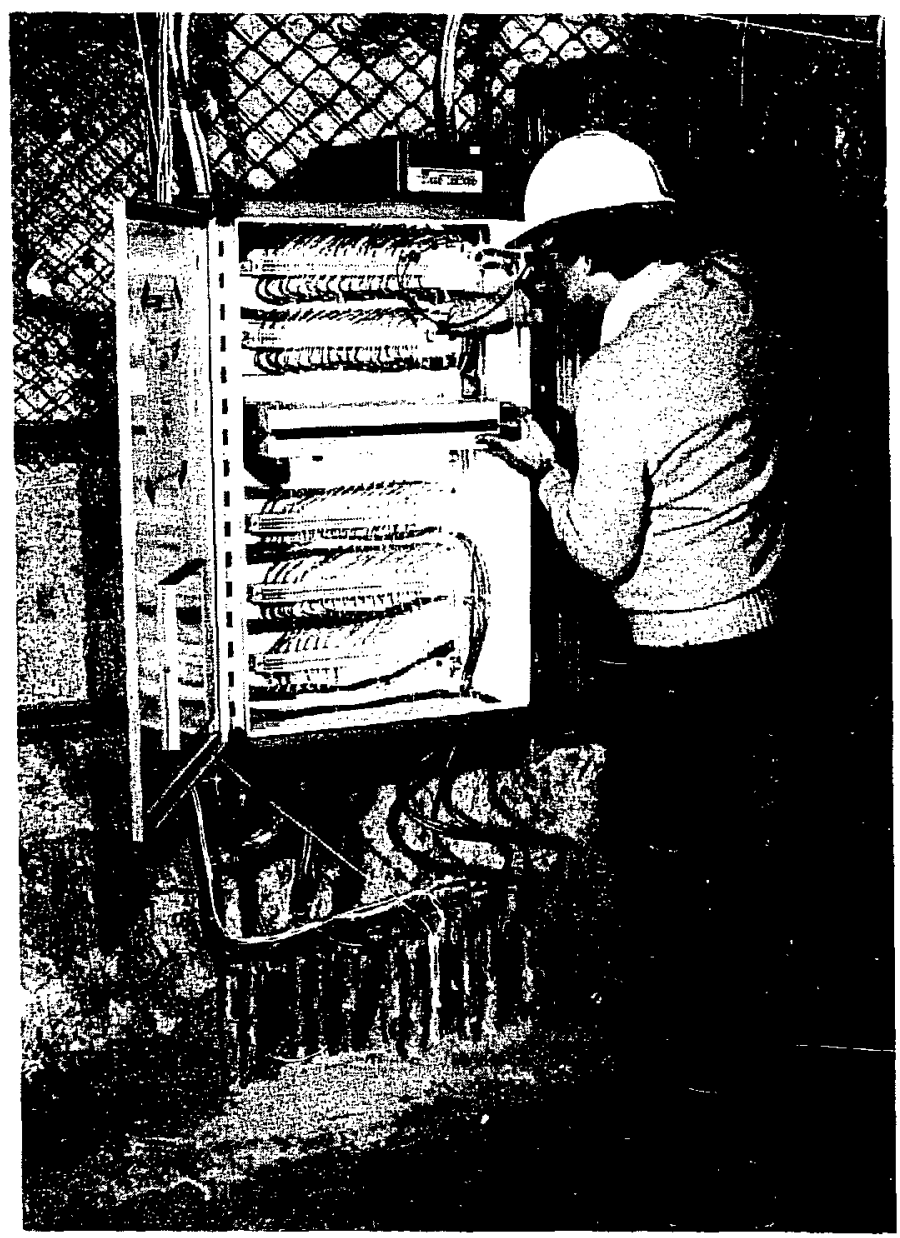

Figure 13. Typical thermocouple reference block confiquration. 
5. Input leads: 4-wire copper, $\sim 1 \mathrm{~m}$ ( $3 \mathrm{ft}$ ) long, 22 gage min.

6. Single-point calibration at $0^{\circ} . "$

These RTDs are of industrial grade (German standard DIN 43760). The higher, laboratory-grade RTDs were not needed and would have taken too long to procure. The accuracy of the RTDs was an order of magnitude better than for the thermocouples. They were delivered to EG\&G, Las Vegas for a second, independent calibration check in November 1979.

INSTALLAT ION

Ideally, all thermocouples should be installed so that each has a short, continuous run to a single, central, $0^{\circ} \mathrm{C}$ reference junction where a conversion to copper wire would be made. The copper leads for each thermocouple should then have a short $r$ un to a digital voltmeter for measurement. Each thermocouple should be mechanically fixed to the point or surface being measured and not act as a heat source or sink. It should also be in equilibrium with that point. In cases like the Spent Fuel Test, there are sometimes physical and cost-benefit limitations that prevent the ideal from becoming a reality. The installation of thermocouples is a critical part of providing accurate measurements. Considerable thought and care went into thermocouple installation and the results to date indicate that thermocouple measurement approaches, if not equals, the accuracy expected from an ideal installation.

The two major concerns for good installation were the depl syment of thermocouples over a physically large area (nearly $2000 \mathrm{~m}^{2}$ ), and the large number of thermocouples (over 480) that needed to be properly installed and calibrated. A possible source of errors could result from differing qround potentials throughout the test facility that could be picked up by the thermocouples (which could then produce thermocouple offset errors). Careful monitoring of design and installation of the utility power network ensured a minimum of ground potentials. The concern over installing and calibrating a large number of thermocouples was due to the likelihood of improper wiring and terminations, resulting from a reduction in the number of man-hours involved in performing simple checks. Over $8 \mathrm{~km}(5 \mathrm{mi})$ of thermocouple wire, $96 \mathrm{~km}$ $(50 \mathrm{mi})$ of instrumentation wire, and 10,000 connections were checked. End-to-end system calibrations were performed wherever possible as a final check to verify thermocouple accuracy and proper installation. 
End-to-end and any future calibration would require access to the thermocouples. In most cases this was possible, but in some cases the inaccessibility prevented end-to-end checks and calibrations.

The thermocouples divided into three types of installations. The first was used for air temperature measurements. This involved a tatal of $s i x$ thermocouples. These units were suspended from the $r$ ib or back of the drifts and were wired into their appropriate reference blocks. Fiqure 14 shows a group of thermocouples terminated to a reference block. End-to-end calibration checks were then performed, and an RTD was mounted in the central underside of each reference block (Fig. 15).

The second group of thermocouples (numbering 62) was inserted into boreholes and permanently grouted into place. Depths ranged from ahout 1.5-12 $\mathrm{m}(5-40 \mathrm{ft})$. The thermocouples were attached to rod extensometers and stressmeters, and could not be connected to the reference blocks before empiacement in the boreholes. As a result, no end-to-end calibrations could be made. The thermocouples themselves were, however, calibrated in the laboratory before being sent to the field. The thermocouples on the central arift rod extensometers were epoxied to the anchor bladder assemblies, and routed through electrical conduit (cemented in the floor), and over to the reference blocks.

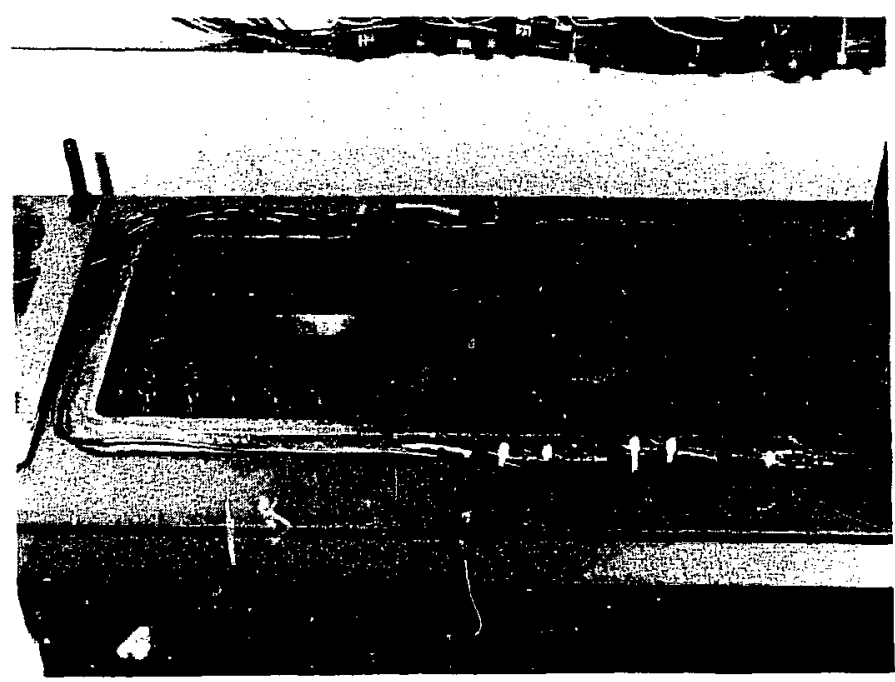

Figure 14. Typical thermocouple terminations on reference block. 


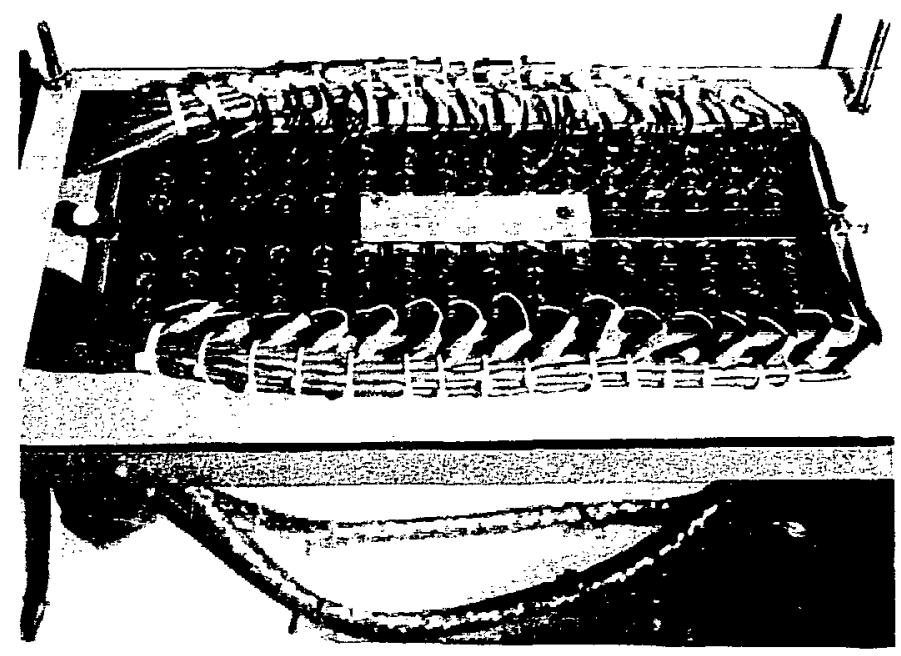

Figure 15. Typical bottom view of thermocouple reference block showing RTD and cabling.

The thermocouple length was cut for termination to the reference block. The sealant used by the marufacturer at the piqtail leads was not considered a durable moisture barrier, so all the thermocouples were reterminated using the following procedure:

1. Cut to length, allowing for a few feet of slack.

2. Trim back the metal sheath about 1 in. by using a standard thermocouple metal-sheath-stripping tool.

3. Clean magnesium oxide from the wire leads using a sandbiaster and silicon dioxide beads.

4. Drive residual moisture from magnesium oxide in the last fost of the thermocouple sheath using a heat gun. Heat gun temperature at the sheath cannot exceed $300^{\circ} \mathrm{C}$ or permanent damage might occur in the thermocouple.

5. Separate the pigtail leads and seal the end with epoxy (Epoweld 8173 by Hardman, Inc.). Let stand $30 \mathrm{~min}$ for curing.

6. Test for electrical resistanct, lead to lead and lead to sheath. If good, the thermocouple should be connecter to the reference block. If bad, the thermocouple should be repaired or replaced. The third group of thermocouples (totaling 413) has been irstalled so that they can be removed for calibration or replacement with a minimal amourt of 
effort. Of the 413 thermocouples, 102 are mounted on the spent fuel and electrical simulator canisters, and 102 are mounted on the 17 canister liners. The canisters and liners were designed and fabricated by Westinghouse, to include sections of 6.4-mm (1/4-in.)-diam stainless-steel tubing with varying lengths of $19-\mathrm{mm}\left(3 / 4-\mathrm{in.}_{\text {) }}, 60^{\circ}\right.$ stainless-steel angle to facilitate guiding the thermocouples into position. The routing of the thermocouples went from the canisters and liners into the sidewalls of thro storage pits. From the storage pits, the thermocouples wore routed through electrical conduits embedjed in the concrete floor, over to the wall of tire drift, and into the reference blocks in the NEMA 12 enclosures.

Installation of the thermocouples on the spent fuel assemblies occurrod after fuel emplacement, but before the storage pit plugs were emplaced. In fact, access to any of the 306 thermocouples installed close to the fuel assemblies and electrical simulators requires the storage pit plugs be removed by the railcar hoist. Witn the pit plugs removed, there is a small, but measurable amount of radiation in the storage pits containing the spent fisel assemblies. A special procedure was written to ensure proper thermocouple installation on the spent fuel canisters and to monitor all radiation exposure received by the technicians installing the thermocouples. Figure 16 shows thermocouples being installed onto an emplaced fuel canister.

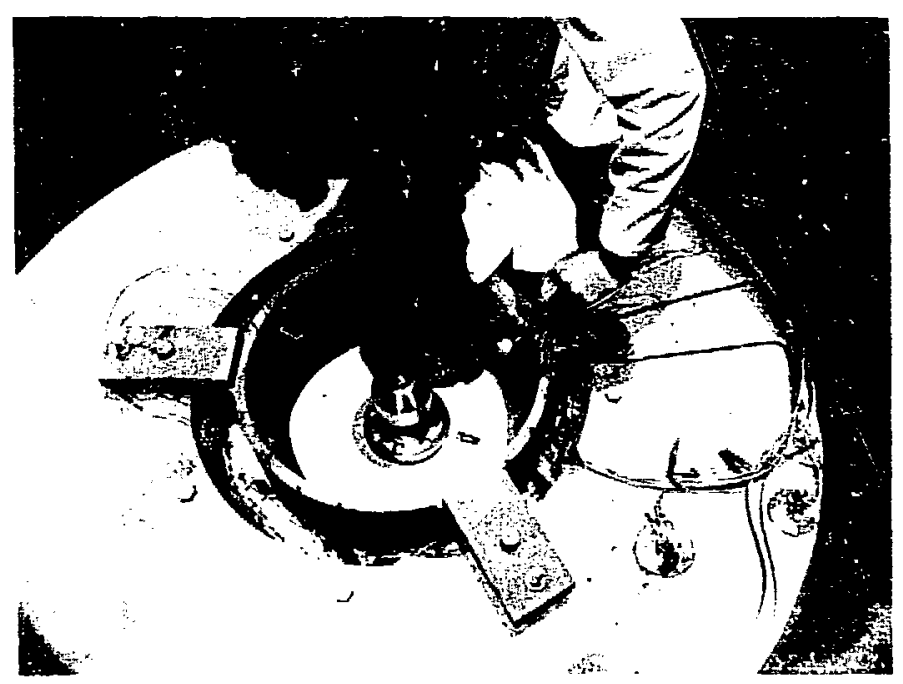

Figure 16. Installation of thermocouples on a nuclear fuel canister. 
Into the Eloor of each storage pit two boreholes were drilled (as depicted in Fig. 17). Three thermoccuples were installed in each borehole, requiring 102 thermocouples 13 thernocouples/borehole " 2 boreholes/storage pit 17 storage pits) for the center drift. These thermocouples are reinovable and are routed through the same electrical conduit as the canister and liner thermocouples.

Fiqure 18 depicts the 60 thermocouples installed in the boreholes running adjacent and parallel to the rod extensometers in the north and south drifts For the "mine-by" phase of the experiment (executed during the construction of the test facility?. Also shown in Fiq. 18 are 16 other thermocouples that were installed below the floor elevation in boreholes angled toward the center drift. All of these units are removable.

Figure 19 shows the location of 28 thermocouples added to the tost as result of a peer review. (A request had been made for some additional intermediate-field thermal measurements.! Four of these thermocouples were clamped to a tubular heater located in one of the nor th drift heater holes.

The remaining three thermocouples emplaced in boreholes were located in the tail drift adjacent to the Electronics Enaineering Alcove. All three thermocouples are installed about $15 \mathrm{~m}$ (50 ft) into the rock where the temperature is not expected to vary during the course of the experiment. These thermocouples act, therefore, as system references and verify the stability of the ice bath.

The 205 thermocouples associated with storage pits, mine-by extensometers, and intermediate-field temperature measurements were mounted into boreholes using a common technique. It was considered vital that the thermocouples be easily retrievable were failures to occur, or for periodic recalibration. Figure 20 depicts the basic mechanism for positioning thermocouples in the boreholes and Fig. 21 shows a typical installation. stainless-steel tubing was cut to lengths corresponding to the depths the thermocouples were to be inserted into boreholes. Tubing for the shorter lengths $(\leq 6.1 \mathrm{~m}[\leq 20 \mathrm{ft}]$.$) was 4.76-\mathrm{mm}(3 / 16-\mathrm{in}$.$) O.D. \times 0.51-m m$ (0.020-in.) wall. If a borehole had a thermocouple emplaced deeper than $6.1 \mathrm{~m}$, all the tubes for that borehole would have to have been cut from the 6.35-mm O.D. stock. Only one thermocouple was $r$ un in any given tube. The assemblies were grouted into place with the same grout mix used on the storage liners (H\& $N 79-I G)$. 


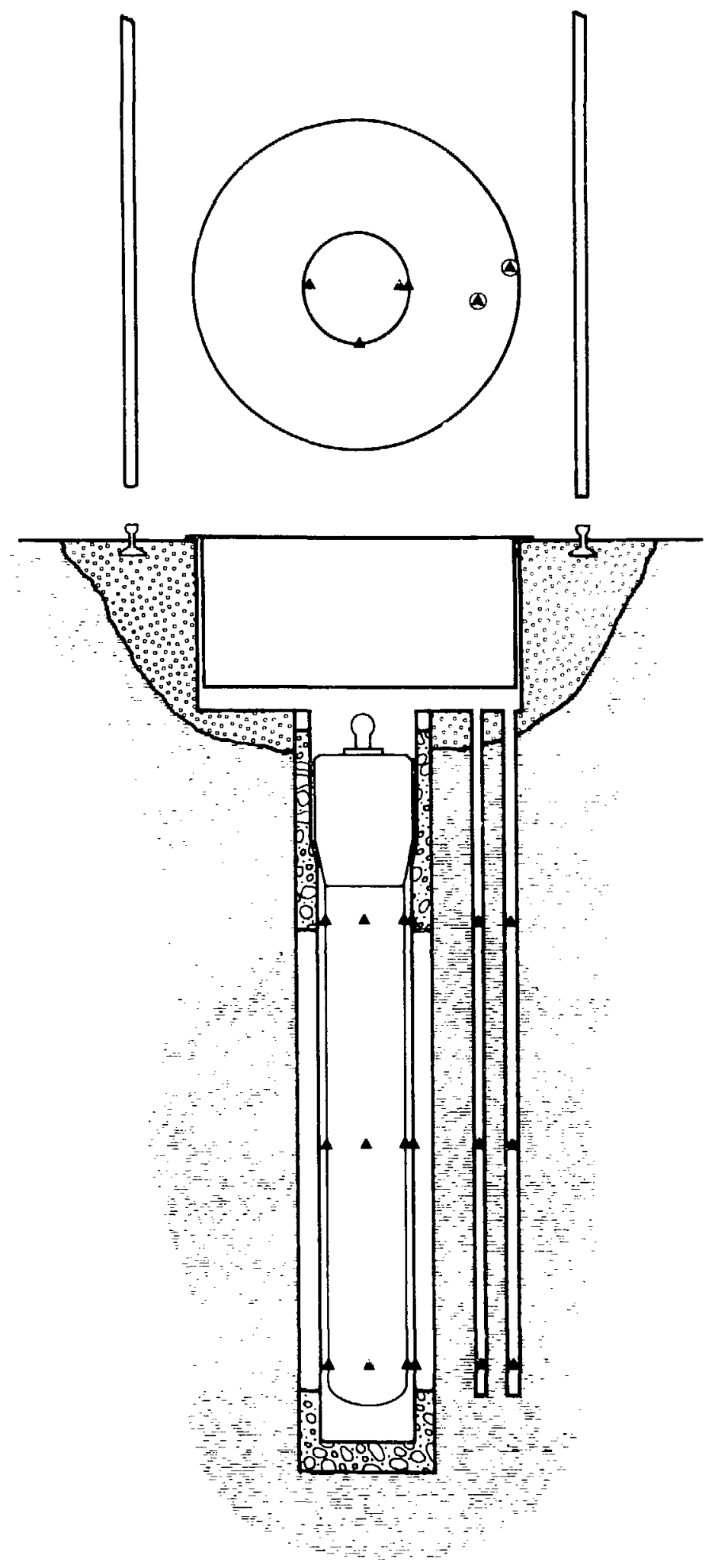

Figure 17. Near-field thermocouple locations are designated with triangles. 

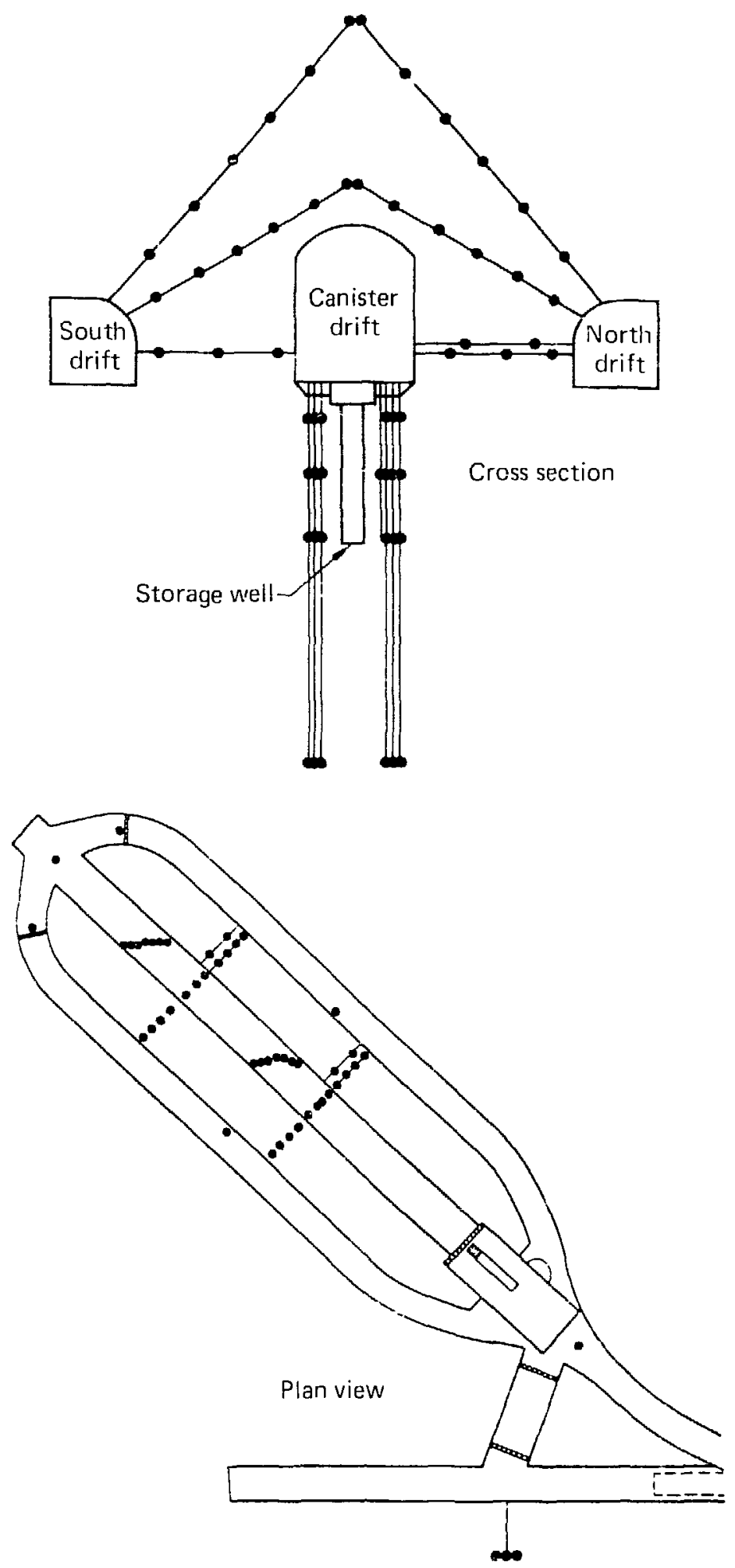

Figure 18. Intermediate-field thermocouple locations in the storage facilicy are indicated by dots. 

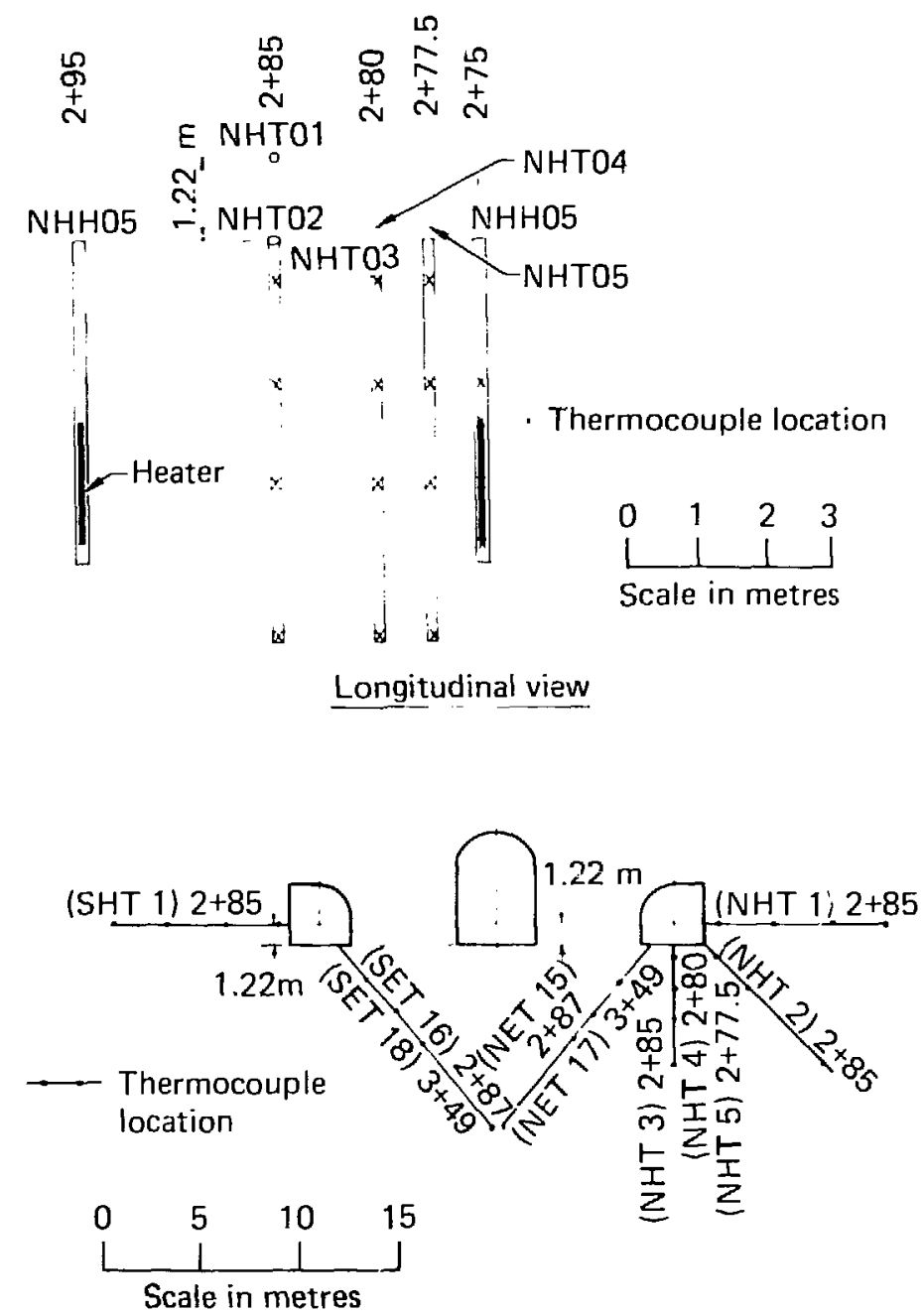

Axial view

Figure 19. Additional intermediate-field thermocouple locations.

All thermocouples installed in this manner were cut to length, reterminated, wired to the reference blocks, and then calibrated. The length of thermocouple wire to be inserted in the borehole was uncoiled and tagged at the point where it would be flush with the tube-assembly face once fully inserted into its tube. If, for some reason, the thermocouple could not be placed to the planned depth, the difference was measured and recorded in a field notebook. 


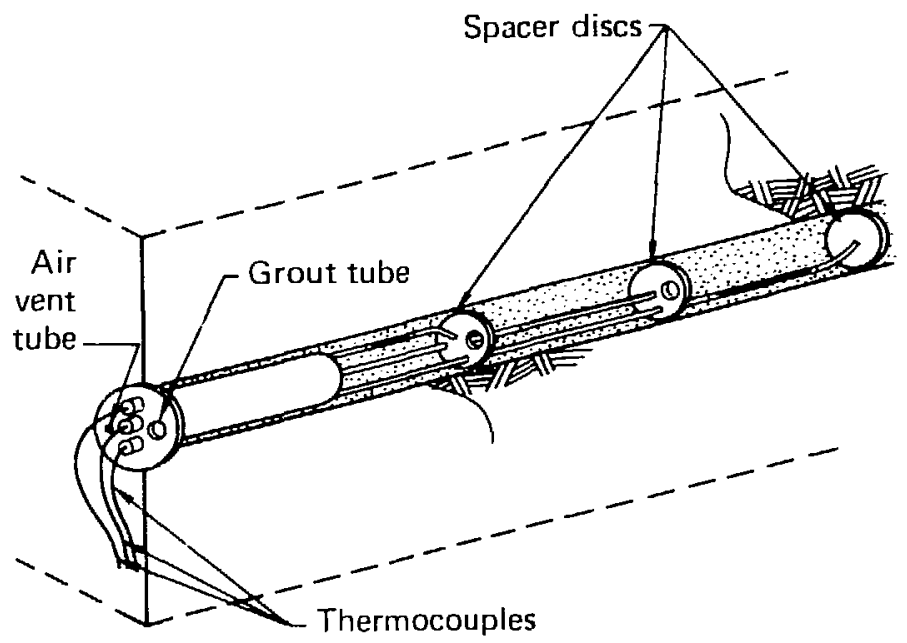

Figure 20. Typical mechanical configuration of installed thermocouples.

After the installation of all thermocouples, the DAS measured the loop resistances of all the thermocouples as a base reference.

\section{CALIBRATION}

\section{Incoming Inspection}

Before proceeding with calibrations, a loop resistance check was made on each of the 525 thermocouples. A total of 13 thermocouples failed the loop resistance check and were returned to the manufacturer for repair. The 13 thermocouples were repaired and checked again on return. At the time, all the repaired thermocouples passed the loop resistance test. The Chrome1-Alumel loop resistance was measured at the pigtail leads of each thermocouple and the measured values were recorded along with the thermocouple serial number. Calculated estimates of loop resistance are given in the table based on material, wire size, and length.

\begin{tabular}{|c|c|}
\hline Nominal length $(\mathrm{m}[\mathrm{ft}])$ & $\begin{array}{l}\text { Calculated } \\
\text { resistance (S })\end{array}$ \\
\hline $12.2\langle 40\}$ & $178+46$ \\
\hline $18.3 \quad(60)$ & $264 \mp 67$ \\
\hline $24.4 \quad(80)$ & $553 \mp 89$ \\
\hline $48.8(160)$ & $703 \pm 175$ \\
\hline
\end{tabular}




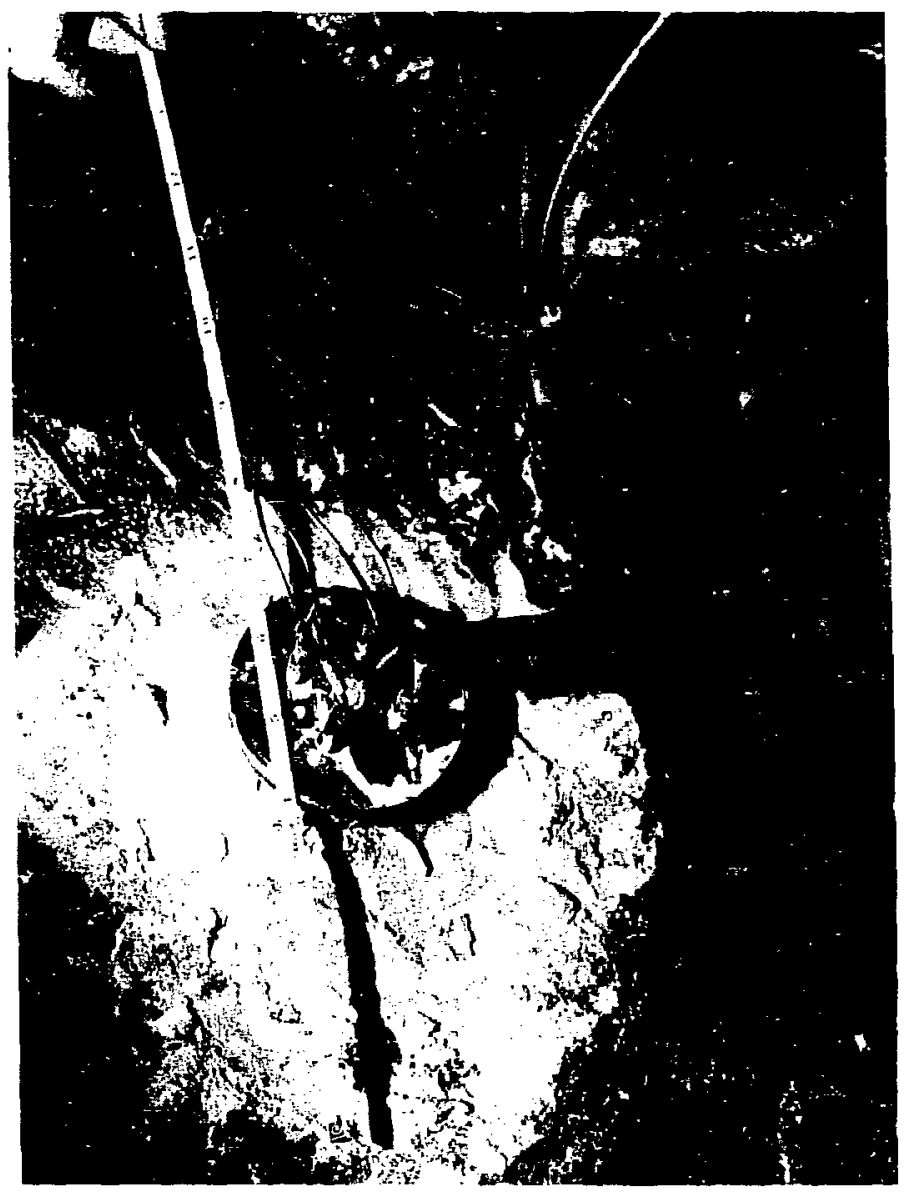

Figure 21. Typical grouted thermocouple installation.

\section{Laboratory calibration}

In addition to the loop resistance check, a temperature cycling check was performed on 12 thermocouples. The objective of this test was to observe whether a change occurred in thermocouple sensitivity or offset due to temperature cycling. This was accomplished by first calibrating the 12 thermocouples at temperatures of approximately $20^{\circ}, 50^{\circ}$, and $150^{\circ} \mathrm{C}$. The thermocouples were then baked at $275^{\circ} \mathrm{C}$ for $30 \mathrm{~min}$ and thereafter calibrated again at the same temperatures. The differences from the two calibrations were on the order of several $1 / 100 \mathrm{~s}$ of $1^{\circ} \mathrm{C}$, which is within the range of uncertainty of the calibration equipment. During all phases of manufacturinq, testing, and calibration, the thermocouples were not permitted to exceed a temperature of 
$310^{\circ} \mathrm{C}$ in order to avoid short-ranqe atomic ordering effects that cause thermal emf drifts. During the course of the experiment, only a few thermocouples will exceed $310^{\circ} \mathrm{C}$, and those will be for noncritical measurements on a resistance heater element.

The remaining laboratory calibrations involved only the 62 thermocouples that would be impossible to calibrate once taken to the field isince they would have to be grouted in boreholes with other instrumentation before being wired into the DAS). Calibration was performed at EG\&G, Las Veqas.*

Basically, the calibration consists of measuring each thermocouple at $0^{\circ}$, $50^{\circ}$, and $150^{\circ} \mathrm{C}$. A Rosemount Model 9l1Al ice bath is used for the $0^{\circ} \mathrm{C}$ measurement, a Kaye Model HTRI50 temperature reference for the $50^{\circ} \mathrm{C}$ measurement, and a Procedyne Model TH050 dry bath for the $150^{\circ} \mathrm{C}$ measurement. The reference ice bath for the cold junction is a Kaye Model K140-4. The actual temperatures of the three baths were measured with precision platinum-resistance thermometers. The worst case error of the calibration system is $\pm 0.11^{\circ} \mathrm{C}$, while the typical error is estimated to be $\pm 0.07^{\circ} \mathrm{C}$. All thermocouples calibrated fell within the special limits of errors $\left( \pm 1.1^{\circ} \mathrm{C}\right)$. Table 3 summarizes the results of the laboratory and field calibrations. National Bureau of Standards conversion tables were used to derive the temperatures from the voltage measurements.

The remaining 463 thermocouples not laboratory calibrated were sent to the Nevada Test site to be field-calibrated after installation in the DAS.

\section{Field calibration}

Field calibration was performed to achieve the most accurate calibration possible. Depending on the circumstances, field calibration can be more accurate than laboratory calibration, even though laboratory equipment is generally more precise than field calibration equipment. The problem with laboratory calibrations is that they calibrate the instrument rather than the system. In the field the instrument is in an environment where other material and man-made phenomena contribute to producing a signal that may be different from that generated in the laboratory. Errors result from differences in grounding schemes, cabling, switching networks (when multiplexing), and measuring devices. A common mistake is to confuse the accuracy of collected

* The procedure for the calibrations is detailed in the EG\&G (Laboratory C) SFT-Climax, Field and Laboratory Calibration Data Notebook. 
Table 3. Thermocouple errors measured prior to fuel insertion.

\begin{tabular}{|c|c|c|c|c|}
\hline \multirow{2}{*}{$\begin{array}{l}\text { No. } \\
\text { thermocouples } \\
\text { cal ibrated }\end{array}$} & \multirow{2}{*}{$\begin{array}{l}\text { Calibration } \\
\text { temp }\left({ }^{\circ} \mathrm{C}\right)\end{array}$} & \multicolumn{3}{|c|}{ Error $\left({ }^{\circ} \mathrm{C}\right)$} \\
\hline & & Mean & $\begin{array}{l}\text { Std } \\
\text { dev }\end{array}$ & $\operatorname{Max}$ \\
\hline 404 & 0 & 0.020 & 0.059 & -0.414 \\
\hline 179 & 50 & -0.016 & 0.059 & 0.227 \\
\hline 394 & 150 & 0.250 & 0.367 & 1.232 \\
\hline
\end{tabular}

data with the accuracy of the instrument itself, especially without taking into consideration the accuracy of the whole system used to collect the data, and the effects of the surrounding environment.

One of the objectives of field calibrations was to wire in instruments and, as far as possible, to locate physically where they would be during the experiment. A portable calibrating system was configured for use in the three drifts. The procedure for field thermocouple calibration is recorded in detail in the EG\&G Field and Laboratory Calibration Notebook. Most of the equipment used in laboratory thermocouple calibrations was used again for the field thermocouple calibrations.

Instead of being wired into an ice-point reference junction, the thermocouples were now connected to one of 20 passive reference blocks (Kaye Model UTR-AS!. The temperature of each reference block was measured with a platinum resistance thermometer (PRT)--also called a resistance temperature detector (RTD)--that was mounted on the thermocouple reference block.

To measure temperature, the thermocouple signal, the measuring junction RTD, and the reference junction RTD were measured by the DAS. The DAS tonk the raw data and converted it to engineering units (degrees Celsius in this case!, and then stored both the raw and converted data in a file.

Most thermocouples were commonly inserted into guide tubes in the granite or alongside the fuel canisters. However, to do the field calibrations, those thermocouples had to be left out of the quide tubes, calibrated, and then inserted.

Thermocouple calibrations were performed over a period of four weeks during March and April 1980. Table 3 summarizes the results of that set of calibrations, including laboratory calibrations. 
A similar calibration was performed on a few thermocouples during a fuel exchange in January 1981, approximately 10 mo after the first field caibration and fuel emplacement. These thermocouples were at about $140^{\circ} \mathrm{C}$ the entire 10 months, and were in a nuclear radiation field exceeding $50,000 \mathrm{R} / \mathrm{h}$. The results of that calibration are listed in Table 4.

The differences between the March 1980 and the January 1981 calibrations for these few thermocouples are considered neqliqible and approach the limits of accuracy and calibration equipment resolution. Therefore, no statistically significant differences were detected.

\section{RESULTS TO DATE}

It was concluded from the second calibration that the thermocouples performed very well and can be expected to provide accurate thermal data for the duration of the experiment. Subsequent calibrations will continue to monitor the level of thermocouple performance. To date, two thermocouples were damaged beyond repair during installation, and three others thermocouples were unavoidably destroyed in December 1980 during the removal of some stressmeters. All other thermocouples have performed well.

Table 4. Thermocouple errors measured during January 1981 fuel exchange.

\begin{tabular}{lcccc}
\hline & & \multicolumn{2}{c}{ Error $\left({ }^{\circ} \mathrm{C}\right)$} \\
\cline { 3 - 5 } $\begin{array}{l}\text { No. } \\
\text { thermocouples } \\
\text { calibrated }\end{array}$ & $\begin{array}{l}\text { Calibration } \\
\text { temp }\left({ }^{\circ} \mathrm{C}\right)\end{array}$ & Mean & $\begin{array}{l}\text { Std } \\
\text { dev }\end{array}$ & Max \\
\hline 6 & 0 & 0.096 & 0.050 & 0.177 \\
6 & 150 & 0.290 & 0.085 & 0.411 \\
\hline
\end{tabular}


DEW-POINT SENSORS

SCIENTIFIC CRITERIA

In an effort to quantify the thermal energy absorbed by the granitic rock during fuel storage, it is necessary to measure the outputs of the thermal sources (fuel assemblies, electrical simulators and heaters, liqhts, and incoming air!, as well as the thermal energy lost to the external environment (energy absorbed and carried of $f$ via the ventilation system instead of being absorbed by the rock) .

All but one of the thermal energy sources were measured directly with watt transducers and indirectly with thermocouples. The one other enerqy source (or sink as it may be! is the airstream flowing through the facility. After some preliminary calculations, it was apparent that a significant percentage $(\sim 308)$ of the thermal energy dissipated during the life of the test might be discharged to the airstream. Thus, it was imperative that the energy lost to the airstream be measured.

Water vapor in the air stream represents a potential loss in enerqy. This may occur in one of two ways. First, if air with a qiven dry-bulb temperature at the facility intake has a higher temperature when it leaves the facility through the exhaust, there has been a net increase in energy in the form of heat added to the air/water vapor mixture. Second, if the water vapor is a given percentage (by volume or weight) of the air at the facility intake and leaves with a higher percentage, then there has been a net increase in energy in the form of added water vapor, which is carried off. Since the latent heat of vaporization is 540 times that of its specific heat, much more energy is required to add a kilogram of water to the airstream than to raise the temperature of a kilogram of water vapor a few degrees. The remaining portion of energy in the airstream is contained in the air 1788 nitrogen, 21\% oxygen). If the exhaust dry-bulb temperature is greater than the intake temperature, there is a net amount of energy being carried out by the air.

The net amount of energy entering or leaving the test facility via ventilation could be determined if the elevation $(\sim 1,130 \mathrm{~m}$ or $\sim 3700 \mathrm{ft}$ above sea level) were known, and the air flow rate $\left(\sim 156 \mathrm{~m}^{3} / \mathrm{min}\right.$ or $\sim 5500 \mathrm{ft} / \mathrm{min}$ ), the intake and exhaust dry-bulb temperatures, and the absolute humidities were measured. The measurement discussed in this section is that of absolute 
humidity, i.e., the measurement of water vapor in air. The scientific criteria stipulated that water vapor should be measured to within 10 of actual values.

DESIGN CRITERIA

This subsection will elaborate on the selection of instruments to determine absolute humidity. Measurement of the other parameters (e.g., air-flow and dry-bulb temperatures) is required to determine the energy level of the water vapor and the rate at which it is leaving the facility.

Absolute humidity can be determined directly or indirectly. It can be directly determined by ascertaining the dew point (or frost point), wet-bulb temperature, or volume or mass ratio.

Indirectly, it can be determined by the percentage of relative humidity (RH), and by dry-bulb temperature.

Before choosing from among the various instruments available and the applicable parameters used to measure absolute humidity, the required operating range and accuracy were determined. An RH meter and a bimetallic thermometer were used to measure the relative humidity and dry-bulb temperature in the test facility during its construction phase. The relative humidity was typically 708 , and the dry-bulb temperature was typically $21^{\circ} \mathrm{C}$. This equaled a dew-point temperature of about $15.5^{\circ} \mathrm{C}$. We had estimated that during the storage phase the dew point would probably drop at first (a large quantity of water was being used to mine the facility) and then pick up again, going as high as $32^{\circ} \mathrm{C}\left(1008 \mathrm{RH}\right.$ and $\left.32^{\circ} \mathrm{C}\right)$. That would have left three instruments as candidates for an industrial-type hygrometer--the electronic-percent RH sensor, the saturated-salt dew-point sensor, and the condensation-type dew-point sensor .

The percent RH sensor was eliminated because of possible contamination during use, condensation problems at high percentages of $\mathrm{RH}$, and lower relative accuracy in determining water vapor content.

This left the condensation-type and saturated-salt (lithium chloride) dew-point sensors. The condensation-type is typically twice as accurate, five times as expensive, and harder to maintain from a contamination standpoint. The saturated-salt type sensor has a typical accuracy of $\pm 2^{\circ} \mathrm{C}\left( \pm 3.6^{\circ} \mathrm{F}\right)$, which translates to a maximum error of \pm 108 of water vapor content, which was felt to be acceptable. 
PROCUREMENT

In September 1979 a purchase order was placed with Weather Measure Corp. for three of their Model H361-DPYA dew-point sensor assemblies and two Model H36-PPY dew probes.

The dew-point assembly consists of a dew-point sensor, ac transformer, bailast resistor, and translation resistors. The dew-point sensor is a Yellow Springs Instrument Co., Inc. (YSI), Model 9400 dew-point cell. The cell consists of a bifilar electrode wound around a lithium-chloride-impreqnated wick containing a platinum temperature sensor.

The Weather Measure specifications for the dew-point sensor assembly are

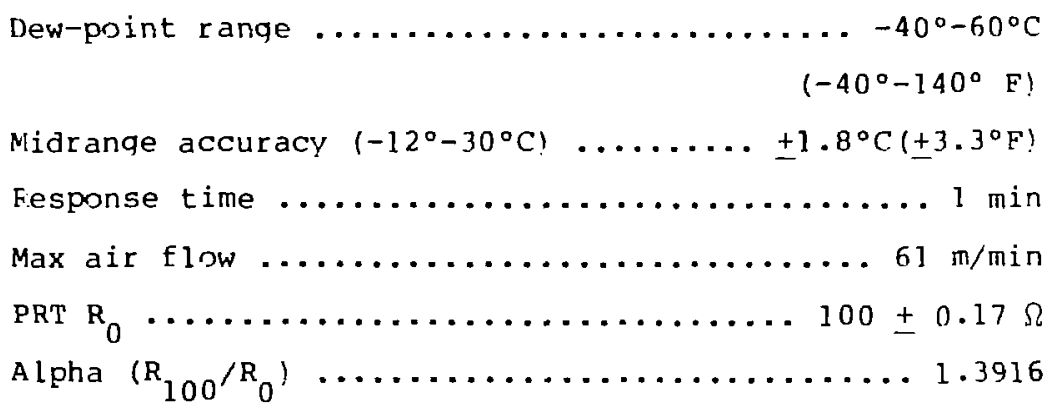

The units were received in October 1979 and forwarded to EGsi;, Las Veqas for calibration.

As mentioned in the previous section, only two assemblies would be required. The remaining unit and parts are intended for spares.

\section{INSTALLATION}

The importance of locating the two dew-point sensors lies in obtaining an accurate, representative sample of the air stream at the intake and exhaust points of the test facility.

The test facility design and ventilation controls provide for a nominal ventilation rate of $2.6 \mathrm{~m}^{3} / \mathrm{s}(5500 \mathrm{cfm})$, with half the flow qoing through the central (canister) drift, and the remaining half split evenly hetween the two side (heater) drifts. The direction of $f l o w$ is from the surface, down the main-access shaft, through the three parallel drifts, up the canister-access hole, and back to the surface. One of the two ventilation fans on the surface at the exhaust point maintains the airflow. 
There is a single drift with a $3.6 \times 3.6-m$ cross section where the three drifts come together at the inlet point. Sample measurements at various points where the single drift opened up in the railcar room (junction of the three parallel drifts) indicated that the air was well mixed and that almost any point would provide a representative sample. The dew-point sensor was located in the center of the drift, about $0.6 \mathrm{~m}$ down from the roof (Fig. 22). Determining the location for the exhaust sensor was more difficult. Several things had to be consioered. The best location for the dew-point sensor would have been inside the 0.48-m (19-in.) canister access hole. However, emplacement there was rot possible since it would have blocked the fuel canisters as they were lowered and raised in the access hole. Aiso, any cabling going into the hole could be easily damaged by the railcar cask during fuel handling operations. The sensor could have been located in the vent line on the surface, except that the dew-point temperature would have been different as a result of the air cooling as it traveled the $420 \mathrm{~m}$ to the surface through the access hole. Therefore, a smoke test was conducted to determine whether there was a good sampling location in the receiving room that was representative of the exhaust airstream as it started up the canister access hole, and which did not interfere with the fuel handling operations.

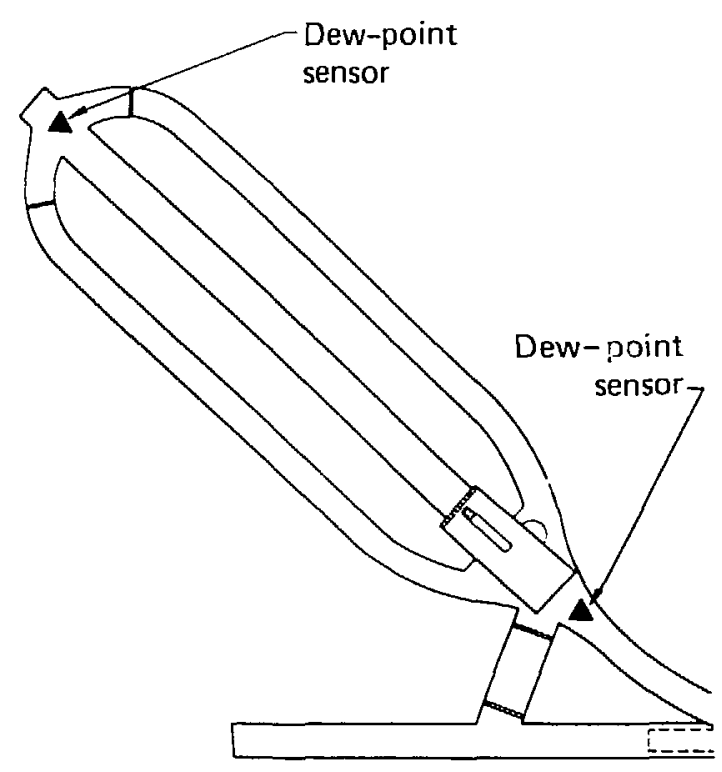

Figure 22. Dew-point sensor locations. 
The smoke test results indicated chat there was no pronounced vor tex at the bottom of the canister access hole and that diffusional mixing oi the air from the three drifts was more apparent than any mixing by swirling. We decided to place the dew-point sensor as cloze as possible to the bottom of the fuel access hole without its being in the way of the railcar during fuel handling operations. The sensor was mounted on the outer perimeter of the access-hole shielding collar (Figs. 22 and 23 ! .

Power for the irtake dew-point sensor is taken from the UPS in the electronics alcove. Standard utility power energizes the exhaust dew-point sensor.

\section{CALIBRATION}

As mentioned in the subsection on procurement, the dew-point sensor assembly contains two translation resistors. The translation resistors (68 ksi/825 Si) in parallel with the platinum-resistance thermometer translate the call temperature to dew-point temperature. The translation resistors were disconnected from the vircuitry to minimize errors due to their unknown temperature coefficient of resistance.

Becausc we were unable to do an accurate field calibration, all the dew-point assemblies and spare sensors were sent to Sandia Laboratories in Albuquerque, $M$ for calibration. The calibrations there were performed at two

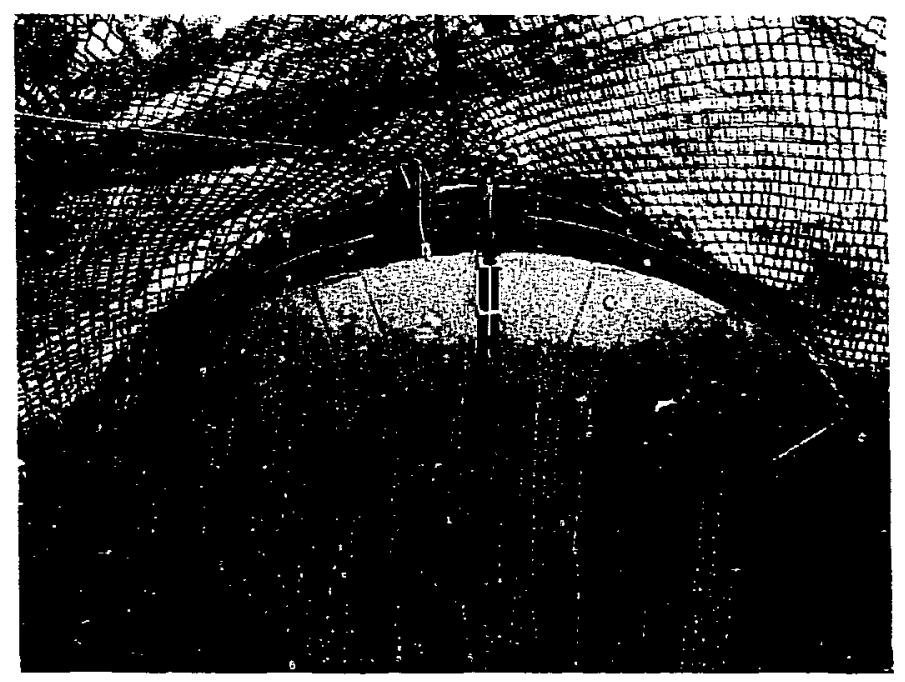

Figure 23. Dew-point sensor installation near canister access shaft. 
dry-bulb temperatures, $24^{\circ}$ and $49^{\circ} \mathrm{C}\left(75^{\circ}\right.$ and $\left.120^{\circ} \mathrm{F}\right)$, and varying humidity levels that resulted in dew points between $-7^{\circ}$ and $44^{\circ} \mathrm{C}$ or $\left(19^{\circ} \bar{a}_{i l a} 112^{\circ} \mathrm{F}\right)$. The uncertainty of the reference dew-point temperatures was estimated not to exceed $\pm 0.17^{\circ} \mathrm{C}\left( \pm 0.3^{\circ} \mathrm{F}\right)$. The calibrations were performed in November 1979 .

There were no additional errors from the DAS, except for those possible in ground loops. This was because the DAS digital voltmeters used for field measurements were more accurate than the laboratory resistance meter used during the calibrations.

RESULTS TO DATE

No problems have been encounter ed to date with the sensors. Early in the testing, the dew-point sensor was wired to area lighting, causing loss of data when the lights were turned off. That was easily remedied by rewiring the power to the sensor so that it was not interrupted. There was no apparent damage to the cell since the humidity level was not very high (<50\% $\mathrm{RH}$ ). The measurements were well within the calibrated range and the sensors performed as expected.

\section{WATT TRANS DUCERS}

SCIENTIFIC CRITERIA

One of the two main technical objectives of the spent Fuel Test has been to compare the effect (if any) of heat plus nuclear radiation from the fuel assemblies and heat, alone, from the electrical simulators. To do this, the amount of thermal energy being produced by electrical sources would have to be measured to quantify the results.

The primary sources of electrical heat are the electrical simulators, the side-drift heaters, and the drift lights. The maximum possible output from the electrical sizulators is $24 \mathrm{~kW}(6 \times 4 \mathrm{~kW})$, from the side-drift heaters it is $50 \mathrm{~kW}(20,2.5 \mathrm{~kW})$, and from lights it is $22.4 \mathrm{~kW}(20 \times .15 \mathrm{~kW}+[8 \times .30 \mathrm{~kW}]$ $+34 \times 0.50 \mathrm{~kW} !$, and totals $96.4 \mathrm{~kW}$. An accuracy of $\pm 2 \mathrm{~kW}( \pm 1.5 \mathrm{~kW}$ when lights are off? was determined sufficient to measure total power output. The power level for each electrical simulator had to be measured individually. The side-drift heaters and lights in each drift could be 
measured collectively since the distribution of the units was known, and since the units were not close enough to the model cell (five central storage holes) to warrant individual measurement of each unit.

\section{DESIGN CRITERIA}

The design or selection of a watt transducer when measuring standard utility power is quite simple. During the spent Fuel Test, only the power for the lights comes directly from utility power. The power to the electrical simulator and heaters comes from utility power by means of 12 siliconcontrolled rectifiers (SCRs).

The SCRs enabled remote power setting control of the simulators and heater. The single-phase rectifier controllers (Loyola Industries BPACseries) incorporated zero-crossover firing SCRs to eliminate transients and difficult to measure, partial-duty cycles. Controller power levels are determined by regulating the ratio of the number of cycles the controller is on to the number it is off. The highest ratio (indicating full power) is $1: 1$. This means the controller is on all the time. The lowest ratio llowest setting without being completely off! is about 1:350. To achieve 20\% power. the ratio was set at $1: 5$. This turned the controller on for one cycle and off for four cycles, and then repeatei.

Using the SCR controllers at high ratios (low power output) requires a slow watt transducer (integrated output) response time. The loads (lights, simulators, and heaters) are resistive, so that apparent power will be equivalent to real power in all cases, and there is no particular need for power factor compensation (unity power factor).

PROCUREMENT

Measurement of all electrical power being consumed by the various devices required the following types and numbers of units.

\begin{tabular}{cccl} 
Power range $(\mathrm{kW})$ & Nominal voltage & Quantity & Measurement \\
\hline $0-4$ & 208 & 6 & Electrical simulators \\
$0-10$ & 115 & 2 & Heaters (4) \\
$0-7.5$ & 115 & 4 & Heaters (3) \\
$0-2$ & 115 & 4 & Lights (No. and So. drifts) \\
$0-6$ & 115 & 3 & Lights (Central drift)
\end{tabular}


An order was placed in May 1979 with American Aerospace Controls, Inc. for the following types and quantities of watt transducers.

\begin{tabular}{cccc} 
Power range $(\mathrm{kW})$ & Nominal voltage & Quantity & Model \\
\hline $0-5$ & 208 & 7 & $413-25-230$ \\
$0-2.5$ & 115 & 5 & $413-25-115$ \\
$0-10$ & 115 & 10 & $413-100-115$
\end{tabular}

The manufacturer's specifications were

$\begin{array}{ll}\text { Nominal freq } & 60 \mathrm{H} \pm 5 \% \\ \text { Load voltage range } & \\ 115 \text { Vac nominal } & 80-150 \mathrm{Vac} \\ 230 \text { Vac nominal } & 160-300 \mathrm{Vac} \\ \text { Excitation } & 5 e l f-e x c i t e d \\ \text { Output voltage } & 0-5 \mathrm{Vdc} \\ \text { Output impedance } & 2.5 \mathrm{k} S i \text { max } \\ \text { Accuracy } & \pm 2 \% \text { full scale } \\ \text { Ripple ipeak! } & 28 \mathrm{full} \mathrm{scale} \mathrm{max} \\ \text { Response } & 400 \mathrm{~ms} \text { nax } \\ \text { Temp coefficient } & 0.15 \text { full scale }^{\circ} \mathrm{C} \\ \text { Temp range } & -20^{\circ} \text { to } 60^{\circ} \mathrm{C} \\ \text { Power factor range } & 1-0 \text { (lead or laq! } \\ \text { Burden } & 1 \mathrm{~V} \cdot \mathrm{A} \text { typical }\end{array}$

The response time of the units was not slow enough to allow for low-duty cycles of the SCR controllers. Therefore, on receipt of the watt transducers in July 1979, a small integrator was built on a printed circuit board and mounted on the transducer. The modification was made before calibrations were initiated. Figure 24 shows the installation and component values.

\section{INS TALLATION}

The watt transducers for the electrical simulators and heaters were mounted in the NEMA enclosures with the SCR power controllers (Fig. 25). The watt transducers for the lights were mounted in smaller NEMA enclosures (Fig. 26). The enclosures, located at various points in the three drifts, 


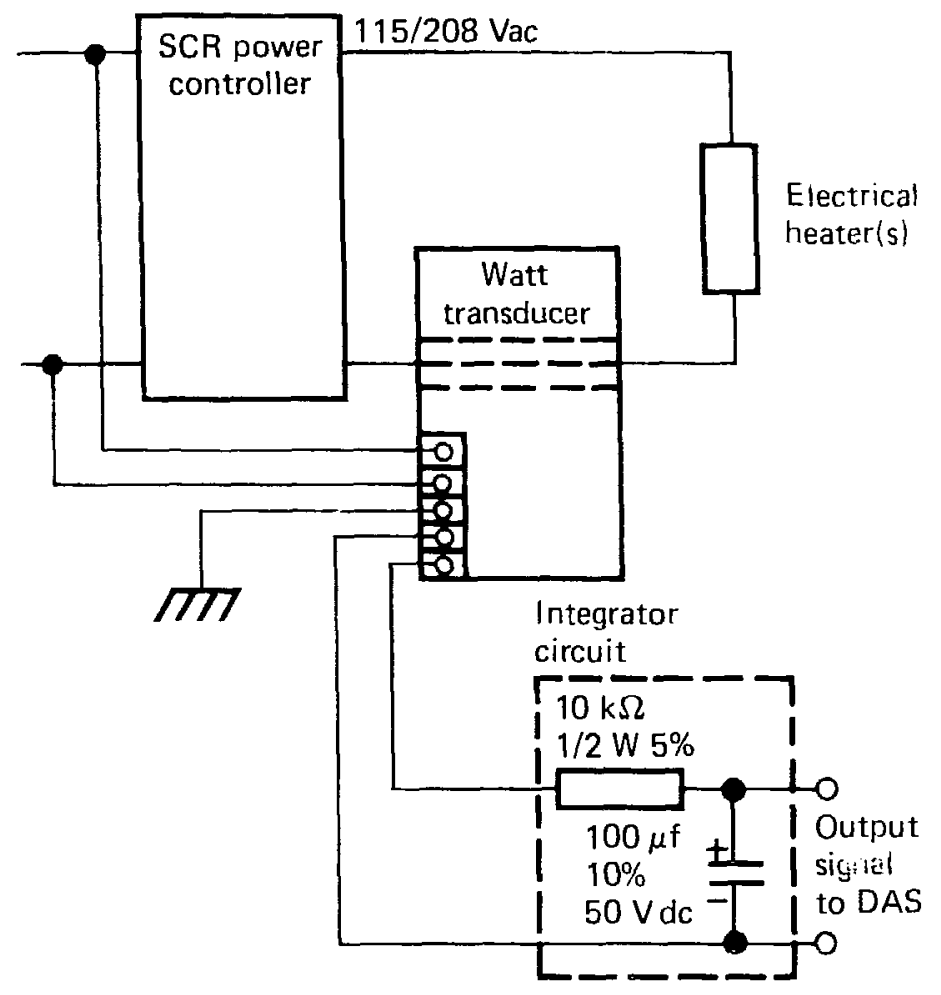

Figure 24. Watt transducer with an integrator.

provide protection from rock spalling and moisture. The units were installed and the wiring checked by REECo. Chemical corrosion inhibitors (Hoffman part №. A-HCI-24OR) were placed in all the enclosures. The chemical vaporizes and then condenses on all surfaces in the enclosed area to protect the components from corrosion.

\section{CALIBRATION}

Field calibrations were not attempted on the wat: transducers because a need for highly precise measurements did not exist, and because of the difficulty in setting up the calibration equipment and test load. A considerable amount of time was spent over several months to establish some repeatable, representative field conditions in the laboratory that would generate calibration sets with accuracies better than the manufacturer's specification of \pm 2 full scale. The accuracy of the laboratory calibration 


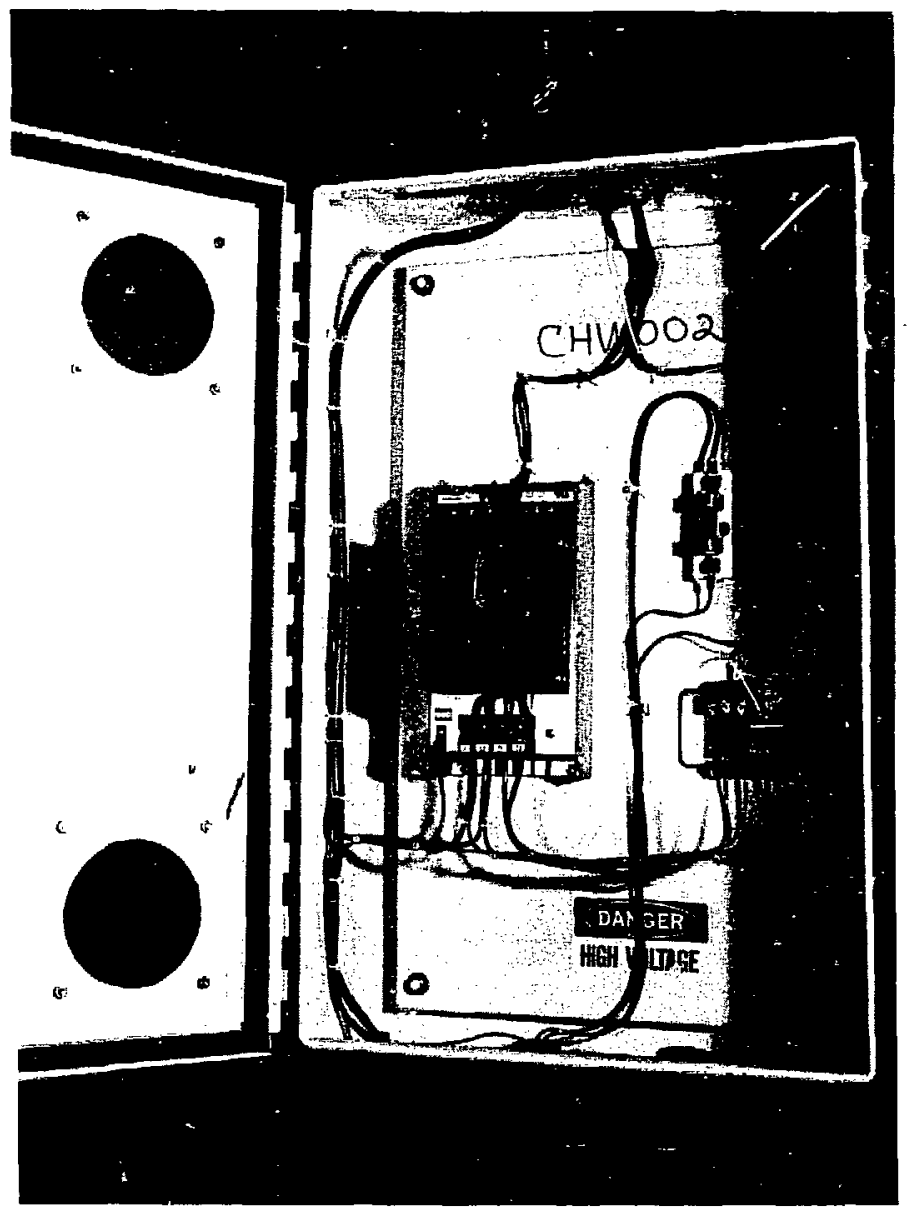

Figure 25. Typical heater controller and watt transducer configuration.

setup turned out to be typically \pm g of reading over the range of watt transducer calibration.

Several test configurations were used to simulate the different ways the watt transducers would be configured during the experiment (SCR controller vs no controller, 110 Vac vs $208 \mathrm{Vac}$, and 0-10 kW loads).

The first step was to obtain some known test loads. Large, incandescent light bulbs proved satisfactory. Two test loads were fabricated. The first (used for 110-Vac tests) consisted of four parallel light bulbs rated at $750 \mathrm{~W}$ each at $125 \mathrm{Vac}$. This resulted in a $2.5 \mathrm{kw}$ test load at $105 \mathrm{Vac}$. The second 
test load was fabricated from a single incandescent liqht bulb rated at $1500 \mathrm{~W}$ at $250 \mathrm{Vac}$. This resulted in a $1.2-\mathrm{kW}$ test load at 208 Vac. The two test loads were calibrated to generate a set of curves and tables that gave load resistance as a function of voltage.

The watt transducers could now be calibrated. Those used to measure the Dower being dissipated by lights in the three drifts and in the railcar room would not be associated with SCR power controllers and they were, therefote, calibrated without SCR controllers in the test confiquration. Twn calibrations were run on each watt transducer. The first was dinne by varyina the input voltage, and the second by varying the number of current lonps passing through the watt transducer. The latter calibration was more representative of actual field conditions (constant voltage and varying loads). However, because only a few test points could he obtained $(0,1$, or 2 current loops), the other calibration (varying voltage) was performed and checked for correlation between the two techniques.

The remaining 115-Vac watt transducers were to be used with SCR power controllers to measure power being delivered to the heaters in the two side drifts. Here, under actual conditions, the voltaqe would vary and the heater

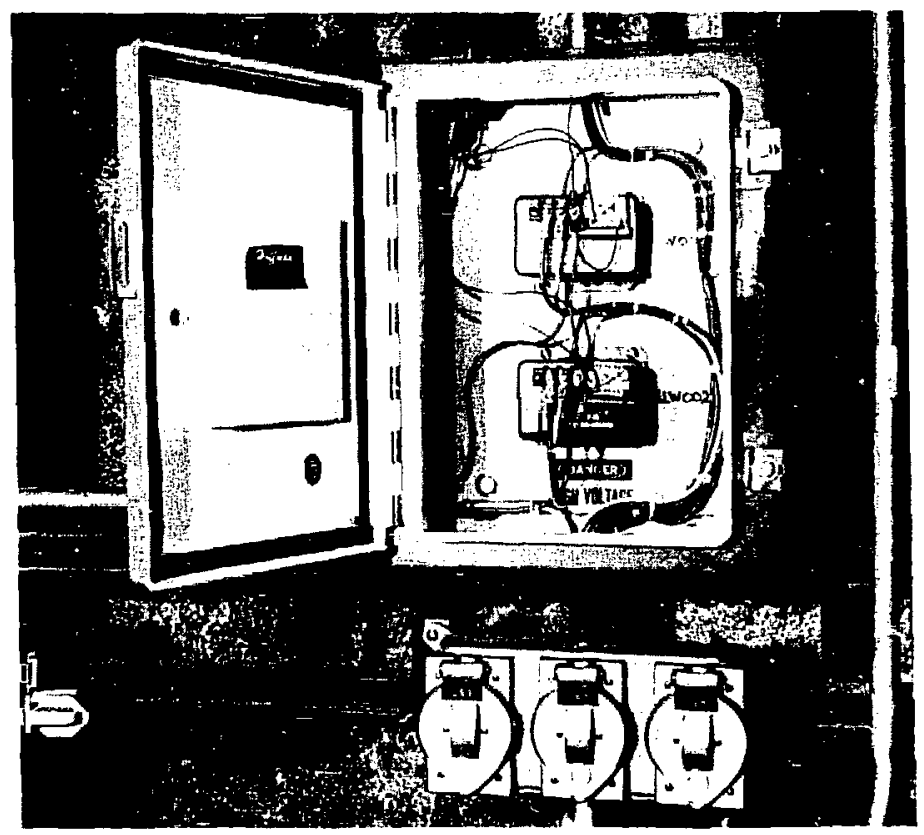

Figure 26. Watt transducer installation for lighting circuits. 
loads would be fairly constant. For the calibration, the current loops through the watt transducers were set at either 3 or 4 loops (depending on the expected field load! and left there. The control voltage to the ScR was then varied to produce a different rms voltage delivery to the test load. The rms voltaqe and the current to the test load were then measured. Also measured were the ratios of output to input cycles to the SCR controller. By measuring the voltage and current being delivered to the load land having the previously calibrated voltage vs resistance tables of the test load!, the actual power delivered would be calculated two different ways $\left(P=I E\right.$ and $P=E^{2} / P$ ) ant compared to the output of the watt transducer. Because of the difficulty in measuring the rms current with an rms voltmeter and a current meter shunt, the other method of measuring the voltage and using the test load resistance tables proved to be better. It also aqreed more consistently with the watt transducer readings. The 208-Vac watt transducers were also used with SCR power controllers and measured power being delivered to the six electrical simulators in the canister drift. These transducers were calibrated the same way the transducers for the heaters were, except that the 1.2-kw test load was used. Also, the number of current loops through the transducer was always set to 4 .

The calibration results have not yet been tabulated, but from general observations, the $110-$ Vac units were accurate to within \pm 28 of reading, and the 208-Vac units were within +48 (which, at the higher ends of the $r$ ange, did not appear to meet manufacturer's specifications). Because the calibrations were repeatable and the offset errors known, it was not necessary to return the 208-Vac units to the manufacturer.

RESULTS TO DATE

All indications to date are that the watt transducers are performing satisfactorily. There have been no failures in the field and no maintenance other than that on the corrosion inhibitors in the NEMA boxes where the watt transducers are installed. 


\section{STRESSMETERS}

INTRODUETION

Determination of both displacement and stress are important in analyzing rock response. The stressmeters discussed here were selected to measure changes in existing stresses expected to occur due to both excavation and introduction of thermal sources. Figure 27 shows a stressmeter. Data from these instruments are applied to assess rock stability and validate thermomechanical computer codes.

\section{SCIENTIFIC CRITERIA}

Use of stressmeters was planned from the outset of the SFT-C (as described in the Technical Concept document ${ }^{1}$ ! since changes in stress near canister emplacement holes and in the pillar between drifts needed to be measured and recorded. During the mine-by experiment, three stressmeters were installed in the north pillar. An array of stressmeters was selected to measure stress changes during the heated phase. As in all projects, available

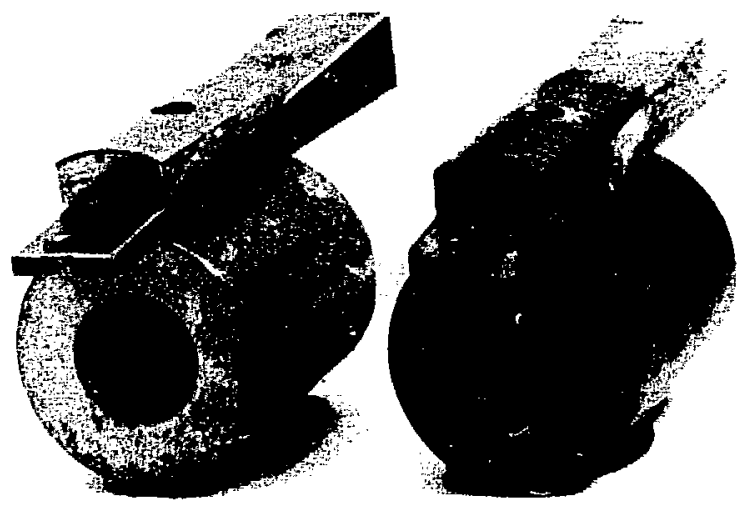

in.

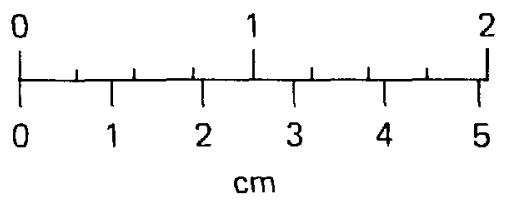

Figure 27. Stressmeter gage. 
resources constrained the number of stressmeters that could be deployed. This constraint led to selection of locations near two emplacement holes and in only one pillar (Fiq. 28). No stressmeters were placed in the outer $r$ ibs of the heater drifts, although measurements at those locations could have provided significant, additional information.

DES IGN CRITERIA

A variety of instruments is available to record changes in stress in drilled holes. Among the types to be considered are borehole pressure cells (both Pittsburgh and Colorado School of Mines types), a CSIRO cell, USBM-type
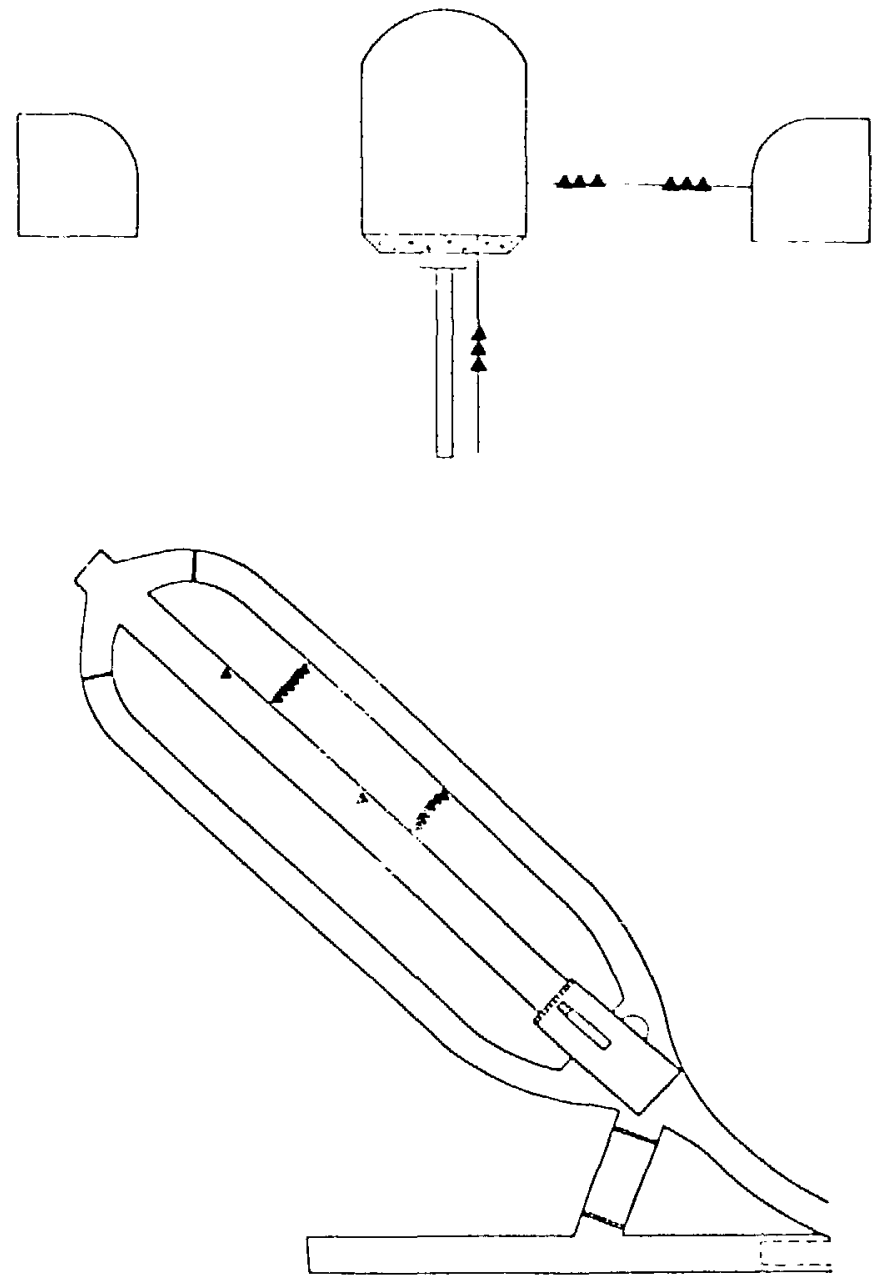

Fiqure 28. Stressmeter locations. 
borehole deformation gage, vibrating wire embedment stressmeter, and vibrating wire borehole stressmeters. Each gage type has distinct advantages and disadvantages. All have a common problem of calibration in the sense that changes in rock stress are not measured directly for a variety of reasons. Although pressure cells have the potential of measuring changes in stress directly, they are unproven in elevated temperature applications, and are sensitive to transverse loading. The CSIRO cell, embedment stressmeter, and borehole stressmeter each interact with the borehole in which they are placed. It is, therefore, essential to calibrate this interaction both at ambient and elevated temperature. The USBM deformation gage, on the other hand, is compliant, measuring borehole deformation directly. Assuming that the rock modulus can be determined, changes in stress can be calculated from measured displacements.

Of the instruments listed above, the two leading contenders at the time of sel resin were USBM-type borehole deformation gage and IRAD vibrating-wire stressmeter. The former instrument has well-documented time instabilities ${ }^{10}$ and is also expensive enough to discourage even modest use (we had been considering using 18 units). These considerations led to the selection of IRAD vibrating-wire stressmeters (Fig. 28). To overcome the known calibration problem, IRAD Gage Co. was asked to perform a suite of calibrations and develop an algorithm for calculating change in stress from gage readings and temperatures. ${ }^{11}$ The IRAD study examined stressmeter response under uniaxial, biaxial, and triaxial loading, reproducibility and hysteresis, influence of preload, platen geometry and orientation, effects of elevated temperatures, and errors in calibration due to block size and anisotropy. This report has not yet been released.

Stressmeters deployed in the mine-by phase were standard hard-rock units (JBS-1 HR) with mild-steel, gage bodies. On removal after the mine-hv phase (some five months after emplacement!, the three gages were found to be rusted. As a result of these findings, several special features were selected to minimize the effects of the adverse environmental conditions the gaqes Hould be subjected to during the heated phase of the test. The most basic of these features included selection of high temperatrire units with hard-rock platens. Additional steps were taken to limit corrosion of the qages. Since corrosion of stressmeter bodies was observed during the five-month mine-by phase of the SFT-C, the stressmeter bodies were plated with electroless nickel prior to assembly by the manufacturer. 
PROCUREMENT

For the mine-by phase of the experiment, a purchase order (\#3333609) was placed in June 1978 for three stressmeters (Irad Model VBS-1 HR) with 30 m (100 ft) of leadwire, hard-rock platens, and wedges. Also vurchased were two switch modules (Irad Model MA-2SM) and a stressmeter data logqer (Irad Model MA-4P). A previously procured hardcop! terminal (TI Model $743 \mathrm{KSR}$ ! was used to log the field data. A stressmeter manual setting tool (Irad Model T-1) and a retrieval attachment were used to install and retrieve the stressmeters.

After the mine-by phase, another purchase order (\#5447209) was placed in Auqust 1979 for seven high-temperature stressmeters (Irad Model VBS-1HT [HR]! and eleven standarä stressmeters (Ircd Model VBS-1 [HR]!. However, because of corrosion problems associated with the first three stressmeters purchased for the mine-by phase, the second order of 18 was returned to Irad for modification to high-temperature units and special plating to inhibit corrosion. The units were then returned to LLNL for installation.

\section{INSTALLATION}

Installation of the three stressmeters during the mine-by phase proceeded by following the manufacturer's sugqested procedure. No foam or thermocouples were installed during the mine-by phase since the temperature was essentially constant.

Installation is a critical step in the application of stressmeters to rock engineering problems. In a study conducted after the mine-by, LLNL pirsonnel learned that variations in gage placement were subsequently responsible for marked differences in gage response. 12 A relationship was developed that correlates a drop in gage preload with the appropriate calibration curve. It is thus possible at time of emplacement to determine the type of gage response to be expected.

The actual installation procedure employed for heated-phase stressmeters consists of Eive basic steps. First, an approximate gage location is selected based on calculations of expected stresses and examination of core recovered from the 38-mm-diam emplacement holes. The location is then verified or adjusted as necessary, based on down-hole measurement of the diameter and smoothness of the hole. Third, the stressmeter and associated thermocouple are inserted, oriented, and prestressed at the chosen location (see Fig. 29). 


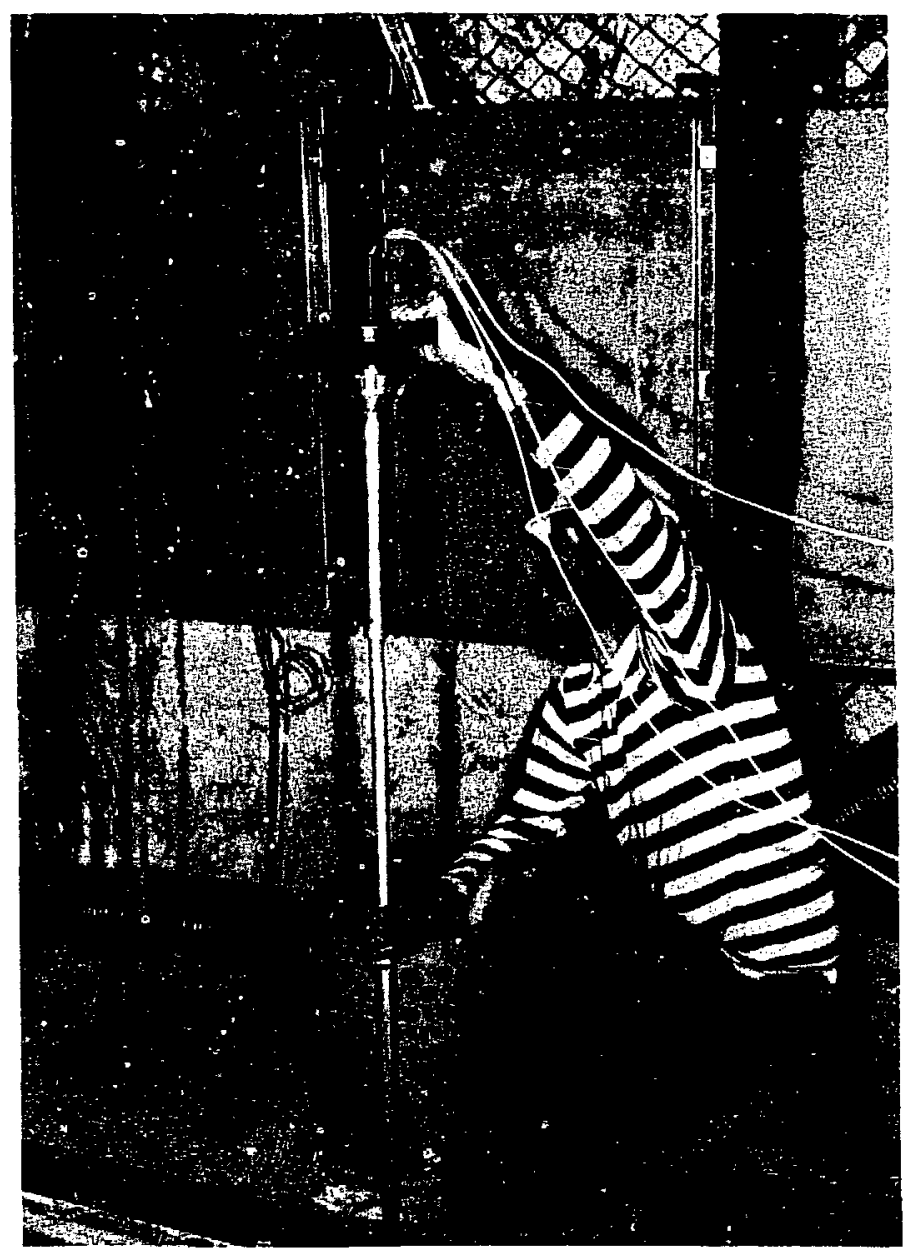

Figure 29. Installation of a stressmeter.

Load loss is then monitored to establish the appropriate calibration coefficients Eor the stressmeter. Once all stressmeters are emplaced, the hole is filled with closed-cell foam to prevent moisture from coming into contact with the gages. Finally, the gage is wiref into a junction box from which its signals travel to the associated data acquisition equipment.

CALIBRAT ION

Calibrations of several types are performed on vibrating-wire stressmeters to develop the relationship between the change in period of the 
vibrating wire and the change in rock stress. Calibrations were performed inhouse by LLNL personnel and by IRAD Gage Co. under contract to LLNL. The results of these calibrations are reported in detail elsewhere. 11,12

RESULTS TO DATE

The three stressmeters installed during the mine-by phase of the SFT-C seem to have functioned reliably. Analysis of data from these gages is reported elsewhere. ${ }^{13,14}$ As was noted previously, the exterior of each gage was rusted and pitted after a five-month exposure to the test environment. Results during the heated phase were not very encouraging. About five months after installation, the stressmeters nearest the canister emplacement holes began to fail, and continued to do so until all six had malfunctioned. In addition, seven stressmeters in the pillars also malfunctioned. Nine of these gages were retrieved and returned to LLNL, where we found that the vibrating wires had severely corroded. In some gages corrosion had progressed to the point that the wire was mechanically damped against the gage coil. Further investigation indicated that the gages were inadequately sealed by the o-rings used for this purpose. It is important to note that none of the gages had been submerged in water nor, for that matter, had they apparently been subjected to free water at all, due to closed-cell foam in the boreholes. The severe corrosion was apparently due to atmospheric moisture only, possibly present at the time of stressmeter assembly.

Replacement vibrating-wire stessmeters, designed and produced by IRAD, incorporate several major modifications to mitijate the problems noted above. Nine of these units have been deployed to replace malfunctioning units. The failure diagnosis and design modifications will be described in a forthcoming report.

ROD EXTENSOMETERS

INTRODUETION

A inajor concern of safe nuclear waste storage is the longevity of the storage Eacility, i.e., how well the surrounding rock mass will hold up to the natural and artificially induced loads imposed on it. Mechanical 
displacements in the rock are a good indicator of the forces acting on the storage medium. There are two artificially induced sources of rock Jisplacement--removal of rock during mine excavation and thermally induced forces from the fuf: 1 assemblies, electrical heaters, lights, and the ventilation system. The ventilation system also has an effect, since the $\exists i r$ making its way down the vertical shaft is cooler than the natural ambient temperature of the rock mass.

Multiple-point rod extensometers (3-, 4-, and 6-anchor types) were used to measure relative displacements in the rock during the mine-by excavation, as well as during fuel storage. Figure 30 depicts an extensometer installed in a borehole.

\section{SCIENTIFIC CRITERIA}

In doing scoping calculations, scientists developed estimates for the magnitudes of displacement expected to occur from thermal loading and mine excavation. The maximum displacement at planned measuring points was predicted to be about $2 \mathrm{~mm}(0.08 \mathrm{in.})$ due to mine excavation, and about $1 \mathrm{~mm}$ (0.04 in.) due to thermal loads.

The scientific group requested that an outside contractor (Terra Tek) assist LLNL in developing a plar, fielding the instrumentation, collecting the data, and providing summary reports on the displacements that would occur

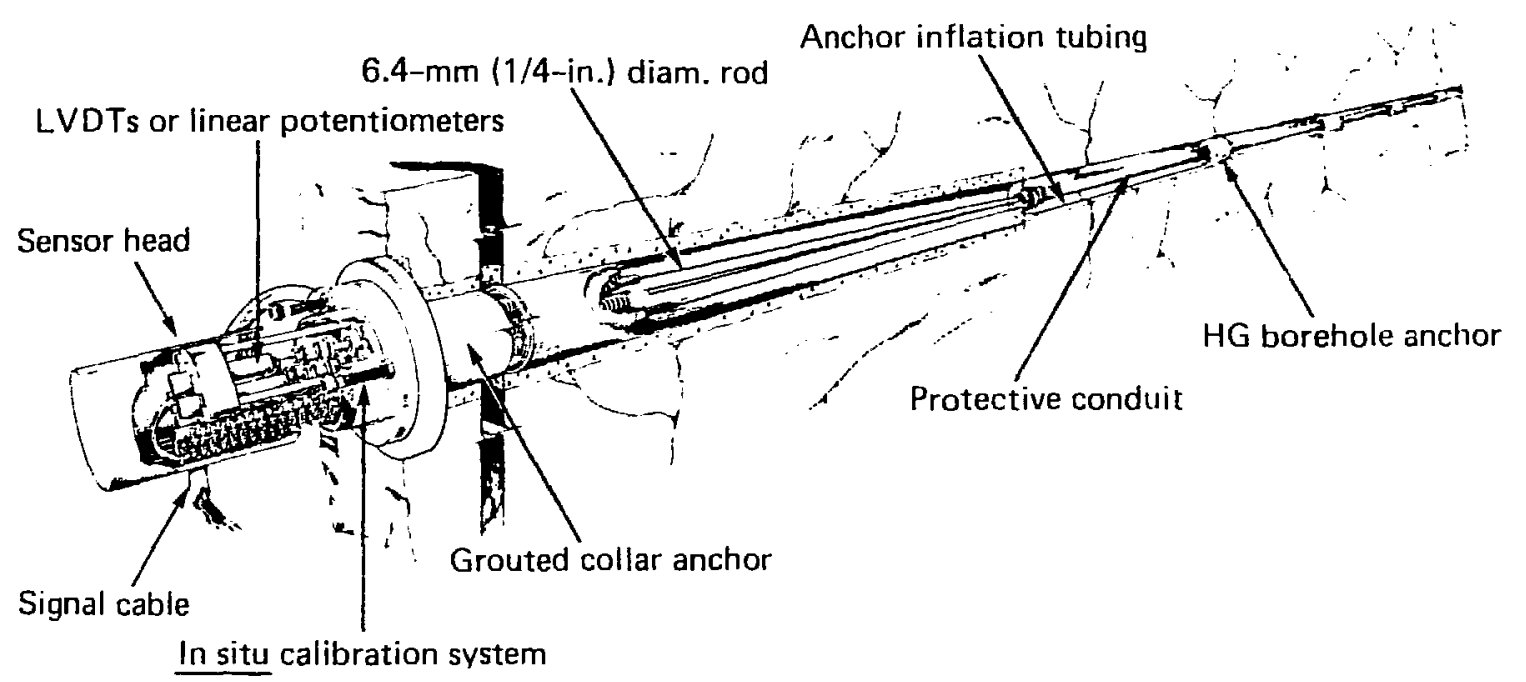

Figure 30. Multiple-point rod extensometer. 
during the excavation of the drifts. All of that work was reported in the summary released by LLNL. 15

The report states that the rod extensometers used for the mine-by phase of the experiment performed well, and that the system accuracy was $\pm 0.02 \mathrm{~mm}$. LLNL scientific estimates were more conservative and expected accuracies in the range of 0.02-0.05 num at constant temperature, and 0.05-0.09 $\mathrm{mm}$ with varying temperatures. The LLNL Electronics Engineering Group was asked to provide backup measurements with a small data acquisition system during the mine-by phase, and all support for additional rod extensometers to be used during the heated phase of the experiment.

\section{DESIGN CRITERIA}

The common instruments used to measure relative displacements that occur in rock during the course of an experiment are extensometers--tape, wire, or rod. Other types of instruments (primarily optical) could also be used, but are either of a developmental nature, difficult to incorporate into an automatic data acquisition system, or expensive on a unit cost basis.

The tape extensometer is a manually read instrument used to measure changes in mine opening dimensions. In addition to using tape extensometers for relatively infrequent measurements, several devices were developed at LLNL to automate more frequent measurements of the mine opening and rock joint movement. These devices are discussed later in the section on convergence mon itors.

The rod extensometer has proven to be a stable and accurate instrument for measuring relative displacement in rock, and can be configured so that it can be automatically read by a DAS. Figure 31 depicts the measurement points used for the mine-by during test facility construction, and also later for the heated phase of the experiment. Fiqure 32 shows the additional measurement points where new sets of rod extensometers were used during fuel storage. The mine-by extensometers are 3- and 6-point extensometers, while the newer sets have four points.

Terra Tek, Inc. selected the mine-by extensometers, which came to be known as the mine-by instrumentation (IABI) extensometers. The MBI extensometers were standard, commercially available units incorporating hydraulic anchors, 6.35-mm (1/4-in.) mild-steel connecting rods, and 31.75-r:m (1-1/4-ir..) flexible conduit and linear potentiometers. Teflon spacers were 


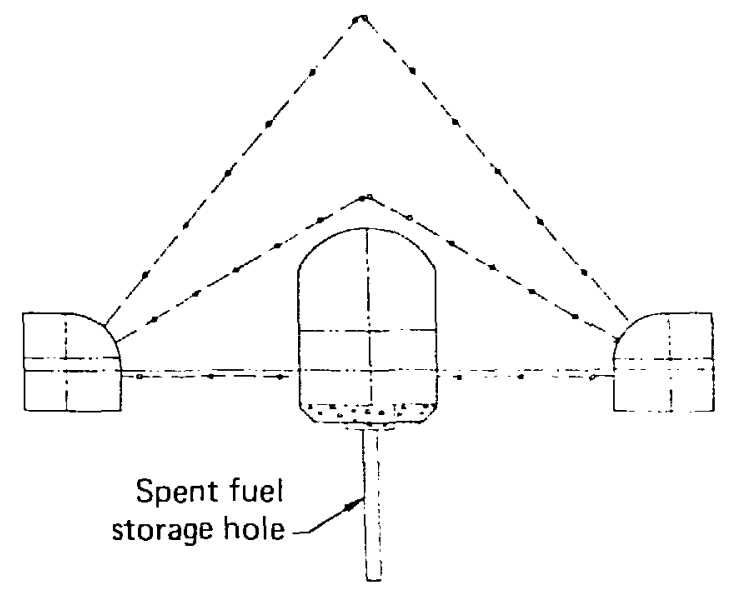

Cross section

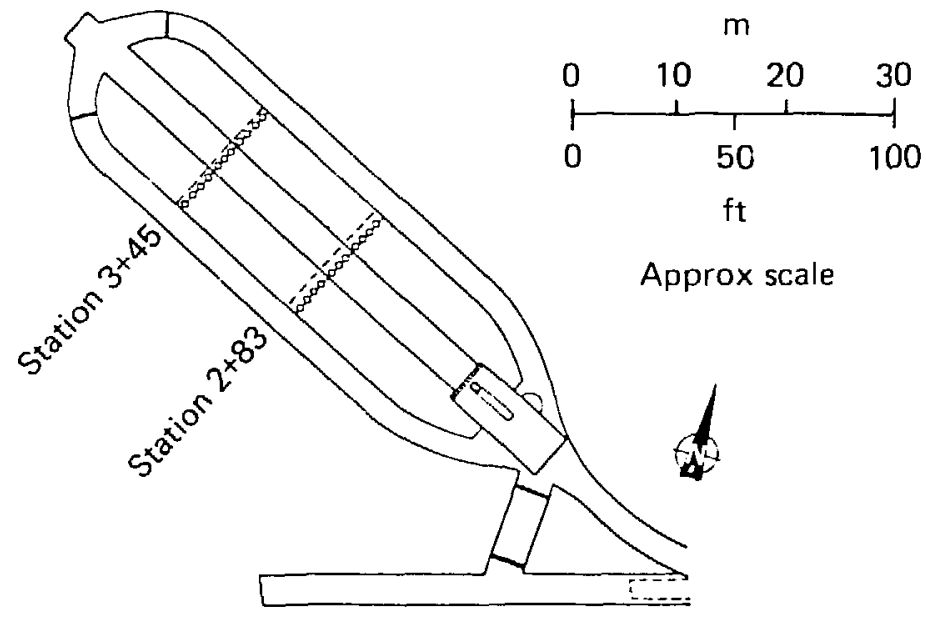

Plan view

Figure 31. Three- and six-point rod extensometer locations.

installed at each anchor to guide and separate the individual rods, thereby reducing catenary and rod-to-rod friction effects. A portable readout device (Terrametrics Model DC-7) containing a 10-VdC excitation source, a selector switch, and a voltmeter was used by Terra Tek to measure extensometer potentiometer positions at selected times.

The extensometers used in the central drift were basically the same as the MBI extensometers. There were, however, some additional considerations that required some modifications to the basic unit. The central drift 


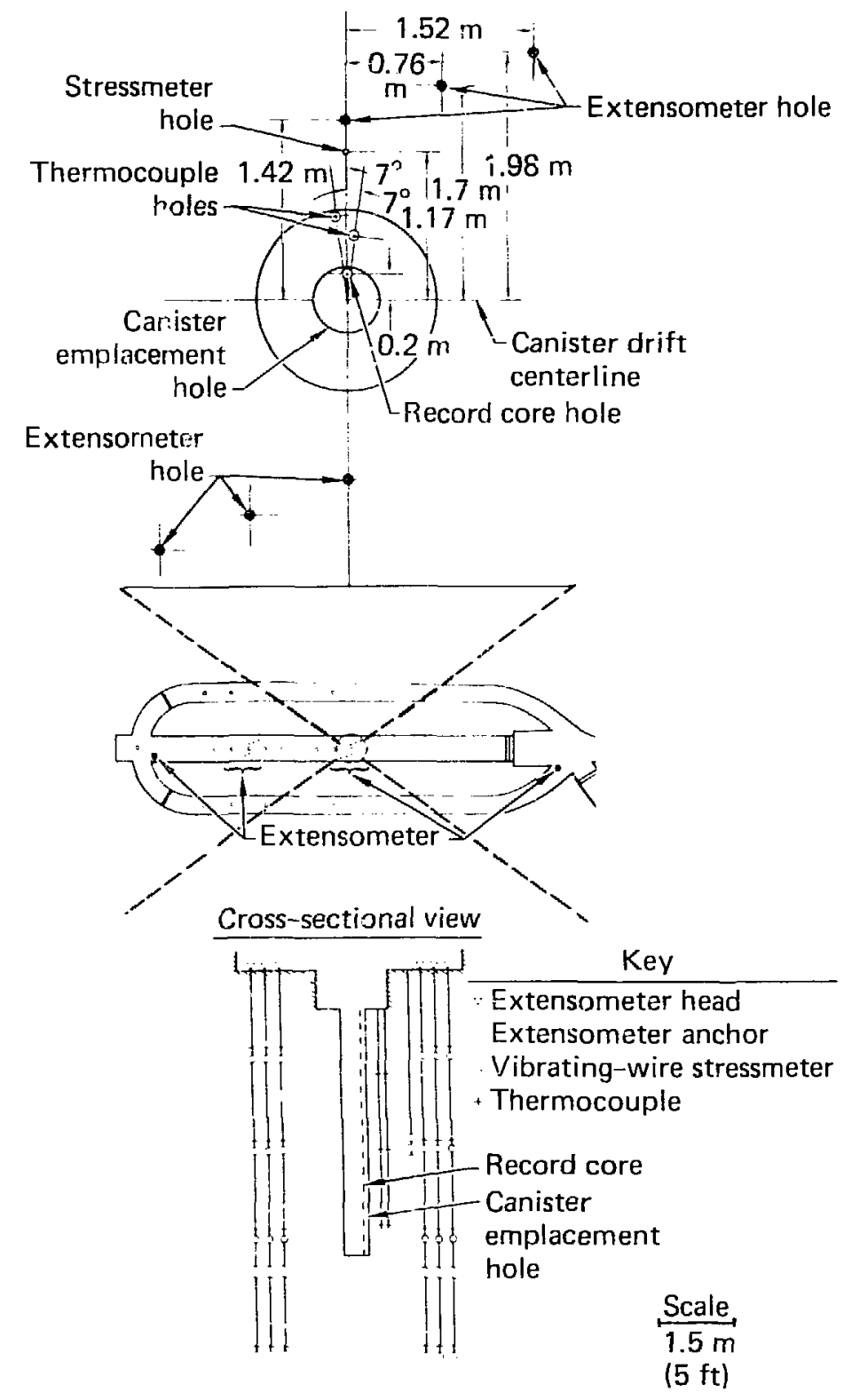

Figure 32. Four-point rod extensometer locations.

extensometers becarne known as the GxE (GAE, GBE, GCE, and GDE) series. The GxE extensometers consisted of 14 four-point rod extensometers. Of the 14 extensometers, 12 were positioned parallel to the canister emplacement holes, within 1.4-2.5 m (4.6-8.2 ft) of a fuel assembly or an electrical simulator. We expected a small amount of gamma radiation at these locations, but the transducer was not expected to be within a radiation field. Thermal excursions were expected to adversely affect the accuracy of the extensometers. 
The temperature of extensometer connecting rods could vary by as much as $40^{\circ} \mathrm{C}$, which would produce a 6-mm elongation of a $13.7-m$ mild-steel rod. With maximum expected rock displacements being only a few millimetres, the thermal effects on the rod extensometers became very significant. In accurately measuring rock displacements, the temperature profile of the connecting rods became very important. Therefore, to help minimize the need for detailed thermal profile measurements of the connecting rods, their material specification was changed from mild steel to Super-Invar. This low-expansion alloy, containing 31.58 nickel and 5.08 cobalt, has a mean coefficient of linear expansion 50 times less than that of mild steel in the temperature range of this test. Although thermal corrections for the rod extensometers will still be needed during data reduction, temperature distribution data do not need to be as precise as they would for mild steel.

Another temperature related consideration associated with the GxE extensometers was the need to maintain the hydraulic anchor pressures in an environment with rising and falling temperatures. Normally, the hydraulic anchors use check valves and the pressure is set only once, when the anchors are inflated. If this technique were followed, the anchor pressure could exceed the permissible level on heating, possibly causing damage to the anchor, then dropping to an insufficient level on cooling, and resulting in the anchor loosing full holding power. To alleviate the problem, a new design was incorporated, which provided a chamber for the hydraulic oil to expand and contract in while maintaining a fairly constant pressure on the anchors. Figure 33 is a sketch of that system.

The sensor (transducer) used to measure the relative movements of the anchor with respect to the head assembly had to have a $12.7-m m-(1 / 2-i n .-)$ diam cylindrical body to fit existing rod extensometer assemblies. Two available sensors were felt to be appropriate for the job--the linear variable differential transformer (LVDT) and the rectilinear potentiometer. The dc-LVDT, however, had two characteristics that were difficult to control or to compensate for. The first was temperature sensitivity and the second was long-term stability. A year's use or more and temperature excursions of $15^{\circ}-20^{\circ} \mathrm{C}$ in the LVDT could have produced an erroneous signal on the order of 18 full scale. In a $\pm 13-m m$ stroke LVDT with a possible total displacement of $\pm 2 \mathrm{~mm}$, the error translates to 12.58 of the reading.

One might, as a result, have concluded that a shorter range LVDT should be chosen. However, care had to be taken not to underestimate the range of 


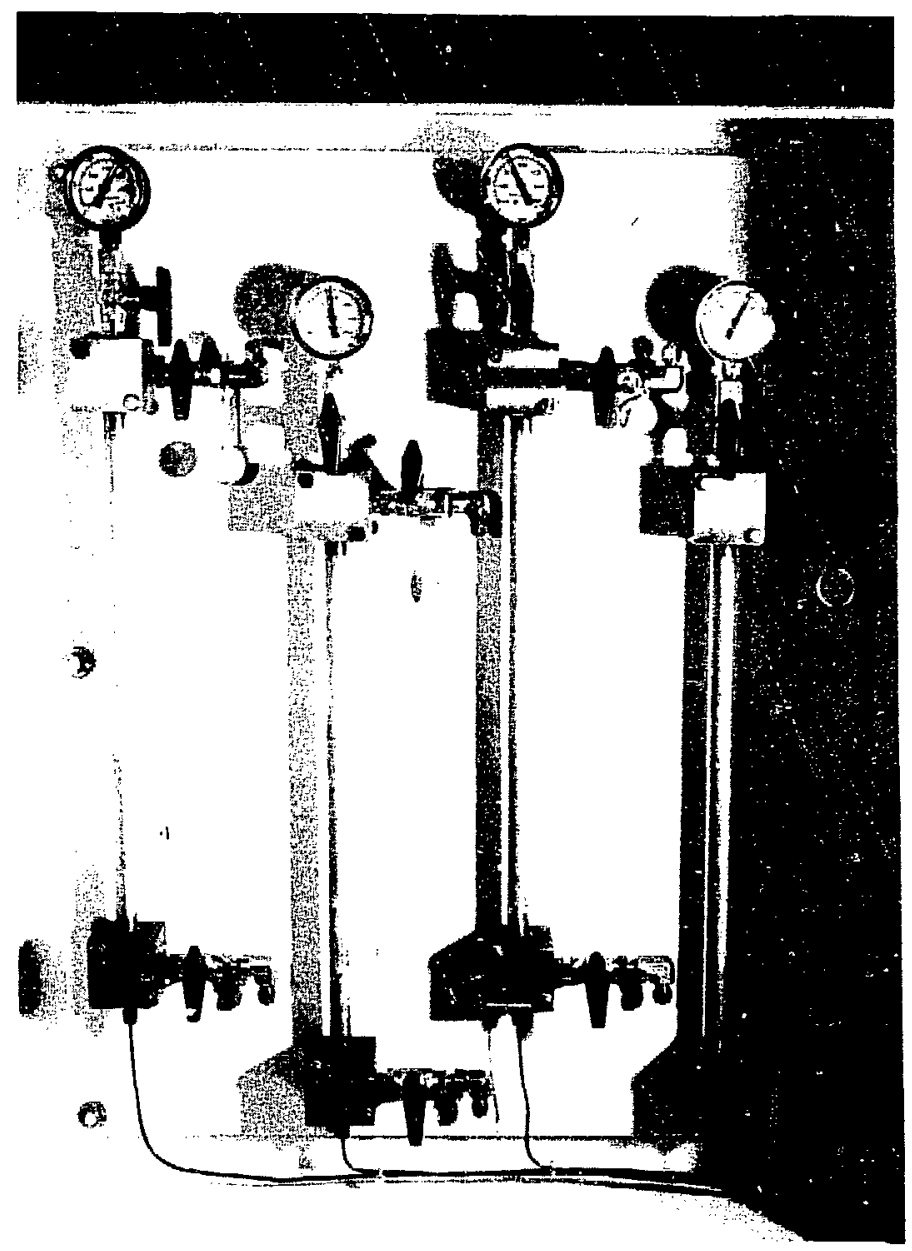

Figure 33. Rod extensometer anchor expansion sys tem.

actual displacement. Other, perhaps less crucial, sources of potential errors for LVDTs were output sensitivity to excitation source variations, ground-loop, and common-line effects due to lack of input-output isolation. There was also a potential problem from corzosion of the LVDT core. However, this could usually be minimized by using metal foil or teflon coating.

For the application in mind, the rectilinear potentiometer offered much more promising characteristics. If the voltage ratio were measured, temperature variations and long-term stability would have no effect on accuracy, as long as changes in the potentiometer resistive material were uniform (linear). This device had fewer components than the LVDT, thus was less likely to fail as a result of a single component failure. 
To allow for movement either in or out, the potentiometer would have to be set at the midway position. A lo-Vdc excitation source would generate a 5-Vdc nominal signal output. To achieve high resolution, a wide dynamic-range voltmeter would be required. If a pair of matched resistors (with a total resistance equal to that of the potentiometer) were used as one half of a Wheatstone bridge and the potentiometer was used as the other half, a null voltage could be achieved at the midway position of the potentiometer. Figure 34 is a schematic of the circuit. This technique was incorporated in the extensometers.

There were a few changes made to the collar stabilizer tube to decrease the amount of flair in the rods as they entered the head assembly. The changes also increase the structural strength, provide better surface finishes for accurate calibrations, and standoffs to protect the thermocouple wye branch from damage during installation. These items are detailed in the procurement subsection.

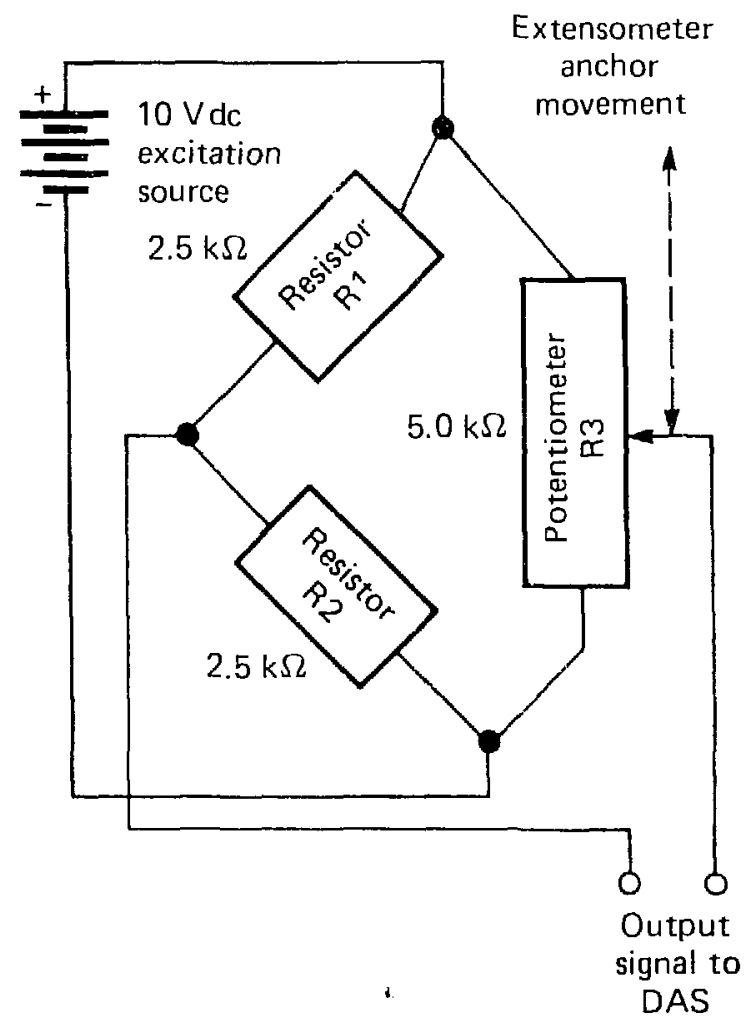

Figure 34. Rod extensometer electrical schematic. 


\section{PROCUREMENT}

\section{MBI-Series Extensometers}

In November 1978, purchase order 4129509 was placed with Terrametrics, Inc. for four 3-point (3-CSLT-R) rod extensometers and eight 6-point (6-CSLT-R) rod extensometers. The units were delivered to Terra Tek, Inc. in December. Terra Tek, Inc. had been subcontracted to install the extensometers. The units were to be inspected by them and then forwarded to the NTS in February 1979. The collar stabilizer tubes were rejected by LLNL on receipt at NTS, because they were constructed of polyvinyl chloride (PVC). Steel assemblies were manufactured at LLNL for installation.

The Bourns Model 5184, 5 ks, 25-mm (1-in.) stroke rectilinear potentiometers were selected as the transducers for the extensometers. Five spare units were purchased in addition to the 60 units required.

\section{GxE-Series Extensometers}

In July 1979, purchase order 6169809 was placed with Terrametrics, Inc. for fourteen 4-point (4-CSLT-R) rod exterisometers.

Options or modifications to the units were stipulated as follows:

1. Hydraulic down-hole anchors (4 ea.) without check valves for 76-mm (3-in.) boreholes.

2. $38 \mathrm{~m}$ (125 ft) of copper-plated, high-pressure (172-MPa [25,000-psi]-burst strength! steel tubing used in setting and maintaining the pressure on the hydraulic anchors.

3. $33 \mathrm{~m} \times 6.4-\mathrm{mm}$ (108 $\mathrm{ft}$ of 1/4-in.) Super Invar rod with steel couplings. Rods shall be cut and threaded in 3.7-m (12 ft) lengths.

4. $13.7 \mathrm{~m} \times 31.8-\mathrm{m}$ (45 ft of 1-1/4-in.) Elexible metal conduit with silicon, waterproof jackets.

5. De? $r$ in bushings throughout.

6. Rectilinear potentiometers, 5-k $\$, 25-m m(1-i n$.$) stroke, Bourns$ Model 184 (4 ea.).

7. One 16-pair screw terminal mounted on the main frame assembly.

8. One 12.7-mm (1/2-in.) feedthrough on main assembly for instrumentation cable (LLNL-supplied and -installed). 
9. Three 6.4-mn (1/4-in.) plate qussets welded to the stabilizer tube to support the flange isee Fiq. 35).

10. Three $0.3-m$ (l f.t) lengths of $12.7-m m$ (1/2-in.) reinforcoment bar welded to the end of the collar stabilizer tube (see Fiq. 35).

11. Finish and roughness as shown (see Fiq. 35).

12. Zinc plating of the stabilizer tube after arove modifications.

13. Provisions for $1.6-m m(1 / 16-i n)-.0 . D$. metal-sheathed thermocouple mounting at each anchor thermocouple shall $r$ un inside the flexible conduit to just helow the bottom end of the stabilizer tube. There the thermocouples (LLNL-supplied and -installed) will exit through a wye-branch pipe into a $12.7-m m(1 / 2-i n$.$) flexible conduit that runs$ $152 \mathrm{~mm}$ ( 6 in.) past the stabilizer tube flange.

Subsequently, the stabilizer tube was substituted since it was somewhat difficult keeping the tube diameter at a minimum because of the support rods mounted to the side of the tube, and the addition of the thermocouple wye section below the tube. Also, the contractor drilling the boreholes for thr. extensometer dı not meet the drill depth specifications. As a result, greater flexibility was needed in the overall length of the tube to properly position and support the extensometer in the borehole. The stabilizer tube

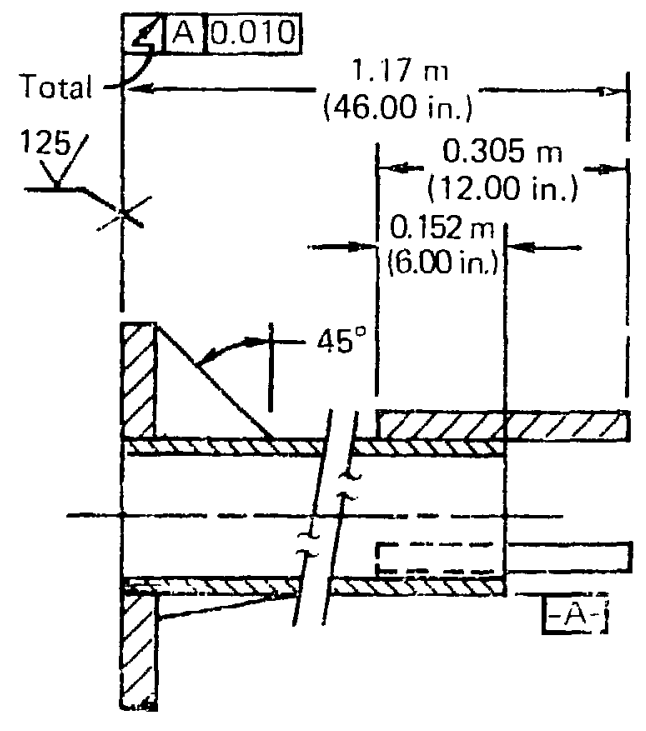

Cross surtion

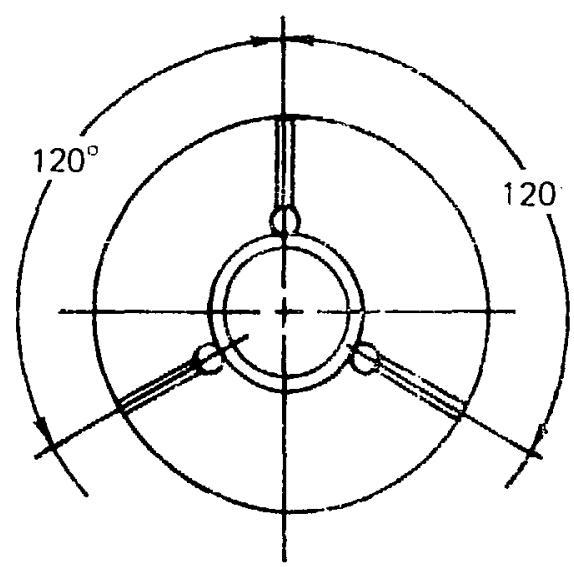

End view

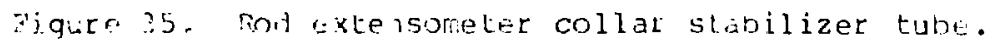


was modified by discarding the 12.7-mm (1/2-in.) reinforcement bar support legs, then welding three 1/2-in., 13-threaded nuts to the bottom plate of the stabilizer tube. Then lengths of 1/2-in., 13-threaded rod were included to be cut to the required lengths during installation.

The extensometers (except for the Super-Invar rod) were shipped to EG\&G, Las Vegas in September 1979 for inspection and preparation. The Super-Invar rod was shipped directly to the NTS in November 1979.

The last items of procurement to be discussed are the resistors used as part of a wheatstone bridge configuration for the potentiometers. No resistors were used on the MBI units during the mine-by phase. However, they were later added during the refurbishment of the MBI head assemblies. Resistors were used from the start with the GxE series, and the resistors are described as follows:

Fixed, bulk metal, Vishay model S102C, $2.50 \mathrm{kd}, \pm 18$ tolerance for mine-by extensometers, and \pm 0.18 tolerance for GxE series extensometers, $\pm 5 \mathrm{ppm} /{ }^{\circ} \mathrm{C}$ TCR. *

The resistors were bought in October 1979 and sent to EG\&G, Las Vegas for acceptance testing and installation onto the extensometer head assemblies.

\section{INSTALLATION}

\section{MBI Extensometers}

As mentioned in the subsection on scientific criteria, Terra Tek, Inc, was contracted to do the installation of the twelve 3- and 6-point extensometers and that information is contained in the contractor report written by them. ${ }^{15}$ The following irregularities were reported associated with the installation:

E2-1 Moved in $152 \mathrm{~mm}$ (6 in.) further from collar than originally specified.

E5-6 Anchor struck bottom of hole (i.e., actual hole length was less than believed!

E8-3 Same problem as E5-6.

E9-6 Anchor moved $102 \mathrm{~mm}$ (4 in.) closer to collar than originally specified.

+ TCR $=$ temperature a efficient of resistance. 
E10-5,6 Anchors off location due to pinching (jamming! of hydraulic lines during installation.

E11,12,13 Hydraulic tubing bursting at lower pressure levels ( -1000 psi) due to inferior qrade of tubing (E13-6 burst at 500 psi).

Sometime after the mine-by phase, the electrical wiring and the potentiometers were removed. Parts of the head assemblies on some of the extensometers were removed for cleaning or replacement of corroded or broken parts. On extensometer anchor E10-3, the rod was shortened an inch or two to permit a potentiometer to be reconnected (the potentiometer had to be removed because of excessive rod movement caused by improper anchor setting during the mine-by phase).

Just before the Terra Tek installation began, we noticed that the collar stabilizer tubes were fabricated from PVC. We became concorned thist the concentrated force imposed on the tube flange by the three elevator bolts would produce creep in the PVC which would look like artual anchor movement. Some sample plugs were taken from the PVC stabilizer tibe to $r$ un tests on them at LLNL to determine whether there was a problem. The tests quickly revealed a significant creep problem. The PVC stabilizer tubes wern discarded and replaced by LLNL-fabricated steel tubes.

The tubes were never plated and are, therefore, susceptible to rusting. This is what occurred during the mine-by phase with large amounts of drilling water in the drifts. During the refurbishing period, the tube flanges of the mine-by units were sanded down with emery cloth and then coated with grease to prevent further oxidation. That surface is one of the tiro critical ones making contact with the gage blocks during calibration. Therefore, it should remain smooth and clean. In addition, indentations were not provided to maintain the position of the head assembly during calibration. The head rotates slightly during calibrations, thus introducing a small degree of error.

On reinstalling the potentiometers and new electrical cabling, two precision, low-temperature-coefficient resistors were installed in the head assemblies to complete the wheatstone bridge network.

\section{GxE Extensometers}

The installation of the GxE-series extensometers was subcontracted to EG\&G, Las Vegas, which provided almost all the instrumentation technician 
support on the Spent Fuel Test. An EG\&G engineer conducted acceptance testing, assembly, and installation of the rod extensometers.

There were several significant differences in the installation of the GxE series from that of the MBI series. First, the hydraulic anchors would be using a newly designed expansion chamber. Second, thermocouples would be attached to the GxE extensometers. And third, the extensometers would be grouted in place along the entire length of the extensometer.

Tables were set up in the central drift to lay out and assemble the extensometers. The various components were identified by markings, and carefully assembled. As could have been expected, a few problems came up that are worth mentioning.

Before installation commenced, we reviewed the materials certification and annealing history of the Super-Invar rod. We determined that the less complex thermal treatment used by the manufacturer resulted in a material that exhibits detectable plastic strains at the relatively low stresses that these rod extensometers would be subjected to. Rather than return the material to the manufacturer for a final heat treatment, an alternative method was incorporated. 16 This other method involved cold-working the Super-Invar rod. A prestressing fixture was made using some rock bolts for anchors, a load gage, and come-along hoist. Lengths of rod were laid out in the southern drift and put under tension at a load of 2700 lbs. $(320 \mathrm{kq}$ ! for at least $5 \mathrm{~h}$. The rods were then removed from the prestress fixture and used to fabricate the rod extensometers.

The grouting procedure was given careful consideration before we decided to proceer with the installation. The decision to grout was made to minimize thermal disturbances that might be induced by a borehole containing air and water. We felt it would be better if the void between the borehole wall and the flexible conduit would be filled with a grout mix with thermal properties similar to those of the granite. To prevent the grout from acting as a "wedge" that would influence the motion of the anchors with respect to one another (such as when a joint between two anchors begins to close), expansion joints were applied above and below the three upper anchors and above the lowest anchor. These joints consisted of 50-mm (2-in.)-wide, closed-cell, rubber foam with adhesive back on $0.3-m$ (12-in.) centers, equally spaced above and below the hydraulic bladders. Fiberglass tape was wrapped several times around these expansion joints to prevent them from unwrapping during instrumentation insertion. 
The orientation of the rods (i.e., to which each anchor belonged) was a constant concern, since it would have been easy to make an error during assembly. The rods were color-coded with paint, and the head assembly was permanently marked with numbers indicating orientation. Careful monitoring of the assembly also helped ensure proper orientation (Appendix C).

Once the extensometers were in the boreholes, the thermocouples and hydraulic tubing were fished through the conduit in the cement floor and over to the wall. The thermocouples were connected to the reference blocks and the hydraulic lines (four per extensometer) were run over to the expansion chambers and connected. A set of four expansion chambers was mounted on each of the 14 NEMA TYpe-12 enclosures on unistrut along the walls of the drift. While the extensometers hung in the hole before grouting, each rod was clamped and blocked to provide a small upward rod tension. This was " ne to preclude the conduit's unravelling or any other damage prior to setting the anchors and grouting.

The next steps involved getting the hydraulic anchors ready for grouting. This was done by pulling a vacuum down to $5 \mu \mathrm{m}$ of $\mathrm{Hg}$ on the tubing and expansion chamber for $30 \mathrm{~min}$. Because the anchor hydraulic line is small, an estimated 10-20 $\mathrm{mm}$ resulted. Hydraulic oil was then released into the vacuum. Excess oil was left in the expansion chamber for several hours or days to allow the oil to travel through the small-diameter tubing and into the bladder. The quantity of oil displaced to the individual anchor was measured and recorded.

After all the anchors were filled with oil, preparation was made for the grouting operation. A $12 \times 9.5-m m(1 / 2-i n$. O.D. $\times 3 / 8-i n$. I.D.) polyethylene grout tube (previously tied loosely along the length of the extensometer assembly) was used to pump grout mix into the hole. A little less than 30 litres ( $3 \mathrm{ft}^{3}$ ) of mix was required for each hole. The grout tube was pulled out of the borehole as the mix was being pumped in. Care was taken to keep a head $(\sim 5 \mathrm{ft})$ of grout $\mathrm{mix}$ above the end of the grout tube to ensure a good pour with a minimal number of voids.

Immediately after a pour, and hefore the grout mix could set up, the anchors had to be set. That was accomplished by using bottled nitrogen. The nitrogen pressurization system was attached to the expansion chamber and the pressure was slowly increased to $1750 \mathrm{psig}$ to set the anchors. After the grout set, the expansion chamber was purged of oil and replaced with $\mathrm{N}_{2}$ at $1750 \mathrm{psi}$. The amount of oil remaining in the anchors ranged from $75-140 \mathrm{ml}$. 
The differences in oil usage was attributed to varying lengths of tubing and the extent to which the anchors expanded when pressurized.

The final installation steps covered the assembly of the potentiometers and electrical signal cables to the rod extensometer (Fig. 36). The potentiometers were mechanically adjusted to produce an electrical signal less than $50 \mathrm{mV}$ in magnitude. The units were then ready for calibration.

\section{IN SITU CALIBRATION}

\section{MBI-Series Extensometers}

Initial calibration of the MBI series units was periormed by Terra Tek, Inc. ${ }^{15}$ The calibration was perf $\mathrm{frmed}$ by placing three precision-machined gage blocks between the bottom plate of the main frame (head assembly! and the top flange of the collar stabilizer tube, $120^{\circ}$ apart from each other. Each gage block has six ma shined steps $(10,11,12,13,14$, and $15 \mathrm{~mm}$ !)

To begin the first calibration for the mine-by phase, the extensometers were set at $10 \mathrm{~mm}$ with the gage blocks and by raising the head assembly with the three lifting screws (elevator bolts). The three blocks were then

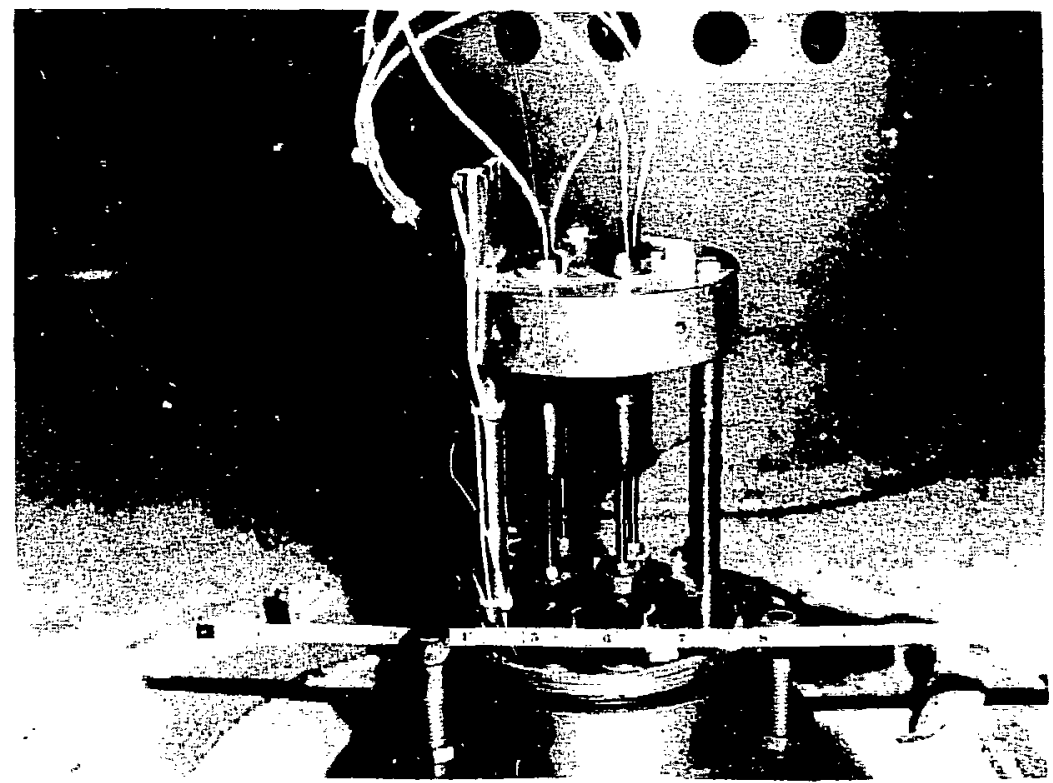

Figure 36. Typical G-series extensometer installation showing potentiometers in place. 
inserted and the lifting screws backed off until the head assembly rested on the blocks. The output signals from the potentiometers were measured and recorded. The head assembly was raised again and set to $11 \mathrm{~mm}$. This procedure was repeated for the 12, 13, 14, and $15 \mathrm{~mm}$ steps. After the signals were measured and recorded from each of the six positions, the head assembiy was returned to the $12-m m$ step and left suspended by the three lifting screws. At this position, the output signal was typically $5.0 \mathrm{Vdc}$ allowina for 12-13-mm travel in either direction. The second calibration for the mine-by phase followed the same procedure, but the order of the blocks was 12 , $13,14,15,14,13,12,11,10,11$, and 12. This pattern was chosen to document repeatability and hysteresis.

When calibrated for the fuel emplacement, four significant changes were made that affected calibrations. First, it had been noticed that the lifting screws had a tendency to walk around on the collar stabilizer tube ilange as they were being turned, which affected the repeatibility of the calibrations. Steel washers were cemented with epoxy to the tube flange to correct the problem. Second, wheatstune bridge completion resistors were added to the potentiometer network and the potentiometers were mechanically adjusted to produce an output signal less than $50 \mathrm{mV}$ at the 12-mm position. Third, we wanted a repeatibility check in the calibration data, so that the calibration step sequence was reordered to be $12,10,11,12,13,14,15,14,13$, and $12 \mathrm{~mm}$. Fourth, the data were measured and recorded by the DAS on the surface instead of by the portable readout system.

\section{GxE-Series Extensometers}

The calibration procedure for the GxE series was the same as the MBI series procedure used prior to fuel emplacement. The GxE series had a drilled recess in the collar stabilizer tube flange to prevent the lifting screws from walking around.

A plot of a typical calibration for a rod extensometer is shown in Fig. 37. The calibrations indicated that repeatibility was typically within $0.03 \mathrm{~mm}(0.001 \mathrm{in.)}$ over the 5 -mm range of the potentiometers, with a few as bad as $0.25 \mathrm{~mm}(0.010 \mathrm{in.})$. Using the terminal point plotting method, the error band over the $5-m m$ range indicated a linearity typically less than \pm 18 of span. In no case aid the band exceed $\pm 5 z$ of span (which in this situation is $5 \mathrm{~mm}$ ). 


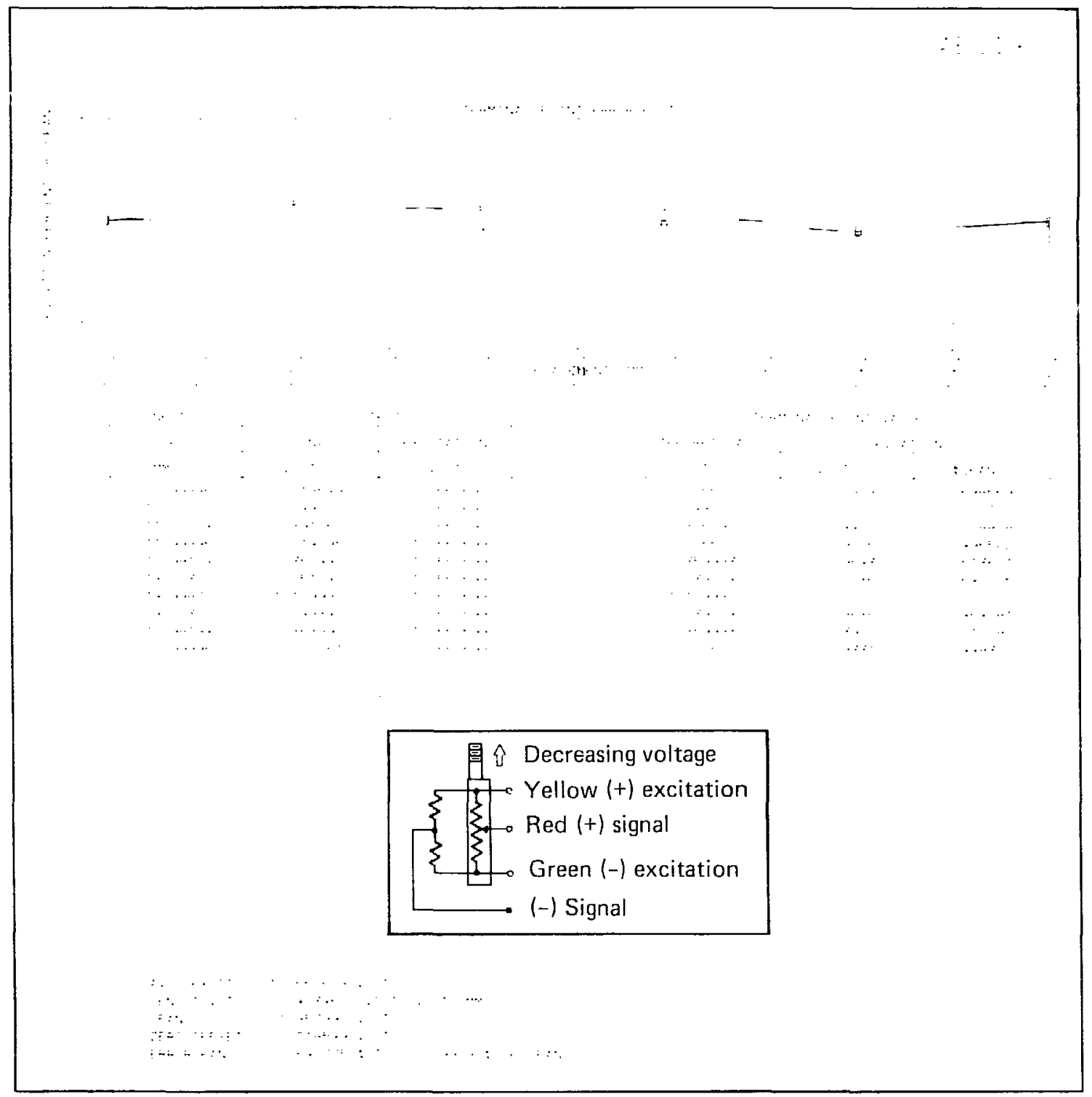

Figure 37. Typical rod extensometer calibration plot.

Since the repeatibility and accuracy of the potentiometers by themselves have: shown to be much better than these calibration results, it is obvious that "in situ" field calibrations are required to account for the effects of the assembly on overall response and accuracy. 
Mine-by Phase

The results to date of the mine-by phase for the MBI-series extensometers are reported by Terra Tek, Inc. ${ }^{15}$ The authors report extensometer performance as being "good to excellent."

During the extensometer refurbishment period, we discovered a number of minor problems with the linear potentiometers that we carefully investigated. $^{17}$ We found that extensometers of this type continued to function reliably even though subjected to accelerations of $1.8 \mathrm{q}$. The linear potentiometers had a survival rate of about $90 \%$ during the first four months of testing at ambient temperatures.

The primary reasons for refurbishing the MBI-series extensometers were verification of potentiometer survivability and removal of corroded parts from the head assemblies. The corrosion occurred where water was able to seep into the head at the points where the rods enter. The water became trapped because the cap had a waterproof seal. This cccurred on the extensometers angled upward over the central drift, an angle which positioned the cap 34-50 below horizontal orientation, enabling it to function much like a sump. At first indication of this problem, holes were drilled through the caps to allow for water drainage. Unfortunately, a few head assemblies had already been damaged.

\section{Fuel Storage Phase}

During the first 10 months of operation, approximately 308 of the GxEseries extensometers have had anchor pressurization problems of one $k$ ind or another, where a significant loss of pressure has occurred. At one- to two-month intervals, the anchor pressures are checked and repressurized, if needed. On a few anchors, pressure was actually relieved to stabilize pressure as much as possible. Pressures at $1750 \pm 50$ psi do not need adjustment. Otherwise adjustment is made by release or addition of $\mathrm{N}_{2}$. Leaks occurred on 308 of the anchor systems. The leaks, however, do not appear to be caused by any one component. Problems rave been found with pressure gages, expansion chamber fittings, and the down-hole components (lines, fittings, and anchors). Approximately $45 \%$ of the GxE anchors have 
required no adjustment since their initial setup and checkout. The other 258 have needed some minor adjustments periodically. There is no way of knowing how well the MBI-series anchors have performed, because they were set with plastic burst $l$ ines and check valves.

Another problem has developed with the linear potentiometers that has not yet been resolved. About three or four months after fuel emplacement, the DAS started setting of $f$ alarms indicating that displacements greater than $2 \mathrm{~mm}$ were occurring in the central drift around the fuel assemblies. To some extent this had been expected and was being supported by the data from the stressmeters. Additional displacement occurred for a couple of months until the validity of the data was questioned. This happened when displacements as great as $9 \mathrm{~mm}$ were observed. A visual check in October 1980 verified that the potentiometers shafts had obviously not moved those amounts. We checked the units in question electronically and found that they were malfunctioning. The resistive material in the potentiometers was changing resistance and becoming nonlinear. The other units were checked and it was determined that 23 of the 56 GxE-series potentiometers were definitely malfunctioning. Tests are presently being $r$ un to determine the cause of the failures. Tests to date show that the failures were limited to the GxE-series extensometers.

We have not comprehensively calibrated the rod extensometers in the interim, and data reduction and analysis is not yet at the point where information relating to the extensometers' performance can be presented.

\section{CONVERGENCE MONITORS}

\section{INTRODUCT ION}

In addition to the previously discussed borehole rod extensometers, we designed, fabricated and installed two types of convergence monitors. These devices augmented the rod extensometers and, thus, addressed technical issues related generally to granitic rock response and to the design of nuclear waste repositories in granite. 
SCIENTIFIC CRITERIA

The decision to incorporate convergence monitors in the instrumentation program came quite late in the SFT-C planning process. The technical concept document had been completed as had most underground construction when this decision was made. There were three reasons for including such instrumentation. First, project personnel felt that drift closure needed to be documented. Measurements were being made with a tape extensometer during the construction phase to meet this need. Secondly, a panel of LLNL reviewers supported installation of additional displacement instrumentation. Finally, a peer review group formed by the DOE-NV strongly recommended additional displacement measurements.

This led to the technical enhancement of the Spent fuel Test. Two types of convergence monitors were selected to augment the previously planned rod extensometers. Convergence-wire extensometer (CWE) units were selected to measure convergence and divergence across underground openings. CWE units measured the integrated displacement between roof and floor, or between two drift ribs. Fracture monitor system (FMS) units were selected to measure three components of convergence and divergence across single fractures, sets of closely spaced fractures, or faults. The three components are mutually orthogonal and oriented along strike, along dip, and normal to the plane of the selected geologic features. Therefore, these units measure the discrete response of individual geologic features to the imposed thermal and mechanical stresses.

DES IGN CRITERIA

Convergence monitors represented a marked deviation from the original plan to use off-the-shelf instrumentation. A survey of existing instrumentation concluded that there were no devices available to remotely measure gross opening response and discrete fracture response.

The decision to design and fabricate the CWE and FMS units in house was based largely on the time constraint. Another factor was the need for close interaction between design personnel and geotechnical engineering staff members. Aside from the need to produce simple instruments that could be quickly and inexpensively designed, fabricated, and installed, both the CWE 
and FMS units were designed with four principal criteria in mind. These are discussed briefly in the following paragraphs.

High levels of resolution and accuracy are required to provide useful data. SFT-C thermomechanical response calculations indicated that displacements as large as several millimetres would occur in some locations, but that most regions would be displaced by tenths of millimetres or less." Bourns precision rectilinear potentiometers were selected as the transducers for both CWE and FMS units. Output voltage was measured to $1 \times 10^{-6} \mathrm{~V}$, providing a precision of $3 \times 10^{-9}-\mathrm{m}$ displacement.

The accuracy is much lower than the resolution because of instrument characteristics and environmental factors. The most important of these factors is error introduced by thermal expansion of instrument components. Thermal expansion can be greatly minimized by selection of Invar or Super-Invar materials, as was done with some of the borehole extensometers. The required forms of these materials were not, however, available for use in CWE and FMS construction. The stainless-steel wire in the CWE units produces nearly all of the thermal expansion due to its length (3-6.2 m) and coefficient of thermal expansion $\left(\sim 16.6 \times 10^{-6} /{ }^{\circ} \mathrm{C}\right)$.

These units will expand 0.05-0.1 mm for each degree Celcius $r$ ise in drift temperature. We anticipate that temperature changes in the underground openings can be measured at least that well and potentially an order of magnitude better. Even so, the apparent precision of $3 \times 10^{-9} \mathrm{~m}$ is degraded to no better than $5 \times 10^{-6} \mathrm{~m}$.

The components of FMS units had similar thermal expansion coefficients, but were much shorter, producing far smaller total expansions. FMS units expand between $2.5 \times 10^{-6} \mathrm{~m}$ and $10 \times 10^{-6} \mathrm{~m}$ for each degree Celcius $\mathrm{r}$ ise in drift cemperature. Displacements could be corrected to about an order of magnitude better if temperature changes were known to within $0.1^{\circ} \mathrm{C}$. Drift temperature measurements and thermal correction algorithms are being used to maximize the precision of these units.

Dimensional stability of instrument components over time is another consideration that effects overall instrument precision. The most commonly discussed form of dimensional instability is the creep associated with hightemperature and high-stress environments. These environments were avoided in the SFT-C drifts in two ways. Drift temperature (and, hence, CWE and FMS temperature) is 1 imited by ventilation to about $37^{\circ} \mathrm{C}$ to permit comfortable, 
manned access to the facility. High stress was avoided by designing instruments that would be subjected to extremely low forces and moments. The most severely stressed component is the wire in the CWE units. These wires are subjected to about 5.68 of their ultimate tensile strength--well below the onset of significant creep.

Another aspect of dimensional stability is the change in dimensions at ambient temperatures and zero external pressure. This occurs due to changes in the crystal structure of various metals. This behavior can be quite pronounced in drawn and tempered metal shapes, such as the spring-tempered stainless-steel wire in the CWE units. Recognizing the potential for this problem led us to heat-treat the wire at $290^{\circ} \mathrm{C}$ for $40 \mathrm{~min}$ (an LLNL standard) prior to installation.

Continuing spent-fuel handling operations in the canister drift requires that the CWE units be removable and replaceable without loss of zero reference. These requirements were met in two ways. First, the inactive end of each wire was permanently attached to a precisely machined, hard-chromeplated pin that slides into a mating block (Fig. 38). This design fixes the zero point for horizontal units completely (Fig. 39). The second design feature applies only to vertical units. Three small plates and washers are glued to appropriate locations on the concrete floor, in the canister drift (Fig. 40), or to steel plates, in the heater drifts (Fig. 41), to provide references for three mated thumb screws located on the CWE unit. The legs are initially adjusted to level the unit and they are locked in place with jamb nuts. The active end of the vertical CWE unit is thus permanently referenced to a floor location. Units can then be removed for fuel handling operations without losing the zero reference.

The final concern was corrosion of the convergence monitors. The water at the SFT-C is corrosive to black iron and galvanized steel. Since the SFT-C is located above the regional water table, there are few sources of free water in the facility. Most of the moisture causing corrosion occurs as humidity in the air. All components that were not stainless steel, brass, or aluminum were plated with electroless nickel to limit corrosion.

\section{PROCUREMENT AND FABRICATION}

Once the CWE and FMS units had been designed (Figs. 38 and 39), procurement and Eabrication were initiated. Electronic components were 


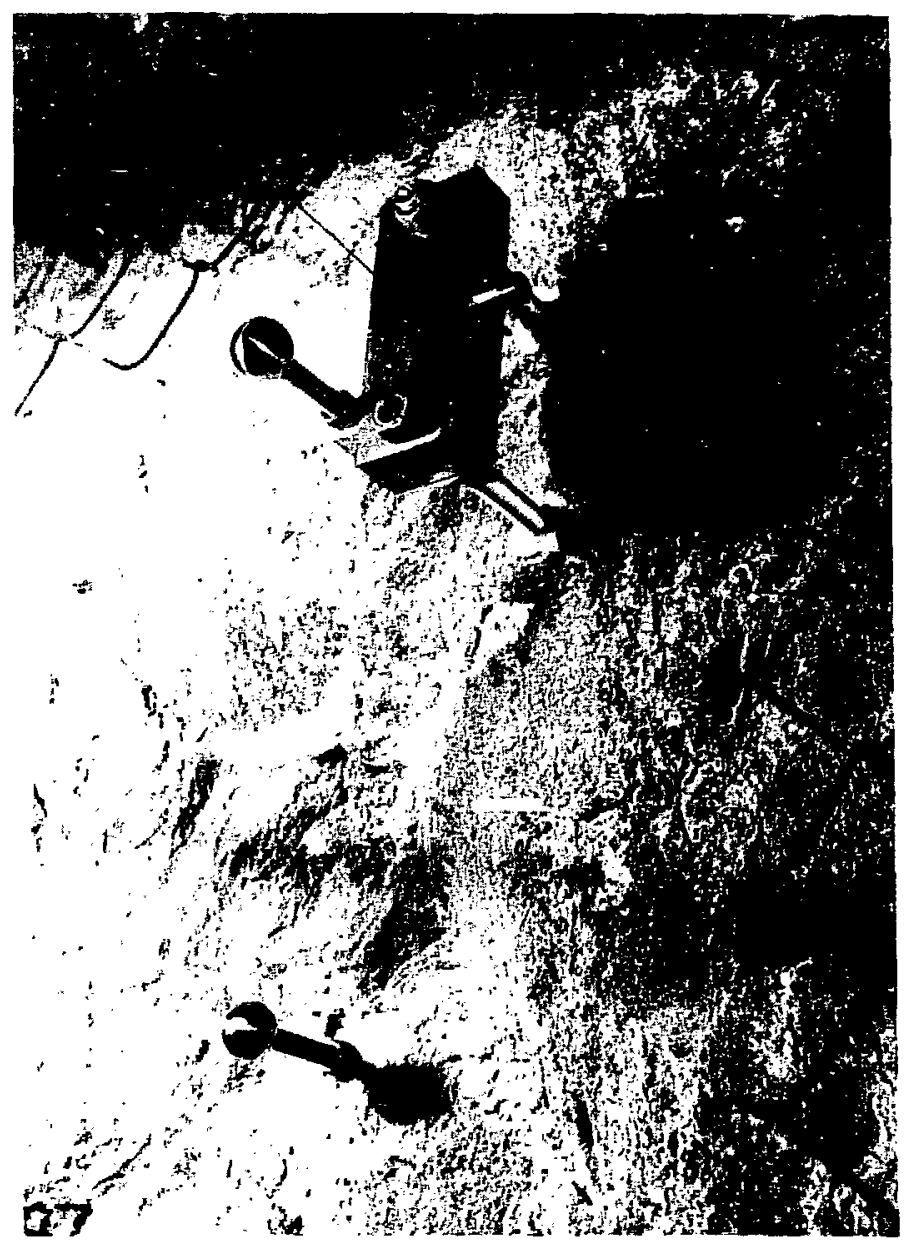

Figure 38. Inactive end of convergence wire extensometer showing spherical mount for tape extensometer.

procured in the same :nanner as for rod extensometers, and will not be discussed here further. Large CWE and FMS unit components, such as base plates, were procured through outside shops. All components requiring close tolerances and rigid quality control were fabricated in house using LLNL stock materials.

Completed components were packaged and shipped to Nevada for assembly underground at the SFT-C. 


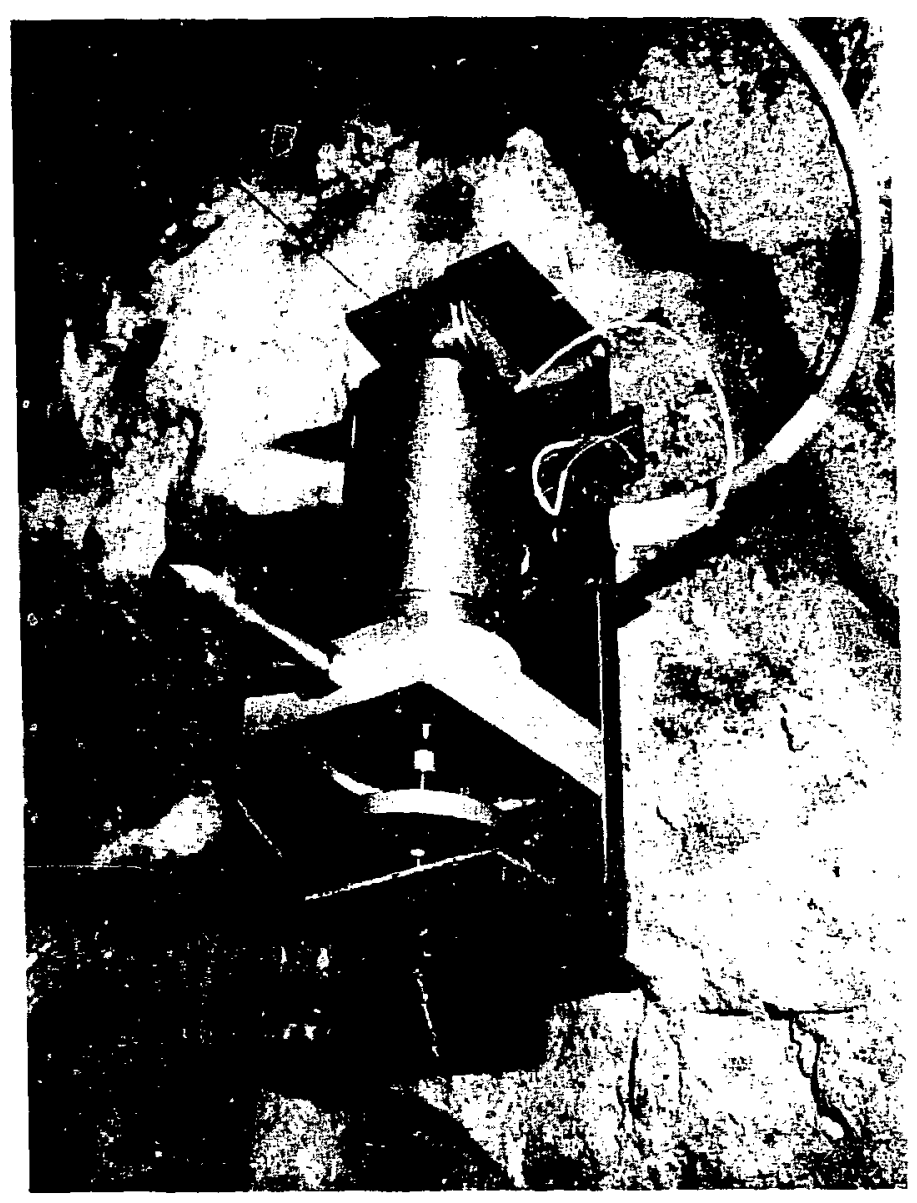

Figure 39. Typical horizontal convergence wire extensometer installation.

INSTALLATION

A total of 34 CWE units were installed at the SFT-C (Fig. 42). Of these, 32 consisted of 16 pairs of horizontally and vertically oriented wire extensometers. The remaining two represented a special CWE, called a through-hole extensometer. These two units bear a THE designator in the DAS, but their function is identical to any horizontal CWE unit. CWE unit placement is designed to profile rock displacement along the axis of each drift. Specific unit locations record rock displacements due to differing extents of fracturing and faulting. 


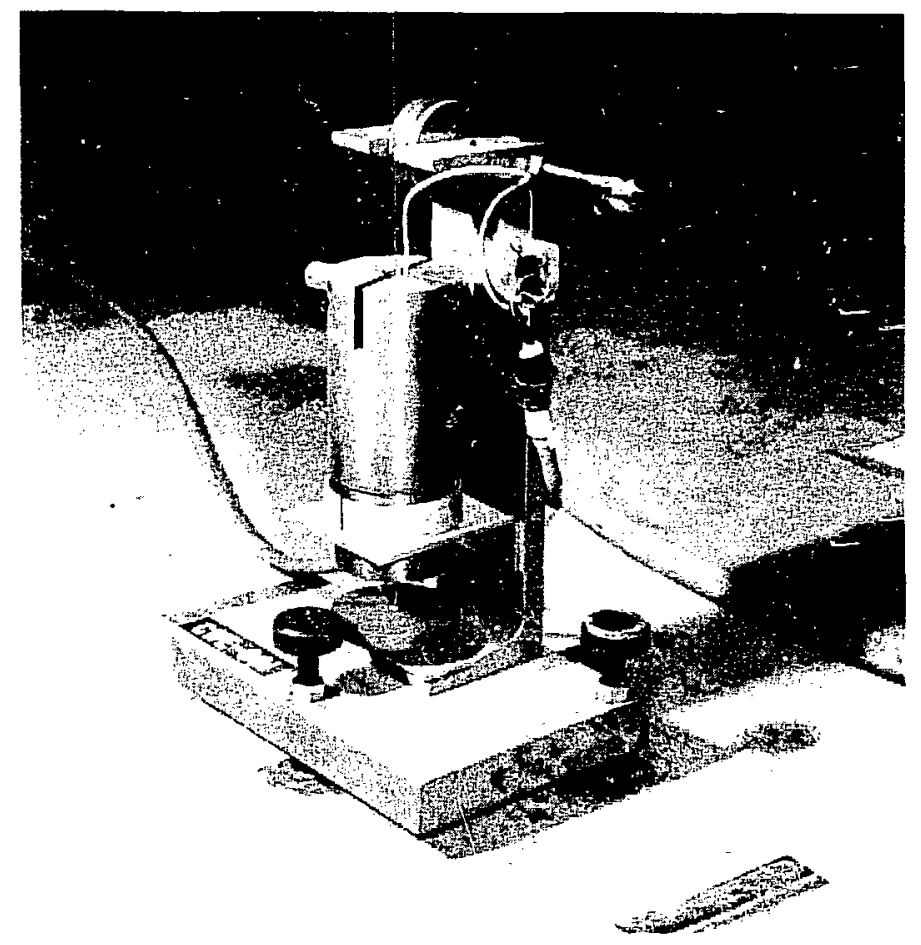

Figure 40. Typical canister drift vertical convergence wire extensometer installation.

In preparation for CWE installation, two 19-22-mm-diam holes were drilled about 150-mm deep at each end of the horizontally oriented units and at the roof location of the vertically oriented units (Fig. 38 and 39). Lengths of threaded rod $12.7 \mathrm{~mm}$ in diameter were grouted into each of the drilled holes. The sulfaset grout was allowed to cure before the instruments were attached. The concrete floor of the canister drift provided an adequate base for the lower end of the vertical CWE units (Fig. 40!. Stainless-steel pads and washers were glued to the canister drift floor to serve as locaters for the three leqs of the CWE units. In the two heater drifts, the same technique was applied to the vertical units, but first a base was prepared on which the pads were glued (Fig. 4l). The base was formed by anchoring three lengths of reinforcing bar in grout-filled holes in the floor. A 6-mm-thick steel plate was then bolted to the reinforcing bars to form a smooth, level base for these instruments.

Seven 3-component FMS units were installed across geologic features of special interest to staff scientists. These units measure three mutualiy 


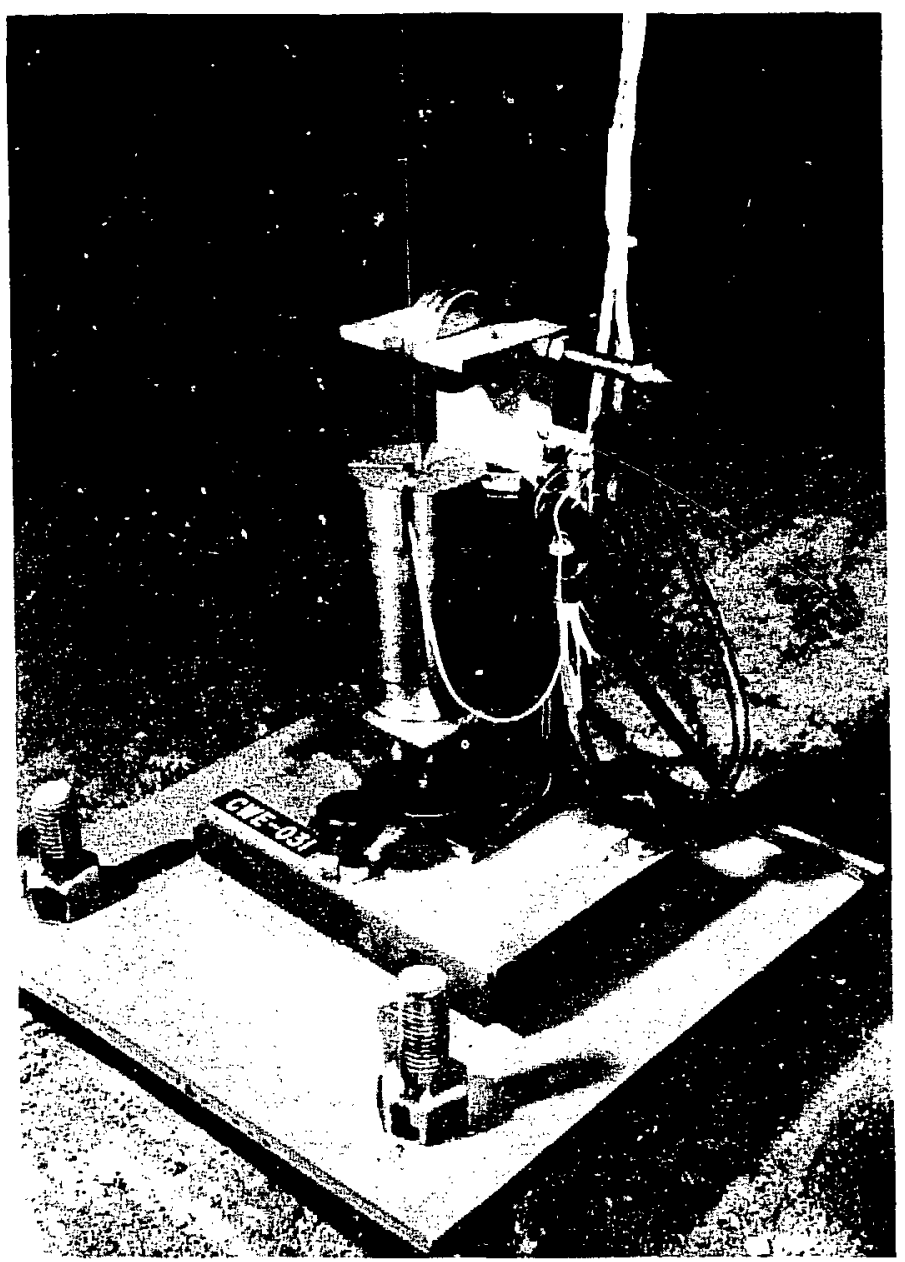

Figure 41. Typical heater drift vertical convergence wire extensometer installation.

or thogonal components of displacement along discrete fractures and faults--along strike, along dip, and normal to the plane of the selected feature (Fig. 43). Thus, those portions of the rock mass believed to be most susceptible to applied mechanical and thermal stresses are measured.

One of the two base plates supports the three potentiometers, and the other supports the pipe section spanning the geologic feature. These were secured on either side of the feature being monitored. The plates were anchored to the rock using lengths of threaded rod in qrout-filled holes, as was the case for CWE units. Once again, all mechanical components wer. assembled and installed prior to emplacement of electronic components. 


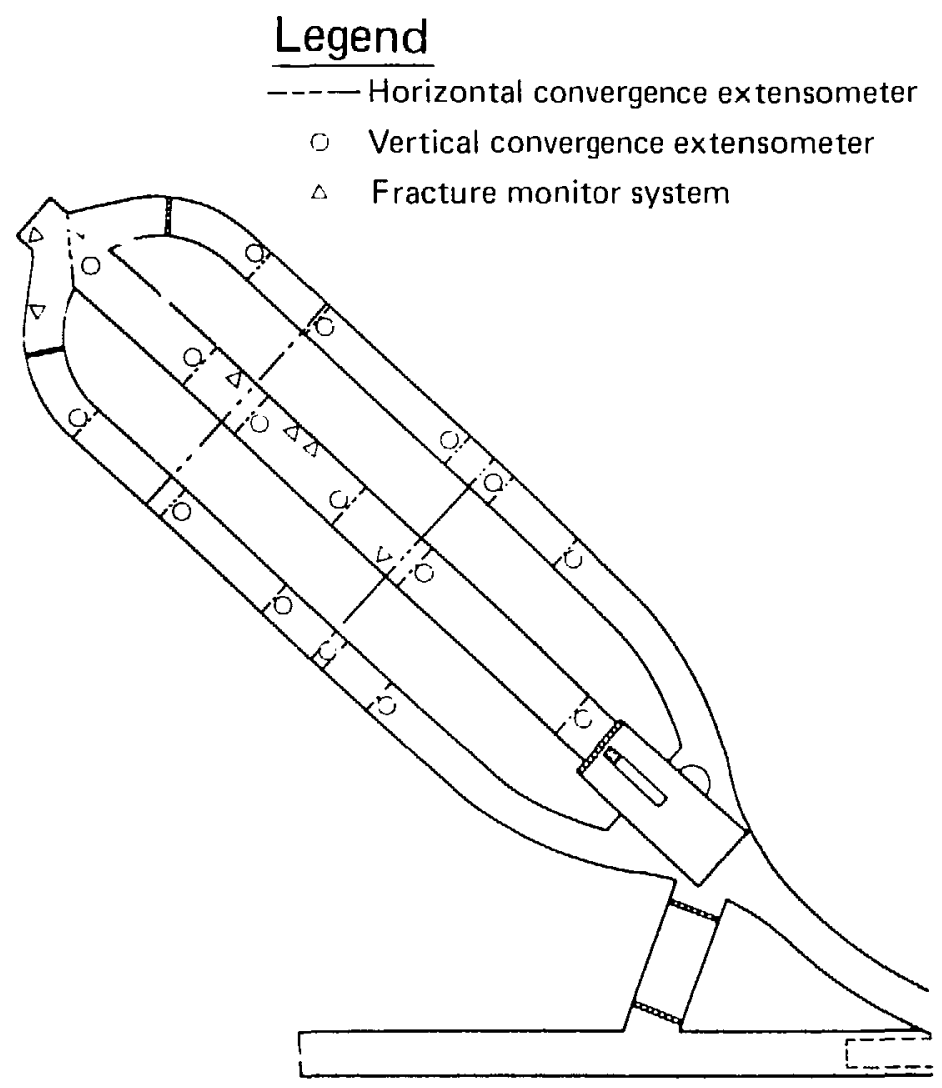

Figure 42. Convergence wire extensometer locations.

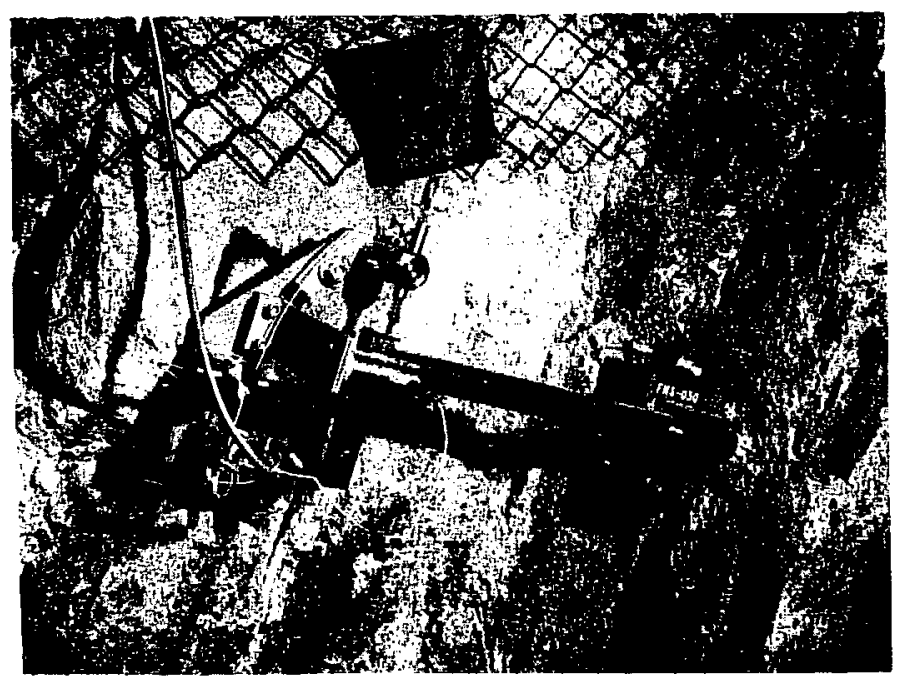

Figure 43. Typical fracture monitor system installation. 


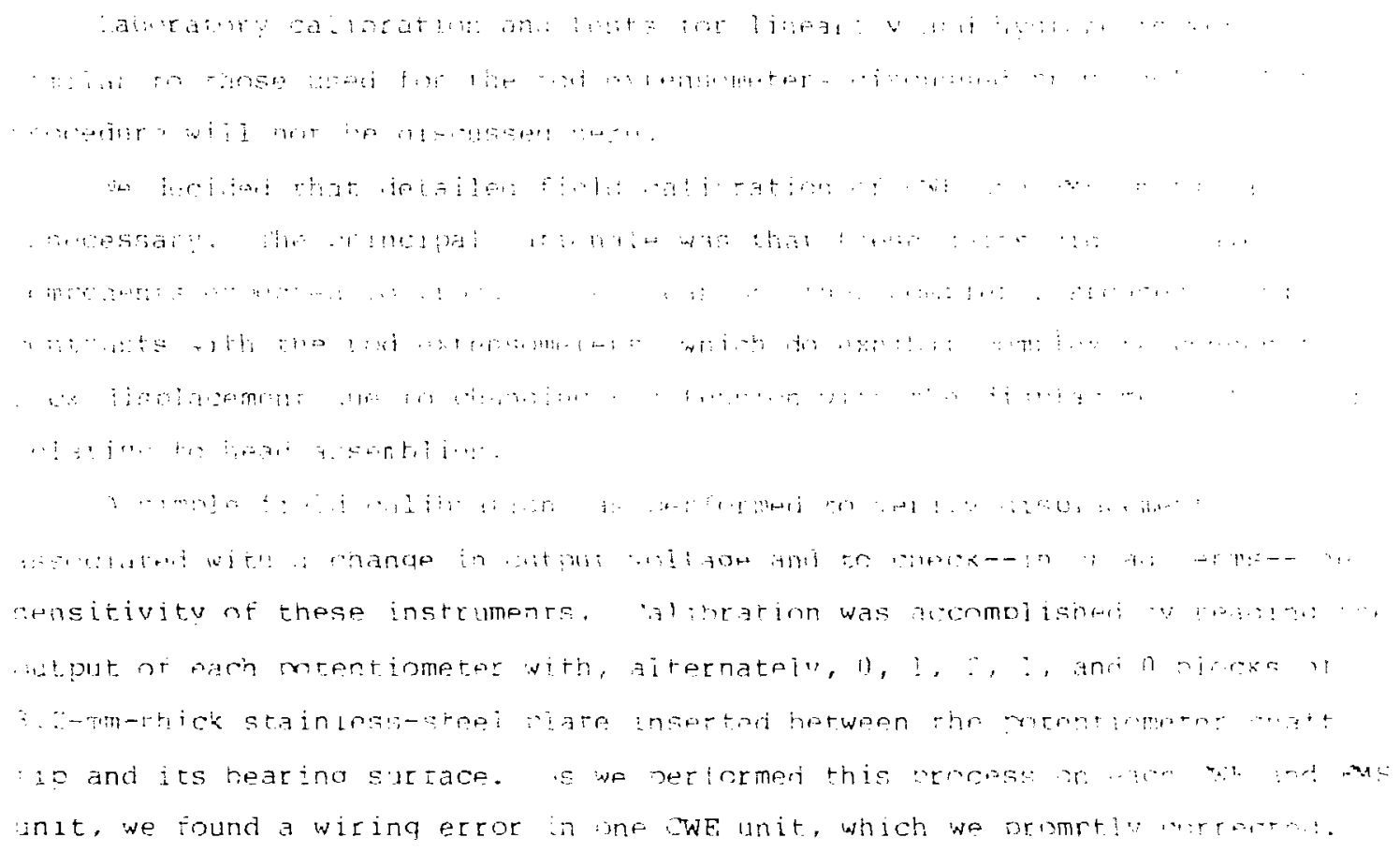

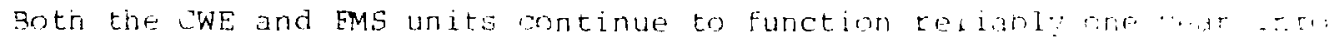
the test. Displacements of as much as $1.5 \mathrm{~mm}$ have bos cocoted ho in mita,

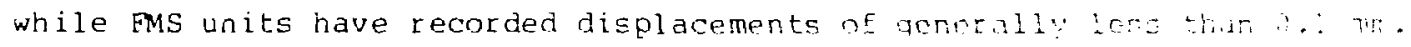
Corrosion has been a problem on only two units. These two have wity splashing on them due to seeps from the roof. However, cuen these arywitir be functioning reliably; the associated potentiometers operatr smothl?

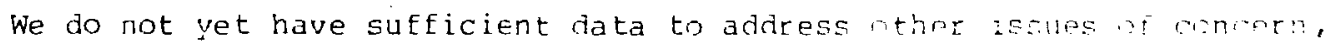
such as thermally induced errors, and problems associated with comouna uns replacing che instruments to accommodate Euel handina pparatins.

\section{SUMMARY}

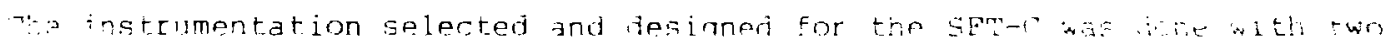

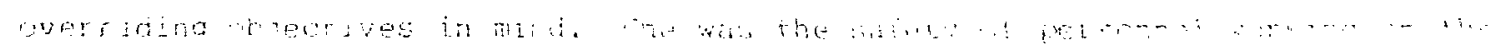

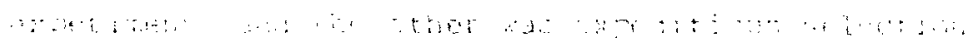


instrumentation to measure the parameters of interest in repository design, construction, and operation.

The first objeccive has been accomplished, and special effort is being devoted to meeting the second. Some instruments (radiation dosimeters, thermocouples, watts transducers, convergence monitors, and dew point sensors! have performed well. There are a few instruments (rod extensometers and stressmeters! that have posed unexpected problems leading to the degradation or loss of scientific data.

In this report we document specification, design, calibration, and installation of several types of instruments and comment on our experience with them. We will analyze our data in detail periodically in subsequent topical reports. One of the purposes of this report has been to document our thoroughness in addressing major concerns in instrumentation.

Our only overriding recommendation is that rock mechanics instrumentation be investigated further. In conducting this phase of the experiment, it became apparent that the quality of data could have been significantly improved, had the instrumentation used the most modern technology.

Little has been said about the design and operation of the DAS. Although it certainly plays an integral part in getting good data, it will be discussed in detail in another report now in preparation, which will emphasize its hardware and software designs. 
REFERENCES

1. L. D. Ramspott, L. B. Ballou, R. C. Carlson, D. N. Montan, T. R. Butkovich, J. E. Duncan, W. C. Patrick, D. G. Wilder, W. G. Brough, and M. C. Mayr, Tecinnical Concept for a Test of Geologic Storage of Spent Reactor Fuel in the Climax Granite, Nevada Test Site, Lawrence Livermore National Laboratory, Livermore, CA, UCRL-52796 (1979).

2. Lawrence Livermore Laboratory Qual ity Assurance Plan, Spent Fuel TestClimax, M-078-08 Rev. 1 (1979).

3. Safety Assessment Document for the Spent Reactor Fuel Geologic Storage Test in the Climax Granite Stock at the Nevada Test Site, U.S. Department of Energy, Nevada Operations Office, Las Vegas, NV, NVO-210 (1980!.

4. R. C. Carlson, W. C. Patrick, D. G. Wilder, W. G. Brough, D. N. Montan, P. E. Harben, L. B. Ballou, H. C. Heard, Spent Fuel Test-Climax: Technical Measurements Interim Report, FY 1980, Lawrence Livermore National Laboratory, Livermore, CA, UCRL-53064 (1980).

5. T. R. Butkovich and D. N. Montan, A Method for Calculating Internal Radiation and Ventilation with the ADINAT Heat-Fl ow Code, Lawrence Livermore National Laboratory, Livermore, CA., UCRL-52918 (1980).

6. D. N. Montan and W. C. Patrick, Thermal Calculations for the Design. Construction, Operation, and Evaluation of the Spent Fuel Test-Climax, Nevacia Test Site, Lawrence Livermore National Laboratory, Livermore, CA, UCRL-53238 (1981).

T. R. Butkovich, Mechanical and Thermomechanical Calculacions Related to the Storage of Spent Nuclear-Fuel Assemblies in Granite, Lawrence Livermore National Laboratory, Livermore, CA, UCRL-53238 (1980).

8. H. H. Plumb (editor- 'n-chief), Temperature, Its Measurement and Control in Science and Industry, 4, Part 3, pp. 1869-1934 (1972).

9. N. A. Burley, R. L. Powell, G. W. Burns, and M. G. Scroger, The Nicrosil versus Nisil Thermocouple: Properties and Thermoelectric Reference Datar National Bureau of Standards, Washington, DC, Monograph 161, (1978).

10. V. E. Hooker, J. R. Aggson, and D. L. Bickel, Improvements in the Three-Component Borehole Deformation Gage and Overcoring Techniques, U.S. Bureau of Mines Report of Investigations, Pittsburgh, PA, RI7894 (1974). 
11. P. K. Dutta, R. W. Hatfield, and P. W. Runstadler, Jr., Calibration Characteristics of IRAD Gage Vibrating Wire Stressmeter at Normal and High Temperature, Vol. 1 and 2, Lawrence Livermore National Laboratory, Livermore, CA, UCID-15426 (1981).

12. A. Abey and H. Washington, Stressmeter Placement at Climax Granite Spent Fuel Test, Lawrence Livermore National Latoratory, Livermore, CA, UCID-18629 (1980).

13. D. G. Wilder and W. C. Patrick, Geotechnical Status Report for Test Storage of Spent Reactor 'ile] in Climax Granite, Nevada Test itite. Lawrence Livermore National Laboratory, Livermore, CA, UCRL-85096 (1980).

14. F. E. Heuzé, T. R. Butkovich, and J. C. Peterson, An Analys is of the "Mine-By" Experiment, Climax Granite, Nevada Test Site, Lawrence Livermore National Laboratory, Livermore, CA, UCRL-53133 (1981).

15. T. Schrauf, and M. Board, Instrumentation Selection, Installation and Analysis of Data for the Spent Fuel Mine-by, Nevada Test Site, Climax Stock, Terra Tek, Inc., Salt Lake City, UT, UCRL-15076 (1979).

16. C. M. Marshall and R. E. Maringer, Dimensional Instability--An Introduction (Tergamon Press, Oxford, 1977) pp. 268-280.

17. W. C. Patrick and W. G. Brough, Response of Borehole Extensometers to Explosively Generated Dynamic Loads, Lawrence Livermore National Laboratory, Livermore, CA, UCRL-53087 (1980). 
APPENDIX A.

DATA ACQUISITION SYSTEM MEASUREMENT SPECIFICATIONS 
APPENDIX A

Data Acquisition System Measurement Specifications

\begin{tabular}{|c|c|c|c|c|}
\hline & $\begin{array}{l}\text { Range } \\
\text { (V) }\end{array}$ & $\begin{array}{l}\text { Resolution } \\
\text { (high resolution } \\
\text { Eunction on) }\end{array}$ & $\begin{array}{l}\text { Accuracy } \\
\left(90 \mathrm{~d}, 23^{\circ} \pm 5^{\circ} \mathrm{C}\right)\end{array}$ & $\begin{array}{l}\text { Temp coefficient } /{ }^{\circ} \mathrm{C} \\
\left(0^{\circ}-50^{\circ} \mathrm{C}\right)\end{array}$ \\
\hline $\mathbf{l}$ & $( \pm 1.499999)$ & $1 \mu V$ & $\pm(0.0068$ of reading $+4 \mu \mathrm{V})$ & $\pm(0.00038$ of reading $+0.15 \mu \mathrm{V})$ \\
\hline 10 & $( \pm 14.99999)$ & $10 \mu \mathrm{V}$ & $\pm(0.005 \%$ of reading $+30 \mathrm{uV})$ & $\pm(0.000158$ of reading +1 uV $)$ \\
\hline 100 & $( \pm 149.9999)$ & $100 \mathrm{HV}$ & $\pm(0.0078$ of reading $+300 \mu \mathrm{V})$ & $\pm(0.00038$ of reading $+10 j \mathrm{~V})$ \\
\hline 1000 & $( \pm 1000.000)$ & $1 \mathrm{mV}$ & $\pm(0.0078$ of reading $+3 \mathrm{mv})$ & $\pm(0.00038$ of reading $+100 u \mathrm{~V})$ \\
\hline
\end{tabular}

\section{Input characteristics}

Input resistance:

0.1 - through $10-\mathrm{V}$ range: $>10^{10} \Omega$.

100- through 1000-V range: $10 \mathrm{M} \Omega \pm 0.1 \%$.

Max input voltage:

High- to low-input terminals: $\pm 1000-V$ peak.

Guard to chassis: $\pm 500-V$ peak.

Guard to low terminal: $\pm 200-V$ peak.

Normal mode rejection (NMR):

NMR is the ratio of the peak normal-mode

to the peak error voltage in the reading.

NMR at 50 or $60 \mathrm{~Hz} \pm 0.18:>60 \mathrm{~dB}$.

Effective common-mode rejection (ECMR):

ECMR is the ratio of the peak common-mode to the resultant peak error voltage in the reading.

ECMR (1-k $\Omega$ unbalance in low lead) at dc: $>140 \mathrm{~dB}$.

ECMR (1-k $\Omega$ unbalance in low lead) at 50 or $60 \mathrm{~Hz} \pm 0.18:>160 \mathrm{~dB}$. 
Ohms

Resolution

Range (high resolution

$(k \Omega)$

Eunction on)
Accuracy
$\left(90 \mathrm{~d}, 23^{\circ} \pm 5^{\circ} \mathrm{C}\right)$
Temp coefficient $/{ }^{\circ} \mathrm{C}$

$\left.10^{\circ}-50^{\circ} \mathrm{C}\right)$

$\begin{array}{rcll}1( \pm 1.499999) & 1 \mathrm{~m} \Omega & \pm(0.00358 \text { of reading }+5 \mathrm{~m} \Omega) & \pm(0.00038 \text { of reading }+0.2 \mathrm{~m}() \\ 10( \pm 14.99999) & 10 \mathrm{~m} ? & \pm(0.00608 \text { of reading }+50 \mathrm{~m} 2) & \pm(0.00038 \text { of roading }+2 \mathrm{~m} \Omega) \\ 100( \pm 149.9999) & 100 \mathrm{~m} \Omega & \pm(0.00358 \text { of reading }+600 \mathrm{~m} \Omega) & \pm(0.00037 \text { of reading }+20 \mathrm{~m} \Omega) \\ 1000( \pm 1499.999) & 1 \Omega & \pm(0.01358 \text { of reading }+5 \Omega) & \pm(0.0005 \% \text { of reading }+0.22) \\ 10000( \pm 14999.99) & 10 \Omega & \pm(0.10008 \text { of reading }+50 \Omega) & \pm(0.0048 \text { of reading }+22)\end{array}$

* Accuracy stated is for 4-wire $\Omega$ measurements. For 2-wire $\Omega$ measurements, add $0.4 \Omega$ to all readings.

Signal source driving unknown (nominal):

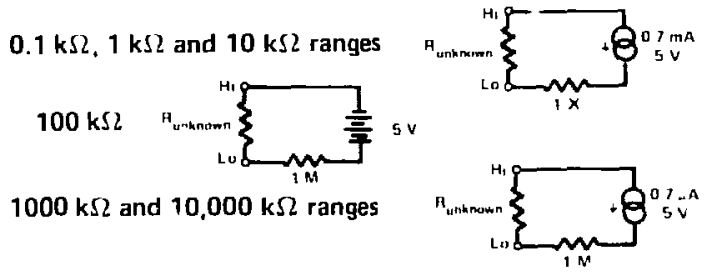

ac voltage (rms converter)

Range

(V)

Resolution

Temp coefficient $/{ }^{\circ} \mathrm{C}$

$\left(0^{\circ}-50^{\circ} \mathrm{C}\right)$

$\begin{array}{rrl}1(1.49999) & 10 \mu \mathrm{V} & \pm(0.0028 \text { of reading }+60 \mathrm{uV}) \\ 10(14.9999) & 100 \mu \mathrm{V} & \pm(0.0028 \text { of reading }+600 \mu \mathrm{V}) \\ 100(149.999) & 1 \mathrm{mV} & \pm(0.0028 \text { of reading }+5 \mathrm{mV}) \\ 1000(1000.00) & 10 \mathrm{mV} & \pm(0.0028 \text { of reading }+60 \mathrm{mV})\end{array}$

Accuracy (ac coupling)*: \pm (8 of reading + digits, or $[8$ of range]) $\dagger$ for 1 year; $23^{\circ} \pm 5^{\circ} \mathrm{C}$

\begin{tabular}{|c|c|c|c|c|}
\hline $30 \mathrm{~Hz}-20 \mathrm{kHz}$ & $20-100 \mathrm{kHz}$ & $100-250 \mathrm{kHz}$ & $250-500 \mathrm{kHz}$ & $500 \mathrm{kHz}-1 \mathrm{MHz}^{\ddagger}$ \\
\hline $\begin{array}{c}0.078+70 \mathrm{dig} . \\
(0.078)\end{array}$ & $\begin{array}{r}0.78+160 \mathrm{dig} . \\
(0.168)\end{array}$ & $\begin{array}{r}2.28+350 \mathrm{dig} . \\
(0.358)\end{array}$ & $\begin{array}{c}5.38+700 \mathrm{dig} . \\
(0.78)\end{array}$ & $\begin{array}{c}6.68+2800 \text { aig. } \\
(2.88)\end{array}$ \\
\hline
\end{tabular}

- ac/dc:

Add 20 dig. or $(0.028$ of range) on 10 to $1000-\mathrm{V}$ ranges.

Add $40 \mathrm{dig}$. or ( 0.048 of range) on $1-V$ range.

† Guard must be connected to iow input. On the $1000-\mathrm{V}$ range, add $0.01 \mathrm{ppm} / \mathrm{v} \mathrm{kHz}$.

$\mp$ Frequencies $>100 \mathrm{kHz}$ specified on $1-$ and $10-\mathrm{V}$ ranges only. 


\section{Crest factor}

$7: 1$ at full scale.

\section{Input characteristics}

Impedance :

Front terminals--2 $M \square \pm 18$ shunted by $<90 \mathrm{pF}$.

Rear terminals--2 $M+18$ shunted by $<65 \mathrm{pF}$.

Max input voltage:

High-low terminals: $\pm 1414-\mathrm{V}$ peak (subject to a $10^{7}-\mathrm{V}-\mathrm{Hz}$ limitation). Guard-chassis: $\pm 500-V$ peak.

Guard-low terminal: $\pm 200-V$ peak.

\section{Note}

1. The above specifications are for the HP Model 3455A digital voltmeter in the SFT-C configuration.

2. The digital voltmeters are ca:ibrated at 90-d intervals (except for the ac voltage, which is calibrated at 1 -yr intervals). Higher accuracy could be achieved with shorter calibration intervals (e.g., 1 mo).

3. For low-level dc-voltage measurements, the HP Model 3495A scanners have a potential effect of $\angle 1 \mu V$ differential EMF on the signal being measured. 
APPENDIX B.

TYPICAL LIST ING OF ALPHANUMERIC DESIGNATORC. FOR INSTRUMENTS TO BE SCANNED 


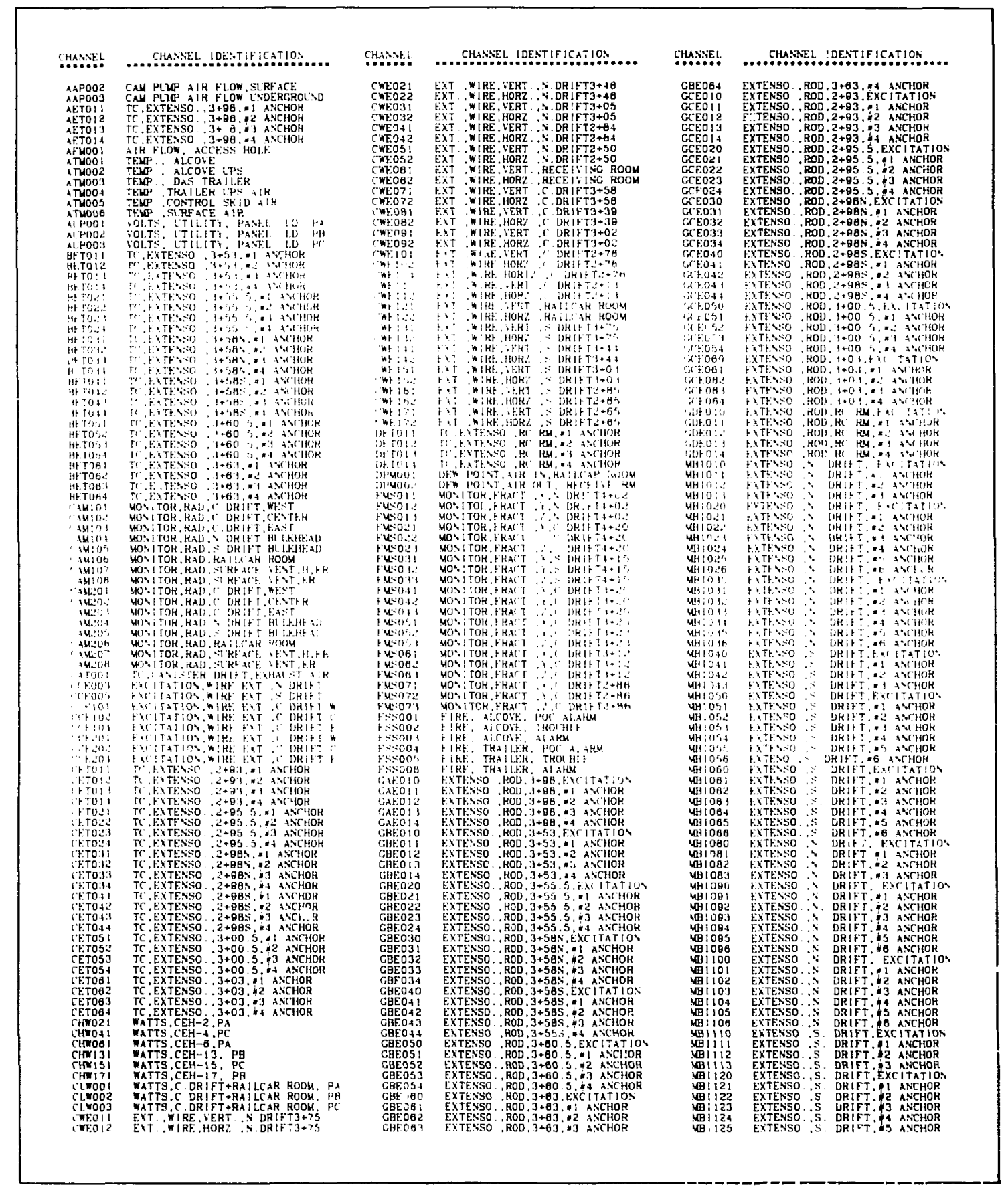




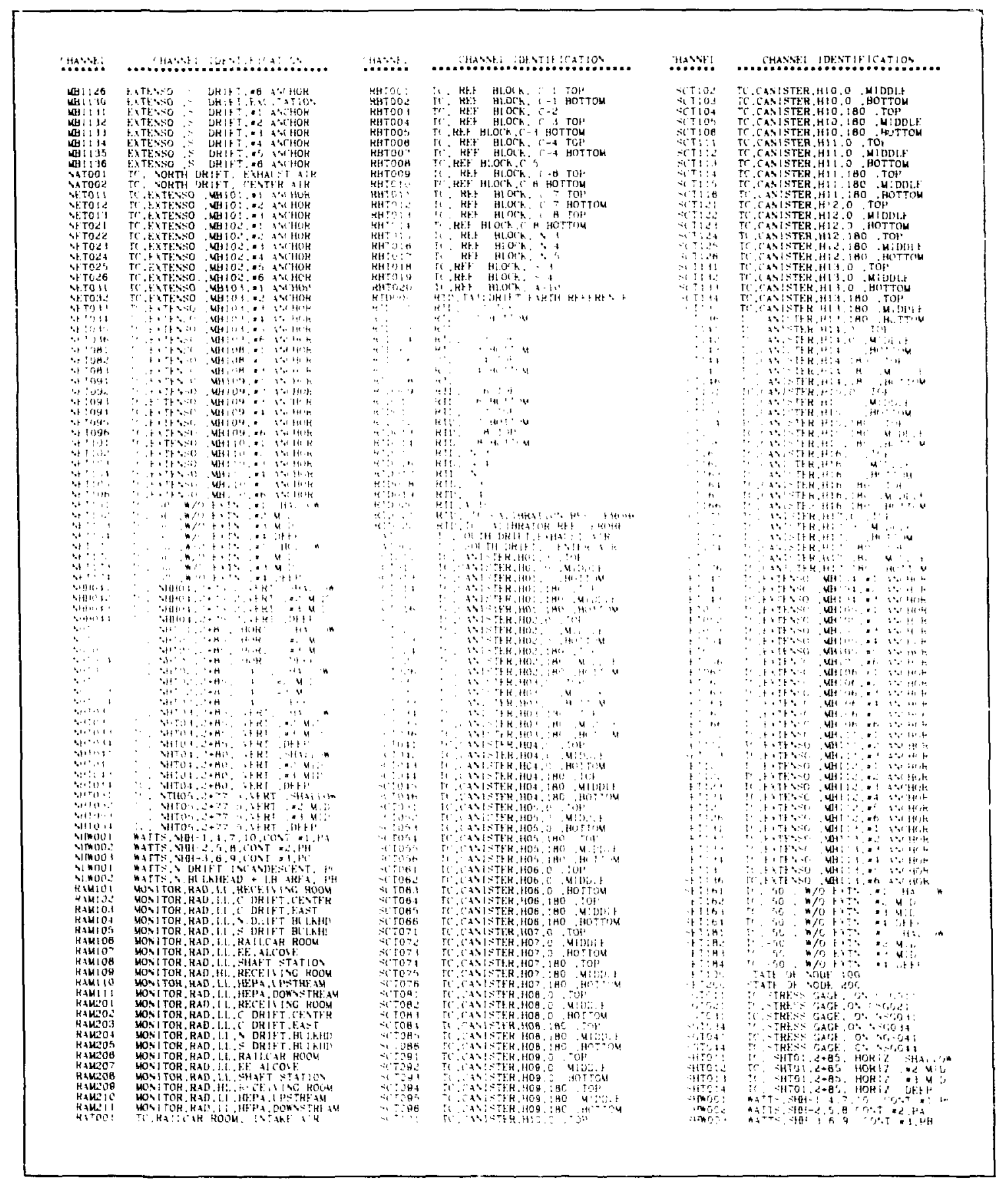




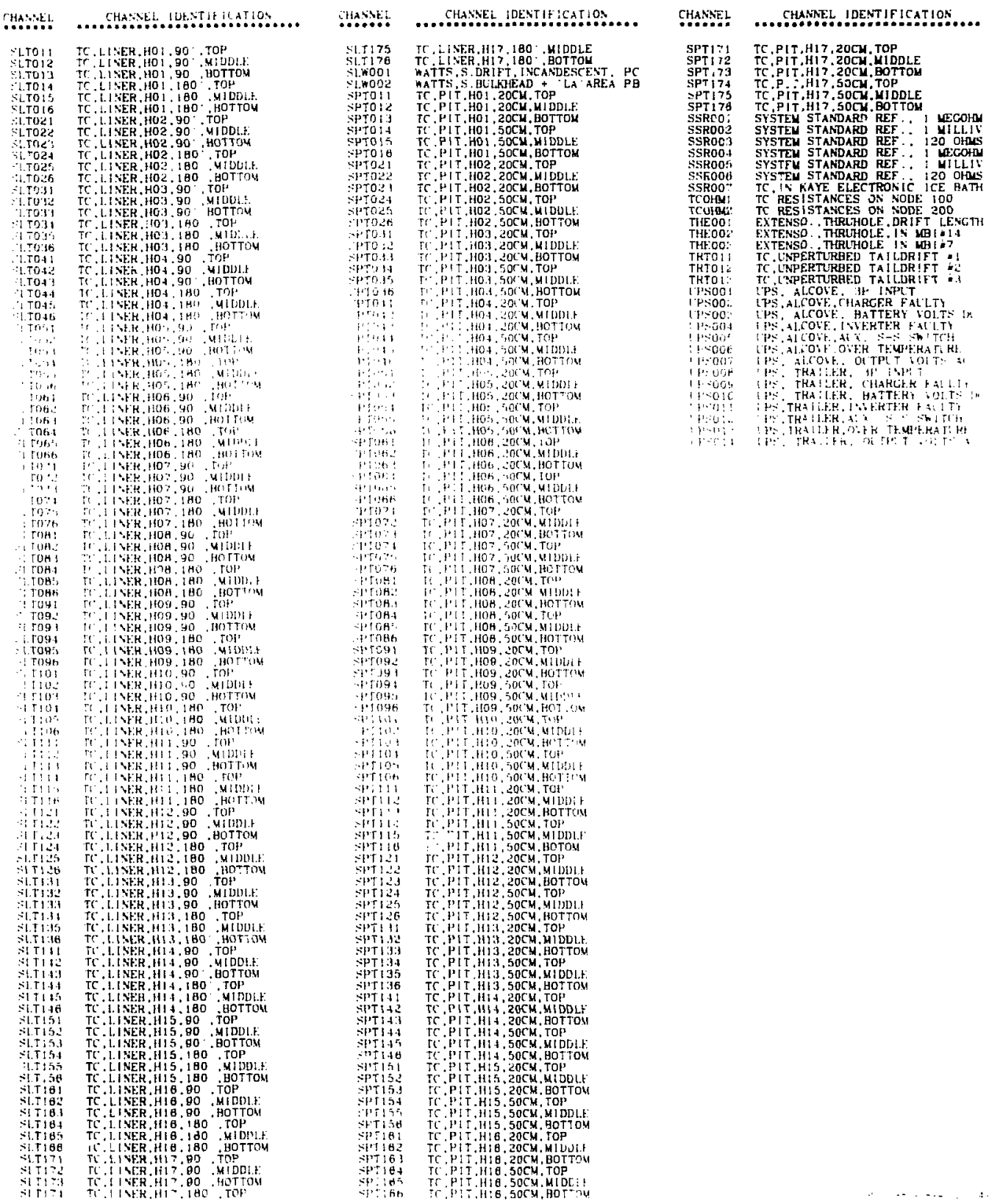


APPENDIX C.

ROD EXTENSOMETER QA CHECKLIST 
EXTENS. DATE CONSTRUCTED DATE INSTALLED HOLE DEPTH TAGGED

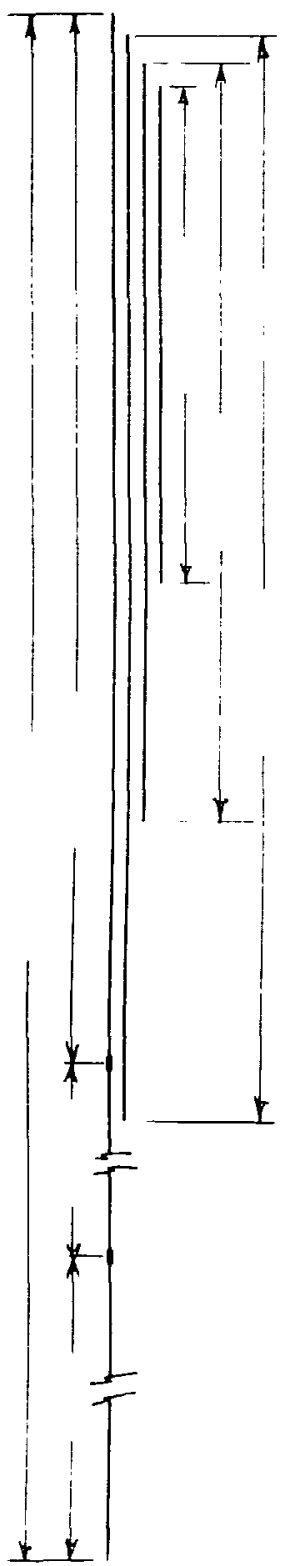

OBSERVED BY

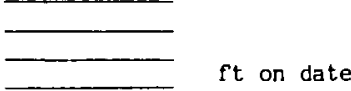

ANCHORS/RODS

Rod Preload

$\begin{array}{ll}\text { Load on date } & \text { time } \\ \text { Load off date } \_ \text {load } \\ \text { time }\end{array}$

Anchor No. 4 (deepest)

ies No

All rods connected w/locktite, tightened \& greased

Thermocouple Serial securely epoxyed to anchor

Protective conduit secured to top of anchor

Sharp edges or abnormalities in conduit/sheath

ANCHOR NO. 3

All rods connected w/locktite, tightened \& greased

Thermocouple Serial securely epoxyed to anchor

Protective conduit, secured to bottom of anchor top of anchor

Sharp edges or abnormalities in conduit/sheath

ANCHOR NO. 2

All rods connerted w/locktite, tightenec \& greased

Thermocouple Sertal \# securely epoyxed to anchor

Protective conduit secured to bottom of anchor

$$
\text { top of anchor }
$$

Sharp edges or abnormalities in conduit/sheath

ANCHOR NO. 1

All rods connected $H /$ locktite, $i$ ightened \& greased

Thermocouple Serial securely epoxyed to anchor

Protective conduit secured to bottom of anchor

top of anchor

Sharp edges or abnormalities in conduit/sheath

COLLAR STABILIZER TUBE - Serial No.

Protective conduit secured to bottom of c.s.t.

Thermocouple leads thru "Y" junction

Explain in comments 


\section{PROTECTIVE CONDUIT/SHEATH}

Any holes in sheathing (note location on sketch)

All holes patched $w / s i l i c o n e$ rubber cement

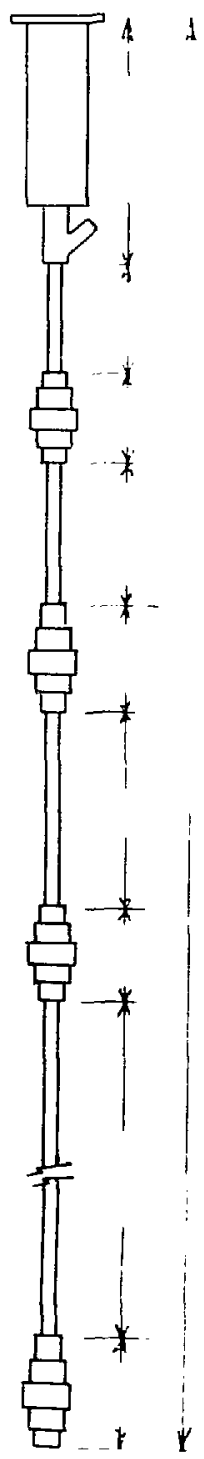

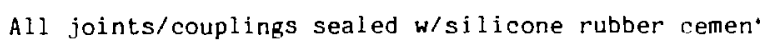

Sisicone rubber sheath cleaned prior to taping

\section{HYDRAULIC INFLATION LINES}

Anchor No. 4 - line passes:

No. 3 frer end of bladder

No. 2 free end of bladder

No. 1 free end of bladder

Secured in position by

Leak tested to $\mathrm{H}_{\mathrm{g}}$ for $\min$.

Helium leak tested

Anchor No. 3 - Line passes:

No. 2 frce end of bladder

No. 1 e rree end of bladder

Secured in position by

Leak tested to $\mathrm{Hg}$ for min. uk

Helium leak tested

Anchor No. 2 - line passes:

No. 1 free end of bladder

Secured in position by

Leak tested to $\mathrm{Hg}$ for min.

Helium leak tested

Anchor No. 1 :

Line secured in position by

Leak tested to

$\mathrm{H}_{\mathrm{B}}$ for min.

ok

Helium leak tosted

OK

All hydraulic lines greased 
EXTENS. DATE

OBSERVED BY

\section{EXPANSION SPACERS (donuts)}

Anchor No. Location (inches)

Approximate Diameter (inches)

4

3

2

1

GROUT TUBE

Tube placed

Attached by
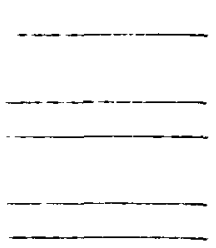

$\cdots$ above anchor mid pt.

below anchor mid pt. above anchor mid pt.

below anchor mid pt. above anchor mid pt.

below anchor mid pt. above anchor mid pt.

Pull loose allowed for Fy

INSTALLATION:

Note any hang-ups ir ledges encountered during placement.

Note damage, sharp bending or other problems during placement. inches above/below anchor No. 4

Top of flange (T.O.F.) inches below floor

Anchor Locations

Anchor Rod - Rod $=\begin{aligned} & \text { Anchor Depth }+ \text { T.0.F. }=\text { Anchor Depth } \\ & \text { No. Length }\end{aligned}$ Stick-up From T.0.F. Below Floor Below Floor
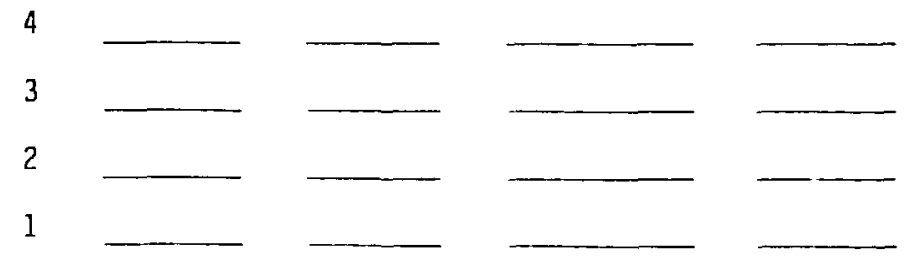
EXTENS. \#

DATE

OBSERVED BY

\section{ANCHOR SETTING}

Anchor No. 4

5 microns $\mathrm{Hg}$ obtained

Hydraulic reservoir filled with c.c.

Fluid left after purging (Step 6.16)

Total in anchor system C.c.

$\mathrm{N}_{2}$ pressure obtained original psig psig

Pressure stabilized after valve closed

Final pressure in expansion chamber psig

Anchor No. 3

Grouted prior to anchor inflation (see page 5)

5 microns $\mathrm{Hg}$ obtained

Hydraulic reservoir filled with

Fluid left purging (Step 6.16)

Total in anchor system

$\mathrm{N}_{2}$ pressure obtained original

maximum

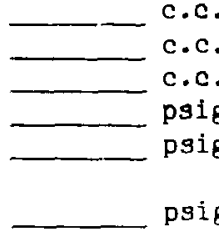

Pressure stabilized after valve closed

Final pressure in expansion chamber

Anchor No. 2

Grouted prior to anchor inflation (see page :)
5 microns $\mathrm{Hg}$ obtained
Hydraulic reservoir filled with
Fluid left purging (Step 6.16)
$\begin{aligned} & \text { Total in anchor system } \\ & \mathrm{N}_{2} \text { pressure obtained original }\end{aligned}$
$\begin{aligned} & \text { Pressure stabilized after valve closed } \\ & \text { Final pressure in expansion chamber }\end{aligned}$

Anchor No. 1

Grouted prion to anchor inflation (see page 5)

5 microns $\mathrm{Hg}$ obtained

Hydraulic reservoir filled with

Fluid left purging (Step 6.16)

Total in anchor system

$\mathrm{N}_{2}$ pressure obtained original

c.c.

c.c.

c.c.

psig

Pressure starilized after valve closed psig

Final pressure in expansion chamber psig 
EXTENS. \#

DATE

OBSERVED BY

GROUTING

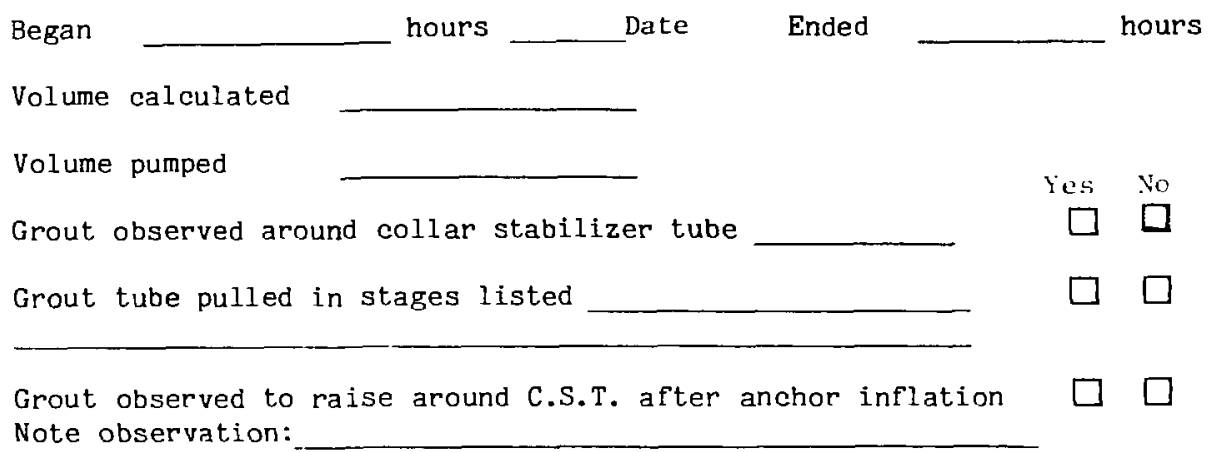

\section{COMMENTS}

